University of Louisville

ThinkIR: The University of Louisville's Institutional Repository

Electronic Theses and Dissertations

$5-2021$

\title{
Acting on what we hear: the impact of a listening methodology in a community literacy program.
}

Megen Farrow Boyett

University of Louisville

Follow this and additional works at: https://ir.library.louisville.edu/etd

Part of the Rhetoric and Composition Commons

\section{Recommended Citation}

Boyett, Megen Farrow, "Acting on what we hear: the impact of a listening methodology in a community literacy program." (2021). Electronic Theses and Dissertations. Paper 3634.

https://doi.org/10.18297/etd/3634

This Doctoral Dissertation is brought to you for free and open access by ThinkIR: The University of Louisville's Institutional Repository. It has been accepted for inclusion in Electronic Theses and Dissertations by an authorized administrator of ThinkIR: The University of Louisville's Institutional Repository. This title appears here courtesy of the author, who has retained all other copyrights. For more information, please contact thinkir@louisville.edu. 


\title{
ACTING ON WHAT WE HEAR: THE IMPACT OF A LISTENING METHODOLOGY IN A COMMUNITY LITERACY PROGRAM
}

\author{
By \\ Megen Farrow Boyett \\ B.A., Christopher Newport University, 2009 \\ M.A., University of Louisville, 2014

\begin{abstract}
A Dissertation
Submitted to the Faculty of the

in Partial Fulfillment of the Requirements

for the Degree of
\end{abstract} \\ College of Arts and Sciences of the University of Louisville \\ Doctor of Philosophy \\ in English/Rhetoric and Composition \\ Department of English \\ University of Louisville \\ Louisville, Kentucky
}

May 2021 

ACTING ON WHAT WE HEAR: THE IMPACT OF A LISTENING METHODOLOGY IN A COMMUNITY LITERACY PROGRAM

\section{By}

Megen Farrow Boyett

B.A., Christopher Newport University, 2009

M.A., University of Louisville, 2014

A Dissertation Approved on

April 16, 2021

by the following Dissertation Committee:

Dr. Mary P. Sheridan

Dr. Bronwyn Williams

Dr. Beth Willey

Dr. Katrina Powell 


\section{DEDICATION}

I dedicate this dissertation to my mother, who taught me that listening intently and asking good questions is love at its most sincere. 


\section{ACKNOWLEDGEMENTS}

Dissertations are a community effort and am deeply grateful for the people who have shared their time, expertise, and care with me during this season.

Thank you to my director, Mary P. Sheridan, for close reading, for hard questions over cups of tea, and for reminding me that it's okay to be a whole person. I have doubted many things on this journey, but I've never doubted that you had my back.

Thanks to my amazing committee: I asked each of you to be on my team because you were great scholars and good people, and I knew I'd need both. Bronwyn Williams, thank you for modeling what it means to prioritize people in the work we do. I first accountability for my own listening practices as an MA writing center consultant. Beth Willey, thank you for modeling the daily work of building responsible programs, and for trying to teach me to write shorter sentences. Katrina Powell, thank you for your generative questions and extreme generosity - exemplified by the time you attended my prospectus defense from a Grayhound.

Thanks to the women at Americana World Community Center. Without you, this dissertation would not be. Thank you to the staff for a deep example of intentional community care, and for letting me be a partner. Thank you to the women in Mamas Together for sharing pieces of your lives and mothering alongside me. I hope to have honored your wisdom, bravery, and tenacity in these pages.

I owe an unexpected and deep debt of gratitude to Dr. Vikas Singh, Dr. Nicolas Ajkay, and the chemo and radiation teams at the Brown Cancer Center, for extending my time with the ones I love and the work I love. A special thanks to the chemo nurses on the 
second floor, who let me set up a "writing space" around my infusion chair every week and didn’t judge me for napping instead.

Thanks to the many women in my "squad." To the "Mama PhDs" who provided solidarity at every stage: Amy McCleese Nichols, Jaclyn Hilberg, Layne Porta, and Rachel Rodriguez. I could not have imagined this road if I were not walking it alongside you. Thanks also to the women who worked, wrote, taught, ranted, commiserated, and celebrated PhD life with me, including Megan Faver Hartline, Michelle Day, and Keri Epps. Finally, a deep and humble thanks to the women who watched my children so that I could work, especially Rebekah Borah, Candice Lofton and Jessica Rodenbaugh.

Thanks to my incredible family: my parents, Ellen and Ray Farrow, and my sisters, Jessie Farrow and Shannon McNeely. The deep longing for justice that has surrounded me since childhood made it easy to imagine entering this work. Your love, encouragement, and examples of perseverance keep me in it. To my husband, Ben Boyett, your patience, gentleness, and wisdom are such a ballast in the storm. Thanks for partnering with me in every way. To my sons, Eamon and Rory: you are my greatest adventure. Thanks for sharing me with my laptop, and for reminding me to play. I love you first of all.

Finally, thanks be to the Author, Creator, and Sustainer of all things. You raise up the lowly and humble the proud. Thank you for daily humbling and a tiny part in helping others thrive. 


\title{
ABSTRACT \\ ACTING ON WHAT WE HEAR: THE IMPACT OF A LISTENING METHODOLOGY IN A COMMUNITY LITERACY PROGRAM
}

\author{
Megen Farrow Boyett
}

April 16, 2021

Calls for better listening, especially to racially and linguistically marginalized populations, are popular and necessary in community literacy studies. However, while scholarship has clarified the need for attending to a range of voices across the life of a community program and demonstrated clear results of good listening, it has not sufficiently outlined a methodology for listening, especially as it applies to communityengaged action. Even less scholarship has focused on attending to current listening practices, so that scholars and community partners hoping to practice active listening interpret participants' input through a soundtrack of other, unnoticed, "voices," and have no way of working through misaligned goals and consequences.

This dissertation begins by arguing that we cannot outline engaged listening practices until we understand how we currently listen, and what "voices" we attend to as we interpret participant input. I use a community program for refugee and immigrant mothers that I helped pilot as my central case study, tracing how organizers' listening processes led to program implementation. Demonstrating a methodology I term "listening back," I argue that the gap between our goals and consequences often stemmed from past 
programmatic practices and ever-circulating deficit discourses that "spoke into" planning meetings and program sessions. Using a community wealth model to interpret core participants' literate histories, I outline a set of new narratives that organizers might use as they shift away from deficit discourse, highlighting the rich literate repetoires that women bring into community literacy contexts. Finally, because grassroots community literacy programs are often small and short-lived, but in relationship with sustainable funders and partners, I argue that organizers must look for ways to amplify our listening work. End of program documents, which are used in grant narratives and program proposals, are both a relationship-building tool and a place for gentle critique. In establishing the effectiveness of a program and detailing practices that attend to women's cultural and literate wealth, rather than their lack, we can shift the narrative about immigrant and refugee families on a larger scale than merely in a single program. 
TABLE OF CONTENTS

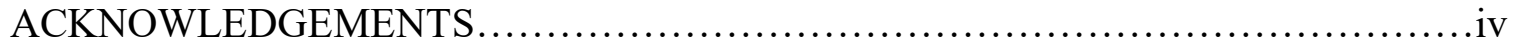

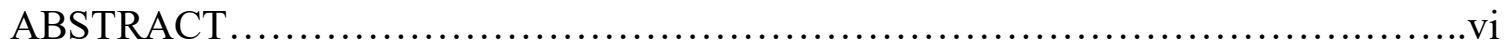

CHAPTER ONE: INTRODUCTION .........................................

CHAPTER TWO: LISTENING TOWARD ACTING.............................42

CHAPTER THREE: LISTENING FOR CULTURAL COMMUNITY WEALTH......99

CHAPTER FOUR: THE LONGEVITY OF SHORT-LIVED PROGRAMS ..........153

CHAPTER FIVE: CONCLUSION.........................................207

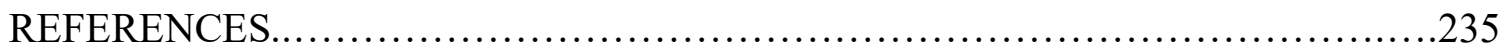

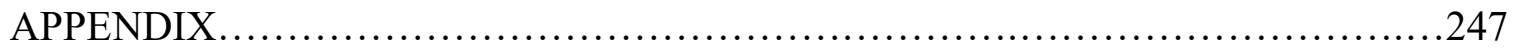

CURRICULUM VITAE................................................... 248 


\section{CHAPTER ONE}

INTRODUCTION:

THE WORK OF LISTENING IN COMMUNITY LITERACY PROGRAMS

\section{Introduction}

Twenty-five years ago, Jaqueline Jones Royster's address at the Conference on College Composition and Communication (CCCC) implored rhetoricians and compositionists, especially those in majority culture, to consider their listening processes more carefully. While she acknowledged the need for response or "talking back," she pointed out how often those in power "talk also" and speak "for, about, and around" others, forgetting to talk with them. Centrally, her call is to pay attention to our listening methodology:

[W]hen do we listen? How do we listen? How do we demonstrate that we honor and respect the person talking and what that person is saying, or what the person might say if we valued someone other than ourselves having a turn to speak? How do we translate listening into language and action, into the creation of an appropriate response? How do we really "talk back" rather than talk also? (38, emphasis mine)

Royster's questions represent (and have inspired) underlying concerns in Composition, Rhetoric, and Literacy (CLR) for the past quarter century. In his 2019 CCCC chair's address, Asao B. Inoue hones in on Royster's structural focus, asking white compositionists and rhetoricians, "How are you attending, exactly? What are the markers of your compassionate attending? How is your attending a practice of judgement that 
your students [participants, community members, etc.] can notice [and] that recognizes their existence without overly controlling them?" (11) Inoue's emphasis on the structures of listening—or the more expansive term "attending"1—underlines Composition, Literacy, and Rhetoric's continued need not only to call for dialogic work, but to outline and critique the parameters we use in such work. ${ }^{2}$

Community-based research, in particular, has taken up the call to speak with rather than to, about and for, in order to forge deep partnerships and make lasting changes toward community-defined issues (Deans, Flower, Royster). Community-based researchers in CLR have clarified the importance of amplifying and listening to participants' voices in a wide array of settings, including in university-community partnerships (Goldblatt, Parks, Wendler Shah), community writing centers (Rousculp, McNichols and Williams), after-school programs (Alvarez), adult literacy centers (Grabill), civic programs (Moss), and grassroots organizations (Sheridan). The variety of projects that enact and encourage listening practices demonstrate its conceptual importance to the work of our field. These projects clarify why, when, and to whom organizers and researchers should listen. Why is the humbling struggle to listen across cultural boundaries and power dynamics important? The impetus in community literacy scholarship is clear: lasting change comes from "intercultural dialogue with others on issues that they define as sites of struggle" (Flower 19, emphasis hers). Listening, without pretense, to voices that do not speak our own ideas back to us does more than demonstrate our value for the speaker; it is the only way to affect lasting change. When

\footnotetext{
${ }^{1}$ Inoue specifies the difference between these terms for his use, but I employ "listening" and "attending" interchangeably, following Krista Ratcliffe's theorization of the term.

${ }^{2}$ The events of Spring and Summer 2020; following the murders of Breonna Taylor, Ahmaud Arbery, and George Floyd; have amplified ongoing calls for re-examining racial and institutional privilege in many social sectors, including community-university partnerships.
} 
should community organizers and researchers make space for listening? Communitybased research advocates for it throughout the process: before program planning (Rowan and Cavallaro), during the earliest stages of design (Grabill, Sheridan), at regular points throughout a program's run (Wendler Shah), and as we evaluate our goals, commitments and efforts (Mathieu). To whom should we listen, as university representatives and/or members of majority culture? To scholars of color calling us to account for our complicity in white savior narratives (García, Jackson and DeLaune, Shome). To community partners doing on-the-ground work and inviting us into their space (Mathieu, Goldblatt, Parks). To program participants who bring their full histories, identities, and range of literacy practices to the table, but are too often reduced to what they do not know, and not invited to share perspectives on our work (Grabill, Wendler Shah). These studies demonstrate how often and ardently scholars working with community programs have noted the dire need for responsible, responsive listening practices. They also act as a sampling of the results of undertaking an intentional listening process.

As the thrust of Inoue's address indicates, scholarship has clarified the need to hear a range of voices across the life of a program, and has demonstrated some of the results of good listening, but it has not sufficiently outlined a methodology for listening, especially as it applies to community-engaged action. How should we create space for listening? What questions should we ask? How should we enact what we have heard and continue interrogating the consequences of our practices? Questions like these are difficult to answer, but must be wrestled with if listening is as important for community literacy programming as our field indicates. While it is common to discuss the results of good (or bad) listening practices, recording the work of a listening process- how one 
listened, what one listened to, and what results came from enacted listening — is much rarer (Rowan and Cavallaro). This dissertation studies a current model for enacting listening in community programs, outlines a new listening model that draws on participant-identified literate resources, and imagines using program documents as places of institutional critique, connecting robust listening practices in a single program to the work of a larger organization.

Throughout the dissertation, I draw on Mamas Together, a community literacy program that I helped pilot, as my central example. Held at Americana World Community Center in Spring 2019, the program was aimed at immigrant and refugee mothers of young children, who have typically been left out of the organizations' programming due to material limitations. While the end of the chapter outlines the program in greater detail, I want to overview some of program organizers' intentions and commitments here, to give context for the theoretical and methodological frames in the next section. Americana prioritizes "keeping an ear to the ground," by listening to participants' stated needs in various venues. From focus groups, held pre-program with women like our future participants, organizers understood that young mothers in the Americana community wanted space and time to draw on one another for support, as well as greater access to community resources and parenting information. A commitment to participants' perspectives is evident at every stage of the program, and thus Mamas Together offers a rich site for examining listening in action, especially in moments of discomfort when intentions and consequences seem misaligned. The phrase "listening in action" stresses the materiality of putting what we hear into practice, and thus the tensions between organizers' commitments and practical realities. The process of 
listening, as with any other practice in community organizing, is always constrained materially and discursively — a point I aim to keep top of mind throughout this dissertation.

This introduction chapter is comprised of three parts. First, my literature review lays out informing theoretical and methodological frames. Transnational feminism acts as an overarching theoretical frame because of its commitment to critiquing white, Western feminism's complicity in discourses that marginalize women like Mamas Together's participants. After taking up transnational feminist frameworks in my analysis, I work through "rhetorical listening" and "community listening" as concepts, and their uses as methodologies. Working through scholarship on listening, especially with a transnational feminist lens, helps me distinguish the methodological commitments I enact in the next three chapters. The second section lays out what concepts in listening mean for community-engaged action. This section, too, is informed by transnational feminist theory, as it enlightens organizing efforts and relationships between Western and nonWestern women. Answering a disciplinary call to consider non-white, non-Western perspectives, I work through what transnational feminist scholarship adds to this project. I also examine what this project might add to transnational feminism as it works at the level of local organizing. The final section of this chapter focuses on Mamas Together and the parameters of this study. It lays out organizer roles and overviews the timeline. It also discusses the data used in each chapter, and the beliefs that lead me to make particular choices. 


\section{Theory and Methodology}

\section{What Makes This a Transnational Feminist Project?}

This dissertation is a community literacy project informed by transnational feminist concerns, because of the importance I place on attending not only to transnational women's perspectives, but also to how white female organizers interpret and create structures using those perspectives. Grewal and Kaplan's Scattered Hegemonies, drawing on many of the ideas in Spivak's "Can the Subaltern Speak?" forwarded transnational feminism as a conceptual framework that "stems from the intersections of feminism, colonial and postcolonial discourses, modernism, and postmodern hybridity" (2). A central project in Grewal and Kaplan's work, and in transnational feminist scholarship as a whole, is to "problematize [...] feminist theory," especially as it has been complicit in "colonial discourses and hegemonic First World formations that wittingly or unwittingly lead to the oppressions and exploitation of many women." Transnational feminist work, therefore, calls on Western feminists to account for their complicity in the spread of marginalizing discourses that figure brown women as victims of their own culture and white governments, economies, and non-governmental organizations as their would-be saviors (Spivak, Mohanty, Grewal).

Because a central project of transnational feminism is "consider[ing] how representational practices are affected by [interconnected] social, political, cultural and economic forces," much transnational feminist work begins with an analysis of globally operating systems, noting how power shifts as it moves across borders, and how it scales from macro-levels to govern individual lives (Dingo 15). Rhetoric scholar Rebecca Dingo undertakes this type of project in Networking Arguments, when she traces the 
consequences of the Beijing Declaration through (trans)national political and economic policy measures, demonstrating how these policies structure women's material lives in several countries. Other work begins at the local level and traces "representational practices" as they scale up and enter national imaginations. Mary Queen's "Transnational Feminist Rhetorics in a Digital World," for instance, begins with the local, situated activism of women in the global South, ${ }^{3}$ and studies its uptake by Western feminist organizations that "fix" women within "neoliberal frameworks of 'democracy' and 'women's rights,' thus erasing the multiple ways in which women across the globe [...] create and claim identities, agency, and political activism outside of the circulation of one-third world rhetorics of power" (471). In both of these instances, as in my project, a transnational feminist frame attends to the ways power scales and shifts, holding wellmeaning white Western feminists accountable for their complicity in circulating seemingly empathetic rhetorics that propagate neo-liberal, neo-colonial ideals.

Perhaps because of its attention to global macro-forces rather than local communities, transnational feminism has not been widely used in examining individuals' or communities' literacy practices. Further, community literacy scholarship has addressed similar concerns to those I outline in this project, so it may seem unnecessary to specify a transnational feminist lens. For instance, Rebecca Lorimer Leonard's Writing on the Move examines how immigrant women's multilingual literacy practices allow and/or inhibit their socio-economic mobility, pointing out the ways in which mobility moves through different speeds and moments, and attending to points of friction. Kate Vieira's

\footnotetext{
${ }^{3}$ Most transnational feminist scholars use terms such as "global North/South" and "one-third/two-thirds world" in place of terms like "developed/developing" and "first world/third world," recognizing the latter terms as ill-fitting descriptors of the nations they describe. I will use both "global North/South" and "onethird/two-thirds world" to describe regions, but I also use the term "Western" to delineate a particular tradition of logic and rhetoric frequently employed by those in power within one-third world nations.
} 
Americans by Paper deals with a Brazilian and Azorean immigrant community, and the ways that representing bureaucratic power, in the form of documents, regulate their lives. Both scholars are interested in their multilingual participants' literate lives and the ways that institutional power enable, complicate, and/or withhold success as participants define it. Not only are their participants and scholarly interests similar to mine, but they also begin with an individual standpoint and attend to the ways power scales up and down within institutions. Neither writer uses a transnational feminist lens. Lorimer Leonard uses a mobility framework rather than transnational feminism. Vieira draws from New Literacy Studies "to develop a sociomaterial theory of literacy" (5). My project, however, is interested in the ways that assumptions about transnational women's literacy and mothering practices impact the ways they are listened to and programed for. Transnational feminism provides a way to study how the relationship between white organizers and brown participants are shaped by unmarked discourses about global motherhood and the need for white Western help, especially as it applies to educational and literate aims.

In this way, the project looks at the rhetorical uses of literacies, joining work by feminist rhetoricians who have used transnational feminism or a related frame to inform their work. In addition to Dingo's and Queen's projects, cited earlier, rhetoric scholars use transnational feminism to examine narratives about and by people that more closely resemble the life circumstances of Mamas Together's participants. Katrina Powell, for instance, describes "rhetorics of displacement," or the ways that displaced groups have historically been made legible to a white/Western audience through mainstream media. She distinguishes displacement tropes made on behalf of displaced groups from those 
made by victims of involuntary displacement. Powell does not focus explicitly on refugee women's concerns, but she shares transnational feminist concerns. She also draws on Wendy Hesford's work with "spectacular rhetorics," which analyzes mass-circulated visual rhetorics of impoverished women and children in the global South, meant to incite Western sympathy, anger, and action. In drawing on the narrative tropes that make refugee families legible to sympathetic white audiences, Powell emphasizes the ways homogenizing discourses are taken up even by well-meaning, charitable organizations. In critiquing this trend, she points out that mainstream displacement narratives circulate outside the communities about which they are written - that is, the central audience for those narratives is not the displaced themselves. Rather, the tropes employed by members of those communities portray displacement differently, often in ways that subvert and resist mainstream rhetorics.

Wendy Hesford's application of "responsivity" to transnational feminist projects aligns with theorizations of listening, outlined in the next section. Like other feminist rhetoricians, Hesford has used a transnational feminist frame to demonstrate the repercussions of white feminism's complicity with nationalist and militaristic aims. As an example, she contrasts the Western media attention given to Malala Yousafzai's attempted assassination by Taliban gunmen with the dearth of coverage given to the estimated "168-197 children" killed during US drone strikes in Pakistan from June 2004September 2012 (Hesford 146; “Living Under Drones,” vi). Malala’s educational activism has been conscripted as "part of the broader neoliberal discourse of global development" that figures girls in the global South, "as a site of international investment." Furthermore, Western feminism has picked up these discourses in ways that 
homogenize poverty and women's rights and obscure the West's role in the socioeconomic marginalization of two-thirds world women (144). Hesford argues that, within a transnational feminist frame, a spirit of responsivity acts as a "comparative, historical, and relational mode of rhetorical inquiry," increasing sensitivity to the ways that powerful political and economic systems create symbols from some lives and obfuscate others (143). It asks white feminists to attend more closely to the narratives propagated by dominant Western-based institutions, such as the belief that women's rights should be cross-culturally homogenous or that the girl-child is the entrepreneurial savior of the global South.

Hesford writes that "to be responsive in this context is to acknowledge the disruptive rhetorical work that others do" and their "intelligibility $[\ldots]$ as "agent[s] navigating the complex political machinery of rights, cultural norms, and the protocols of global engagement" (143). Acknowledging others' "disruptive rhetorical work" is akin to Powell's call to engage with the rhetorical tropes that displaced populations employ. Within a community program, that kind of responsivity means noting participants' pushback on the ways their lives and goals have been figured, and their use of community knowledges and strengths as they get what they need within a community. Beginning from a strengths perspective, as exemplified in the third chapter, allows organizers to amplify the strengths that communities rely on, rather than trying to transfer solutions from white to immigrant communities. In order to "recogni[ze] [...] the intelligibility of [transnational women] as agent[s]" white feminists and community organizers need to pay attention to the symbols we create and uphold, and the ways we fit what we hear into 
learned discourses, so that displaced groups — immigrants and refugees — might have greater space to be legible on their own terms.

Listening is central to responsivity, since response occurs in conversation. As scholarship demonstrates in the next section, however, the act of listening can only occur from within one's own community, a caution to white women seeking to work with transnational populations. Transnational feminist scholarship is clear that while listening to historically othered perspectives to increase awareness of privilege is a necessary project, the belief that white privilege and perspectives can be cast off is a dangerous remnant of colonial logics. Thus, transnational feminism encourages listeners to "recogni[ze] $[\ldots]$ the intelligibility of [transnational women] as agent[s]," and to pay closer attention to the ways we fit what we hear into learned discourses, it also warns against assuming that a more responsive listening process balances power dynamics or helps us shed a privileged position.

Transnational feminism has also been employed as an important frame for community-based organizing practices. Within Western nations, that work shares concerns with whiteness studies, focused on shifting white feminists' understanding of their roles and responsibilities. Irene Gedalof, analyzing focus group conversations at a grassroots organization, notes the complex ways that immigrant and refugee women negotiate their roles as mothers: while the role of passing on traditions and culture to one's children has been treated as static, Gedalof points to the ways that the immigrant mothers in her study reinvent, adapt, and negotiate traditions as they transform home cultures within a new context. Gedalof argues for narratives that figure the "reproductive sphere" as dynamic — something that community organizers working with immigrant and 
refugee families could also attend to, given the ways that families merge cultural knowledges as they interact with new systems post-navigation.

While Gedalof's work suggests adjusting the way organizers imagine community members' agency, Tanja Dreher, whose work with rhetorical listening I explore in depth in the next section, suggests a transnational feminist frame as a way for white allies to decenter their perspectives while remaining active in anti-racist organizing efforts, a common element in much community literacy work. Dreher, co-facilitating an anti-racist coalition between Australian indigenous and Muslim women, describes her decision to take on a secretarial role with participants' permission. Rather than guiding conversation, she took notes on salient points and fed them back into the discussion at opportune moments. In this way, Dreher's colleagues, both women of color, could hold productive discussions with workshop participants while she supported their work. Dreher's explanation of this project is a clear example of transnational feminist ideals put into transcultural practice.

I see a transnational feminist framework as important to my project as I build on scholarship surrounding community-building and organizing practices, and attend to the rhetorics surrounding both women's literacy uses and the literacies advocated for in community programs. I specify a transnational feminist framework for two central reasons. First, transnational feminism asks researchers to pay explicit attention to the normed, unmarked ways that discourses operate within institutions, especially at the intersections of race and gender. It assumes that empathy and good intentions are not enough, and can even be dangerous when coupled with unexamined discourses, given that the vestiges of colonialist logic paint two-thirds world women as victims in need of 
foreign, even military, intervention. Following Hesford's definition of responsivity, the call to attend closely to Western feminism/rhetoric's complicity in marginalizing discourses especially resonates with and further bolsters the listening work done by scholars of color in community literacy studies. Second, work in transnational feminism has specifically addressed the lives and experiences of those groups who shape my analysis: both mothers from the global South whose identities cross national borders and white women in a grassroots organization working to ease immigrant and refugee families' transition to the US. My analysis begins with individual women's standpoints and maps the uptake of values and discourses as they are enacted at multiple levels. Consequently, in addition to having a disciplinary framework, I'm also tying in transnational feminism because of the ways it enables me to listen to participants and draw from scholarship that specifically addresses women like our program participants.

\section{Term and Concepts in Listening}

This section works through prominent terms surrounding listening, on the way to outlining a robust methodology for community-based research. Difficulties pinning down "listening" as a term, or even making distinct separations between terms, indicate that community literacy scholarship, as a field, is still working out how listening translates into action. In this section, I lay out central listening concepts, and clarify the uses and limitations I see, especially in relationship to community action partnerships. My larger project employs a combination of listening concepts, and the following section works through how the theory and methodology I lay out here applies to a community literacy program like Mamas Together. Specifically, I draw from Krista Ratcliffe's rhetorical listening framework, written in response to Royster's address. I then examine more recent 
work with "community listening" as a concept that productively challenges and shifts rhetorical listening. Finally, work in transnational feminist organizing addresses some of the rhetorical listening's methodological blindspots and moves community listening's concerns into the sphere of organized community action.

\section{Rhetorical Listening as a Frame for "Listening Back"}

Writing in light of Royster's chair address, Krista Ratcliffe proposes “rhetorical listening" as a "trope for interpretive invention" that can be "employed as a code for cross-cultural conduct” (“A Trope" 196-7). Listening, as a process distinct from reading, leads to different responses: we read for what we can "agree with or critique," but we listen to the "exiled excess," reflecting on how what's being silenced or marginalized "relates to our culture and ourselves" (203). The result of rhetorical listening, is not mastery of what is heard, but "apprenticeship," meaning that the listener commits to act on what they hear, while continuing to listen and learn. Ratcliffe describes it as "an ethical responsibility to argue for what we deem fair and just while simultaneously questioning that which we deem fair and just" (203).

To minimize the possibility of confusing "understanding" with mastery, especially in a space of unequal power dynamics, Ratcliffe productively inverts the term, asking listeners to pay attention to what they "stand under" as they hear ("A Trope" 205). This pictures the listener working through another's claim while in the midst of the flow of "swirling" discourses (208). To understand, the listener goes through a series of "rhetorical negotiations," operating from within her own "cultural logics"- a set of discourses that she may or may not recognize as informing her standpoint (204). Learning to listen, or intentionally "stand under", means becoming attuned to competing, 
intermingling stories about reality, judging them slowly, and holding space for "commonalities and differences" between cultures, organizational ideologies, roles, and individuals.

Re-casting the definition of "understanding" also moves listeners away from "guilt and blame" logic, and toward an ethic of responsibility, that commits to critically stand under various informing discourses, make careful judgements about responsible action, and then act toward those ethics. This is a central piece of listening-listening toward acting, and acting while continuing to listen, recognizing the certainty of imperfect action. A commitment to holding space for commonalities and differences as we act on a responsibility logic opens us up to discomfort because it calls us to continue questioning our attitudes and actions to "determine whether we need to affirm, revise or reject them" ("A Trope" 210). The recognition of many entangled, circulating logics that "speak" as we listen cross-culturally to something like focus groups or participants indicates that there is much more to listening than careful attention to what is being said, or even attending to silence. There are histories of discourses and practices through which organizers listen. Corresponding to Hesford's call for increased "responsivity," we must examine our histories of discourses and practices from them from a desire to understand how we currently hear, rather than from a place of guilt.

A central problem with listening, widely noted in community-based research, is the difficulty to "listen" from a powerful or majoritarian position. Ratcliffe addresses this issue by employing "eavesdropping" as a metaphor for displacing ones' perspective from the center, especially in trying to listen to a text or conversation from another's point of view. Eavesdropping, which can be used for written, graphic, and aural texts, requires 
some imagination as one stands "on the border of knowing and not knowing"

(“Identification," 105). Ratcliffe demonstrates how eavesdropping might operate with physical texts, by "listening" to the cultural logics that produced a set of advertisements. She also demonstrates its use as an empathetic communication practice, working to rehear a fight she had with her daughter from her child's point of view (106). She specifies a clear ethics of care, "not to overstep another's boundaries or interrupt the agency of another's discourse," which would amount to retaking a center position (105). Given rhetorical listening's premise as a trope for cross-cultural communication, however, it stands that eavesdropping would centrally be forwarded as a way to listen across racial and cultural divides. Recently, several scholars of color have critiqued eavesdropping as seeking to downplay whiteness - the very thing Ratcliffe hoped to correct. The next section addresses the implications of these critiques, and eavesdropping in particular, suggesting a way forward through "community listening" and transnational feminist work. It also furthers the idea that listening must continue once acting begins, suggesting that responsibility logic must also attend to the consequences of enacted listening.

\section{Constructive Challenges from Community Listening and Transnational Feminist Organizing}

The three aspects of rhetorical listening discussed above — standing under discourses, moving from "blame" to "responsibility" in outlining actions, and “eavesdropping" to give another perspective central position-are useful for listening to how organizers drew on values, discourses, and enacted practices to put particular practices into place in Mamas Together. In employing rhetorical listening, however, we must recognize it as firmly entrenched in white rhetorical history. Indeed, Ratcliffe envisioned it as helping white scholars and instructors become attuned to the ways their 
unearned privilege in cross-cultural discourse keeps them from "hearing" others. It's unsurprising, then, that the methodology has been widely taken up by scholars like mewhite feminists seeking to work ethically and listen well, from a rhetorical frame that they recognize.

Using a frame rooted in Western rhetorical history to connect with members of a non-white, non-academic community carries several risks, however. There is great potential to obscure the ways that listening has been used in Communities of Color and transnational rhetorical traditions for centuries (García; Jackson and DeLaune). In fact, Cherokee scholar Rachel Jackson and Kiowa elder Dorothy Whitehorse DeLaune remind us that this is a historical reality. Like all aspects of our rhetorical theories and research practices, listening is one we must come to with an expansive understanding, considering multiple rhetorical traditions as we choose how to move forward with our community practices.

Several scholars have critiqued eavesdropping in particular, questioning the belief that those in majority culture, whose perspectives have been normed for centuries, can choose to stand close enough to the border of "knowing and not knowing" to really "grant others the inside position" (García; Jackson and DeLaune; Jones; Dreher; Ratcliffe, "Identification," 104-105). Romeo García argues that employing eavesdropping is "akin to colonial gazing," in that it "empowers white people to believe they can stand outside their positionality or identification within a dominant white culture" (13). Such strong words require a pause and readjustment, because while we could argue that Ratcliffe's intentions are good, any listening process worth undertaking must leave room for historically marginalized speakers to say "this attempt does not work for me; I am not 
being heard." In other words, even in our theories of listening, we must attend to the consequences. This does not negate the need to read intentions generously, as I'll discuss in depth later, but it does mean that good intentions can never be a stopping place.

Because of the limits of even well-intentioned eavesdropping, as well as rhetorical listening's grounding in Western cannon, García and Jackson opt for the alternate term “community listening." Community listening, as articulated by Fishman and Rosenberg, is in line with rhetorical listening's call to "suspend judgment," and "practice generous openness," creating more productive, substantial relationships that lead to meaningful change (3). It provides a useful counter to eavesdropping, however, recognizing that "none of us is ever outside of our communities. We are never teaching or researching or organizing or writing unmoored from the community to which we belong." Or, as García puts it, community listening "reminds us that while everyone is marked by gender and race, lived experience matters and informs both the 'why' and 'how' we enact culturalrhetorics practices" ("Creating Presence" 13). In community work and in research, when we can attend to our positions and beliefs as rooted within our communities, we are better able to interrogate misalignment between consequences and intentions. I do not mean to suggest that white scholars and organizers must, or even can, do this alone, given the demonstrable pervasiveness of white privilege. Thus, a set of robust listening practices must create avenues in whereby others can speak into our intentions, should they choose to. One way of doing this, noted at the end of the next chapter, is through clearly naming our cultural perspectives when we recognize them, establishing a precedent for others, as they feel comfortable, to add their own community perspectives and/or to point out when a raced or classed practice is treated as neutral. 
Community listening as a framework does not yet possess the methodological heft of rhetorical listening. Still, its attention to the consequentiality of listening from a particular standpoint makes it a productive challenge to the white, Western rhetorical listening frame. Moving forward with García and Jackson's critiques in mind, I want to specify rhetorical listening's uses, and how I see community listening expanding and altering it. Because eavesdropping is a way to shift perspectives as one listens back to a text or conversation, I think it benefits the work of this dissertation, especially in the next chapter, with two caveats. First, the call from community listening encourages all of us, and white folks/university representatives in particular, to recognize the ways we act from within our communities. It adjusts the "strategic idealism" of eavesdropping, requiring us to account for our positions both in research and community work. Second, I want to return to Tanja Dreher's work as a transnational feminist organizer. While Ratcliffe positions eavesdropping as useful in public discourse, community listening and organizing requires more intimate, and thus stickier relationships. Seeking permission and being clear about motives and roles is essential. Thus, Dreher distinguishes between "eavesdropping" and "eavesdropping with permission." In an active listening role, in which she "eavesdrops with permission," Dreher first clarifies her role for non-white attendees, making sure she has permission to remain. By keeping track of the group's conversation and feeding key points back in, she can participate actively without sharing her perspective. "Eavesdropping with permission" in this sense means taking on an agreed upon support role, so that participants of color, rather than the white facilitator, remain central within the conversation. Dreher draws a distinction between the "transnational feminist listening project" and Ratcliffe's "cross-cultural interpretation." 
Cross-cultural interpretation, centrally, is about transforming racial relationshipshearing across cultural lines. Transnational feminist organizing may begin similarly, but, like community listening, it works against privileging a Western rhetorical frame in listening projects, instead setting up space for participants to "explain our selves to our selves," not just to share perspectives but to form coalitions and create structural changes within communities (Chidiac, qtd in Dreher 15).

\section{Articulating a Listening Methodology}

Having established the central concerns for a transnational feminist project, and explored the uses and limitations of relevant listening methodologies, this section applies those theoretical and methodological commitments to community engaged action. To begin, I work through the implications of a phrase within community listening scholarship that I see as the impetus for the type of engaged listening methodology I undertake in this dissertation. Then, I apply the concepts from rhetorical and community listening scholarship, outlined in the previous section, to community engaged action work, since listening to create programs is related but distinct from listening to a set of texts, set of texts, listening in a classroom, or even listening for cross-cultural relationships.

Balancing an understanding of intentions with critical attention to practical outcomes is difficult when establishing a listening methodology with implications for community programs. Without generosity toward mistakes, work may never get off the ground. On the other hand, as transnational feminist scholarship clarifies, an initiative's unexamined good intentions may not only fail to meet community needs, but also cause community harm. Fishman and Rosenberg explore this balance in their introduction to 
the special issue of The Community Literacy Journal. They theorize community listening as "being immersed in the experience of understanding and non-understanding, trying and trying again with empathy" (3, emphasis mine). While their discussion balances generosity and critique, I want to pause on the phrase "trying and trying again with empathy" to explore a common danger in listening literature. As with most other theorizations of listening, Fishman and Rosenberg centrally address an audience whose race or role or both grants them power within a listening relationship. Though they attend to consequentiality, the phrase could sound platitudinous without context, and even excuse harmful results stemming from good intentions. "Trying and trying again with empathy" could suggest that so long as those in power do their best to enact good intentions, then they succeed: that intentions and a commitment to trying are enough. As education scholar Alison Jones argues, the desire of a member of the dominant group to listen is not 'always sufficient to enable their ears to 'hear,' and therefore for the other to 'speak"' (381). Neither an attempt at empathetically hearing the other, nor an empathetic read of our own intentions, are enough to do the kind of critical work that scholars like García and Jackson rightly call for.

Un-reflective attempts at empathy fall short of these calls because those in power have historically expected and received empathy for their merest recognition of unearned privilege, while traditionally marginalized groups have been expected to extend grace, but have not been treated to the same generosity. Jones, who studies colonial-indigene relationships in New Zealand university classrooms, depicts this pattern in Pakeha (white) students' declarations of cultural ignorance and desire to be "taught" by their indigenous peers: "Such confessions of ignorance are interesting in the ways that they 
reproduce power. [Expecting empathy] positions the guileless speaker as helpless, hapless, blameless [...]: 'I am not powerful,' says the confession, 'not threatening, only ignorant,"” (312). This is a common pattern in many "multi-cultural" situations, where representatives of powerful majority groups ask the marginalized other to "teach" them, without either taking responsibility for their own complicity in racist systems, or asking whether the racial "other" wants the burden of proving their marginalization to a majority audience.

And yet, good listening toward equitable outcomes cannot take place without generosity and empathy toward all involved. In context, Fishman and Rosenberg clarify "trying and trying again with empathy" not as an end, but as the impetus to "pay ongoing, unflinching attention where it is needed most" in order to "challenge assumptions and biases as well as preconceptions." They argue that "trying with empathy" and "generous openness" make those committed to community listening more accountable and "better able to do the work," rather than excusing misguided efforts as well-intended. This idea reflects Ratcliffe's assertion that guilt keeps would be allies from engaging in justice work, while responsibility holds those in power accountable, but also allows for mistakes throughout the process.

I see two essential listening issues in the notion of "trying and trying again with empathy." First, empathetic, generous listening is not only kind, but key to the process, whoever the speaker. Second, generous, empathetic listening should cause those studying listening to look past intentions and attend carefully to consequences. Listening entails judging slowly, rather than listening to "talk back," as Royster says (38). Recognizing the historical unevenness of empathy, however, and ways that "good intentions" have been 
conscripted by harmful discourses about brown victims and white saviors, however, I believe that a listening methodology must not equate empathy with excusing, but rather remain attuned to the consequentiality of enacted listening. Empathetic, reflective, listening — not just to others, but to our own processes as well—has the potential to help us better understand our intentions and the factors that inform them so we can move forward. It also clarifies the gaps between what we expected and the real, on-the-ground consequences of our enacted decisions, not from a place of blame, but from a sense of responsibility.

Rhetorical and community listening have specific applications within engaged action projects, including community-based literacy programs. Drawing from rhetorical listening, I find the concept of "standing under" discourses descriptive of the process that organizers undertake as they attend to community perspectives; those researching and planning hear what others say through the spoken or unspoken discourses they have come to believe and seen enacted in past experiences. The concept, as Ratcliffe explains it, implies intentionally working to hear those discourses at play. This is key within community action work, which needs methods of coupling the desire to listen well with a willingness to ask critical questions of ourselves and our partners. The work of critiquing intentions toward doing better work relies on knowing the difference between responsibility logic and blame/guilt logic. Organizers wishing to avoid blame may resist engaging community members at all, preferring to hear their own perspectives echoed back to them. Those acting from responsibility logic, on the other hand, engage deeply with community members perspectives. They provide avenues for critique and use it to critically examine their intentions and practices. When organizers recognize the 
impossibility of pure listening, the certainty of missteps, and the need to attend to the consequences of our actions, they employ a responsibility logic that is willing to help communities get what they need while continually engaging in critical conversations.

Community listening makes it clear that eavesdropping is a stickier concept to import into community-engaged action work because of the ever-present temptation for white organizers to normalize their listening frame. Thus, community listening and transnational feminism offer useful ways to re-think program organizers' role in crosscultural listening. Community listening's reminder that all of us listen from within our communities underscores the need to recognize the discourses we stand under and the narratives we affirm about ourselves and others. It also reminds organizers that we speak and create out of our own rhetorical traditions, just as participants do, and that there are times when we cannot really listen to participants, either because they speak out of a different rhetorical tradition, or because unequal power dynamics make it difficult for participants to talk back.

How then should we proceed, given that we cannot "stand on the edge of knowing and not knowing"? Community listening and transnational feminism call for recognizing diverse rhetorical traditions that frame education, mothering, literacy, etc. differently than the traditions informing white American values. Second, when we listen, it is imperative that we hear trends in situated experiences, rather than universal truths about cultural practices, and that we return to focus groups, program participants, and other organizers for clarification. Given the many reasons that a participant might hesitate to say "you misunderstood me,"-including the role of organizers as gatekeepers of resourcesthose with power must not only ask many people in many ways, but also be faithful with 
follow through as those with less power share their perspectives. Further, as Jones reminds us, organizers must reduce the burden on less-powerful groups to "teach" more powerful groups; instead, racially and linguistically diverse leaders must be included in as many stages of program implementation as possible.

In situations, like program planning, working to hear from another's point of view is important for making plans. And so, recognizing that we always listen and speak from within our own communities, I propose Dreher's term--eavesdropping with permissionas a way for organizers to "listen in" on a cultural others' conversation as part of their agreed upon roles. Receiving clear permission to listen to others speaking within a different rhetorical frame means that when organizers recognize gaps between intentions and consequences, we can move beyond working to re-hear and instead return to participants to ask about a practice, to own what we heard, and to clarify what they said. In this way, eavesdropping is the beginning, not the end, of becoming aware that our community knowledge and best intentions are not enough. Recognizing that we may have misheard as we sought to stand under metaphorical eaves should push us back into intentional conversation with partners who have agreed to help craft solutions to community problems.

While transnational feminism has not been widely taken up in community literacy work, its use for programming work focused on transnational women is at least two-fold. First, it warns white feminists—including white organizers seeking social justice- - to recognize complicity with deficit-model and white savior discourses. In doing so, it discourages organizers from self-congratulatory stances while encouraging us to reexamine who benefits from our programs, and how. Transnational feminism 
interrogates even the noblest-seeming initiatives, bolstering a critical engagement with feminist and humanist rhetorics that seek to remake transnational families on white America's terms. Second, transnational feminist organizing traditions incorporate and move through critique to, as Dreher says, "get work done" on a community's terms. I see transnational feminism as expanding community literacies' listening concerns, and I see listening scholarship offering transnational feminism new ways spaces to get work done in cross-cultural coalitions.

One key takeaway from the listening concepts discussed in this section is that understanding where a listener stands as she listens is crucial to understanding both how she listens and what else she listens to as she interprets and enacts. The following section provides specifics on Mamas Together-commitments, creation process, timeline, and central roles - so that the reader can better envision the ways organizers worked to hear and enact intentionally, while rooted in our communities and experiences.

\section{Mamas Together as a Site of Study}

This section clarifies the origins of this project and provides details on Mamas Together, the central case-study explored in this dissertation. The larger project surrounding this dissertation began during Mamas Together, a seven-week pilot program at a grassroots organization, as I noted the gaps between organizers' desire for a program driven by participant perspectives and their unease with some of the consequences resulting from those desires in practice. Some practices seemed not to work for participants the way organizers anticipated, while other practices worked well for participants but caused facilitators discomfort. Further, organizers' unease was not uniform, in spite of our co-planning process and compatible values. From what did these 
diverse moments of stem, I wondered, since organizers enacted responsive listening practices in focus groups, voiced compatible beliefs in planning sessions, and created practices that could be tied directly to participants' stated needs?

The listening methodology that I propose in chapter two and spin out in chapters three and four was theorized as I considered the gap between organizers' voiced intentions and the consequences of enacted practices. Given what I knew about mothering discourses (Smith, Smythe and Isserlis, Shome) and deficit-model assumptions about immigrant literacy (Lorimer Leonard, Vieira), I suspected that there were unnamed assumptions at play causing some of organizers' felt tension. Thus, while an early idea for the project was to look at the ties between participants' everyday literacy uses and how they made use of a family literacy group, I felt that we could not really attend to participants' voiced post-program perspectives until we had paid attention to what organizers did with participants' early perspectives. Because the pilot program, Mamas Together, is central to fleshing out my listening methodology, the rest of this section lays out key information about the program, including timeline and organizer roles, to make the deeper focus in the following chapters clearer. The end of the section describes the data and analysis used in each chapter.

Mamas Together was a seven-week family literacy pilot for refugee and immigrant mothers of toddlers that was half playgroup, half mother-support group. The program, held at Americana World Community Center during spring 2019, was developed to begin filling a known service gap; namely, women with children under two have been left out of traditional family literacy programs, because Americana does not have the space or staff to provide infant care. The program's other aim was to begin data 
collection on the goals and service needs of young mothers in the Americana community for the organization's executive board, which makes funding and grant-writing decisions. Americana staff knew the broad outline of the need from years of close work with immigrant families, but wanted participant input on its specific effects, which organizers helped collect in the form of pre-program focus groups and post-program surveys and conversations.

Structures driven by participant input were central to creating Mamas Together. A staff member and I held three focus groups during summer 2018. Our team wrote lesson plans and created schedules during the fall. The pilot ran from February-April 2019, with practices drawn from a combination of focus group findings and the resources available at Americana during that time. Mamas Together met once a week for two hours in Americana's cafeteria or gym — large free spaces that could be arranged as we needed them. The first hour was a play-group style art or movement class run by a community partner in Americana's space. During this hour, mothers and their children either listened to a book and created a corresponding art project, or participated in movement and songs together. This portion was led by a representative from our community partner and facilitators participated with families but did not lead. During the second hour, Mamas Together organizers facilitated a parenting conversation with mothers while their children played with an AmeriCorps Vista on the other side of a partition. The conversations were themed around common parenting concerns, including some that were specified in focus groups or chosen by program participants. Participants were also given a list of topics during the first session and invited to tell us on anonymous survey forms if they were uncomfortable with a discussion topic (e.g., breastfeeding). Mothers had time to interact 
with their children during playgroup, and to converse with other transnational women in a similar life stage during parenting sessions. They could practice English conversation in an informal setting, have access to community resources, and gain emotional support from other women. Speakers from like-minded community organizations led two sessions, so that women would have direct connections to resources outside of Americana.

Mamas Together was a community literacy program in a couple of key senses. First, it was created as a "younger sister" to Family Education, Americana's largest family literacy program, hosted in partnership with the local school system and funded by National Center for Family Learning (NCFL). Family Education is a traditional family literacy program that focuses on school support, teaching English, and restoring a relationship between children and parents that sometimes becomes strained during immigration (Julie and Leah, personal interview). Mamas Together had its own goals and audience, but was also created with the assumption that participants would transition to Family Education when children were old enough. Sessions focused on some of the socio-emotional elements and health habits that have been linked to strong educational starts, an idea that the mothering discourses section of the next chapter explores more deeply. Second, a key goal of Mamas Together was to bolster participants' community literacy through introductions to community resources and help with navigation. We invited speakers from local organizations for a few sessions to talk about available community resources. We provided weekly "service spotlights" that included free access to material resources and educational programs like HeadStart. During parenting conversations, women and facilitators both shared ways that they had used local 
institutions to meet goals, like the YMCA for fitness and the local library for homework help. Thus, Mamas Together functioned as a community literacy program with a significant emphasis on family life and health, supporting the work of more traditional literacy programs.

One reason that Mamas Together makes such a rich site to study listening is that it was built around many of the principles advocated in community-based research. Before planning began, organizers were already attending to power dynamics and seeking to engage with participants on "issues that they define as sites of struggle" (Flower 19), as my analysis of focus groups shows in chapter two. Within the program, we worked to complicate seemingly binary racial, linguistic, and programmatic positions through bringing our own children to play group and including our own messy experiences alongside our participants during weekly sharing times ${ }^{4}$. We stressed our interest in participants' experiences, and enacted intentional listening practices from focus groups to end-of-program surveys. Practices and program structures were drawn directly from community needs expressed during focus groups and Mamas Together sessions.

Still, no one expected that we would or could do away with power structures in the program. As facilitators, we coordinated the groups' actions. As white, Englishspeaking mothers, we acted as visual and positional representatives for "parenting in the US.” Membership in majority culture complicates listening, because we cannot displace our whiteness: it always impacts participants' speaking and our listening. I have said

\footnotetext{
${ }^{4}$ Whether choosing to be vulnerable is indeed true vulnerability is rightly contested, but outside of the conversation of this chapter. As facilitators and members of a majoritarian community, we could make decisions to step into and out of vulnerability to a greater degree than our participants, both within the program and after we left for the week. Making the choice to include ourselves in sharing experiences did not erase power structures, but it was an intentional practice in humility, which is how I mean to represent it. For a compelling conversation on the limits of vulnerability in engagement work, see Kellie SharpHoskins' chapter in Writing for Engagement: Responsive Practice for Social Action.
} 
earlier in this chapter, and will clarify further, that in order to watch listening-whilepowerful play out, we have to look through intentions to study the consequences of enacted listening. We do still need a clear sense of both intentions and material realities, however, because for a listening process to be any good to the program or organization for which it's purposed, its local situation must be accounted for. The previous paragraphs in this section laid out an overview of Mamas Together as a program. The sub-section that follows details the roles of the four central organizers, myself included, and provides a timeline the program's creation and run.

\section{Setting Up Mamas Together Through Organizer Roles}

In this section, I detail organizer roles to give a sense of the timeline, priorities, and process of creation. Understanding both what we did and how we saw our roles helps establish how our perspectives and experiences contributed to our listening in a way that just overviewing the program can't. Program descriptions show the program as a product, not a process, and certainly not as a network of enacted values, stances, and assumptions limited by time and space. This section, then, gives a sense of the people involved in planning and implementing, because that's ultimately where my listening methodology begins.

Four central organizers planned and implemented Mamas Together. All four of the women directly responsible for planning and implementation are white, between the ages of 22 and 35, and present with middle-class values (if not middle-class income). All of us have at least a bachelor's degree; two of us hold Master's degrees. Two of us were working toward advanced degrees during the program's run. We are all native English speakers and the two full-time Americana staff members are fluent in Spanish. Two are 
Catholic, one is Protestant, and one claims no religious affiliation. Three of us are mothers. Our intersecting social identities necessarily informed how we understood our roles and enacted our values, as well as how we presented to participants.

Julie, who has served as Programs Director for three years, asked me in spring 2018 to lead help lead focus groups to identify service gaps for young mothers in the Americana community. As a former family coach, Julie says she has always known that women with infants and toddlers wanted to stay in Americana's programs to continue working toward goals, but frequently lacked access to resources like childcare. As programs director, she "was finally in a place to program" for this service gap. Additionally, she wanted to use a pilot to collect data evidencing this need for future funders. While Julie hoped to have a heavy hand in planning, existing programs took priority. After we outlined focus group questions, she invited Leah, another full time staff member, to co-facilitate. The other staff members on our team regularly checked with Julie for advice and to ensure that our plans aligned with Americana's larger programming goals. Julie served in a vision-casting role and provided broad perspective from the position of seeing how all of Americana's programs worked together.

Leah was the only full-time Americana staff member facilitating Mamas Together. She has worked for Americana in several capacities for five years; she continued working in Family Education and family coaching during Mamas Together. During Summer 2018, she and I held focus groups and created initial plans for what would become Mamas Together, intending to start in Fall 2019. Leah's first child was born weeks after our final focus group. Thus, she was on maternity leave for much of the early planning, and Danielle did the initial research and drafts of lesson plans. As 
Americana staff, Leah took the lead in program organization and facilitating after maternity leave. She created our lesson plan template, organized weekly tasks, and transitioned the group from one activity to the next each week. The roles she took on were organizational and also looked out for the longevity of the program. Like me, she was always attuned to the consequences of our listening and enacting. Our different standpoints and experiences meant that we sometimes drew different conclusions, explored in chapter two.

Danielle, working as an Americorps Vista during her first year out of college, served Americana in capacities that were in keeping with AmeriCorps" "do no harm" policies. Vistas work in support roles, preparing supplies and creating program resources. They act as support for Americana staff rather than working directly with program participants, in hopes of minimizing the gap left after their year term is up. While Leah was on maternity leave and I was entrenched in exams and prospectus writing, Danielle began research for lesson plans. Danielle was not in focus groups or early planning sessions, however, and lacked experience with medical and social mothering issues. She culled a lot of information from internet research that Leah and I later used to frame mothering conversations. During the program, she participated in the hour-long playgroup and provided childcare during the second hour, while Leah and I facilitated mothering conversations on the other side of a partition. At the end of her AmeriCorps tenure, Danielle took detailed notes on her position with Mamas Together and our postpilot discussions, hoping to smooth the transition from Vista to Vista.

I was involved in most of the planning and implementation of Mamas Together, with a break in Fall 2018 during exams and prospectus writing. Work on Mamas 
Together was initially an act of reciprocity rather than research; I was observing in Family Education with the hopes of interviewing participants there. Because I had some training in early childhood education and experience with lesson planning, I could meet a need for Americana and the community it serves through doing some programmatic legwork. Initially, I intended to lead focus groups, create the program's skeleton with Leah, and then step out. Because the program moved up its start time by a semester, I came into second drafts of lesson planning and saw the pilot through to completion. Preprogram, I collaborated on text revisions, created assessments, and led two sessions. My primary goals were creating space for community-building and making participant knowledge central in our practices. I suggested ways of setting up space that de-centered power, and advocated for discussion rather than long information sessions. I often

brought my own children — three and one at the time—-for the weekly one-hour play group. My "mom" identity remained visible, overlapping with my instructor and facilitator identities. In this way, I worked to show the complexity of my roles, in hopes of creating a space where participants felt comfortable to bring their own overlapping identities.

\section{Methods for Data Collection and Analysis}

During and immediately following Mamas Together, I interviewed each of the women whose presence and insight shaped the program. During the program's run, I held interviews with Julie, Leah, and Danielle. Within two weeks of the program's conclusion, I interviewed each participant who attended more than two more sessions. I chose to interview participants after the conclusion of the program so that they could reflect on the program as a whole, and so that they could be assured that their responses would not 
affect participation in Mamas Together. Each interview took between ninety minutes and two hours. I recorded on my phone or computer and transcribed them using Inqscribe. I also recorded and transcribed the two hour post-program reflection meeting, during which Leah, Danielle, and I talked about post-program surveys and assessed the successes and shortcoming of the pilot's practices using what we gathered from participants during our post-program celebration and our own felt sense as program facilitators. Americana uses an over-the-phone translator service and I offered that service to each multi-lingual participant. Two participants welcomed the chance to practice English and refused a translation service. The third used a translator, who interpreted our conversation as well as the consent form prior to the interview. Participants were given a choice of location in that I suggested Americana as a known, central place, but also offered to meet wherever they felt comfortable. I gave examples of homes, playgrounds, and coffee shops. I met one facilitator in her office at Americana and the other two at a coffee shop within walking distance of the community center. Two participants invited me to their homes while the third met me at Americana.

To support oral data, I also kept track of the texts we, as facilitators, produced, including focus group questions, brainstorming notes, lesson plan templates, pre- and post-surveys (without participant responses), weekly post-session reflections, and the end of program report. These were kept in a shared Google Drive team folder secured on Americana's servers. I also observed during sessions, but in my role as facilitator rather than as a researcher, by which I mean that I kept reflection notes each week along with Leah and Danielle that focused on the successes and challenges of the day rather than addressing my particular research questions. In this way, when I reached the coding 
stage, I could compare interviews to one another, as well as triangulating oral, textual, and observational data. Coding methods are explained below.

Interviews with facilitators and participants had different foci but in both cases interviews were semi-structured conversations. I asked the same questions of each person within the sub-group, with follow-up questions depending on their responses and, in the case of facilitators, their particular program roles. See Appendix One for IRB-approved question sets. With facilitators, I focused on their goals for Mamas Together, including how they created those goals, their role in implementation, and how they saw goals playing out. I also asked about Mamas Together's place within Americana as an organization, and what previous experiences organizers drew from when implementing Mamas Together. Facilitator interviews make up the bulk of the data used in chapter 2. With program participants, I also asked about how past experiences informed their goals within Mamas Together, but I focused much more heavily on the identities, histories, and experiences that they brought with them into the program. I asked specifically about mothering in the United States and in home countries, since all three women had parented in more than one country. I asked about navigating a new community as a parent, and how their literacy uses (including reading and writing physical texts, using the internet, and communicating via video and telephone) changed or adapted when they moved to the United States. My focus on literacy and identity came from a curiosity about the kinds of literate identities and personal goals encouraged and/or accounted for within Mamas Together. Participant interviews make up the bulk of the data used in chapter 3. My initial desire to compare facilitators' assumptions about mothering identities and literacy goals with the ways participants saw themselves became an interest in tracing past 
listening processes (explained in chapter 2) and searching out new discourses, drawn from participants' articulation of their strengths and resources (explained in chapter 3).

I used qualitative coding methods to make sense of my data. Specifically, I broke interviews into themes and made reflective notes on what I saw during a pre-coding stage. Breaking interviews into large themes helped me categorize data before I began coding. I particularly attended to recurrent themes, overlap between interviews, and gaps between desires/goals and program practices. I then adapted what Saldaña refers to as "values coding," using the specific codes goals, values, beliefs, motivations and practices. Themes and codes were both drawn from a combination of my interests and what interview participants expressed.

After coding, I traced the relationships between the codes, particularly looking at how values and beliefs informed goals and motivations, and then how practices were implemented based on what organizers valued and what goals motivated their decisions. With organizer interviews, values coding helped me map out the reflexive relationship between values, goals, and past program experiences that inform listening and program implementation processes. For participants, first round values coding was followed by second round "cultural wealth" codes, using Tara Yosso's "community cultural wealth" model. Specifically, I coded for "aspirational, linguistic, familial, social, navigational, and resistance capital" in the ways participants discussed their literacy histories and current practices, paying particular attention to the values women associated with each type of cultural wealth (77). 


\section{Limitations and Limiting Choices in Data Collection and Analysis}

I wanted to allow women to speak freely during the program without fearing that their thoughts would end up in my research. Thus, I never recorded group conversations or used any participant responses unless they showed up in interviews or as part of the post-program reflection. For instance, both examples in chapter two draw on Leah's analysis of felt discomfort during a session, rather than the event itself, and any references to participants are generalized. In some senses, this was a limitation. Having direct quotes from participants as they voiced their dissent or offered their own experiences on child-rearing would have made chapter discussions that much more rich. I consider this a choice to prioritize participants' sense of safety over making my dissertation more specific, however, and I stand by that decision.

Another limitation of this study is the sample size, especially for participant interviews. While as many as eight women attended in a week, three women attended Mamas Together more than twice, and made up the core group of participants. I interviewed each of these women. One woman attended twice at the end of the program. I invited her to interview, but she declined due to discomfort. Given the small sample size, my goal is not to draw any hard and fast conclusions about family literacy programs as a whole, but rather to use a single pilot program to exemplify a methodology for listening back on a planning process, and then searching out different discourses from which to operate.

\section{Chapter Outline}

A common thrust of community literacy and community-based research is to refocus attention on participant voices and experiences, for the purpose of giving space to 
previously silenced knowledge-making practices, exemplifying strength where only deficit has been noted, and creating a more just, equitable vision of community literacy programs (Alvarez, Grabill, Flower, Wendler Shah). Because Americana shares these aims, and Mamas Together worked to make participant experiences central to planning, my dissertation studies a work in progress: how can an organization already seeking to do the kinds of work called for in our field continue challenging its listening processes, both in single programs and larger organizational structures? In working to answer this question, the next three chapters attend to the listening processes in a community program in three stages: listening back to the processes already being employed, identifying counter-discourses that organizers can practice standing under (or listening for), and using adjusted listening practices to revise larger institutional structures, through texts like grants and end-of-program documents.

The next chapter asserts that we cannot ask how we should listen in a community program until we have attended to current listening processes. It focuses on moments of discomfort within Mamas Together, wherein facilitators found that even though we shared similar values and listened to the same focus groups, we had some conflicting programmatic expectations. Employing the process I'm referring to as listening back, this chapter argues that when organizers listen to participants, they hear needs and experiences through a soundtrack of other voices, particularly local organizational values, discourses about participants' needs, and previous practices that enact both within the program's material constraints. Listening to an unacknowledged soundtrack, through which they interpret participant voices, leads organizers to take up discourse models that do not necessarily match their commitments or the spoken needs of the community. This 
follows Krista Ratcliffe's stance that because unnamed discourses inform our beliefs and thus our actions, we must learn to "stand under" them, or intentionally begin attending to other voices we hear when we listen to participants. It also follows community listening's position that we listen from within our communities, and as such, looks to the local values of the organization, Americana, as another central voice that mixes with larger discourses to inform practices. Finally, it argues that discourses and values speak into new programs most powerfully when put into practice. Existing programs create legacies that tell us how to interpret and enact what we hear.

Given the listening work that the second chapter undertakes, the third chapter argues that we cannot simply work away from deficit discourses about immigrant motherhood and literacy practices or adjust our current interpretive models. We need a new model, with a new set of discourses to practice standing under as an interpretive frame. Drawing from Cultural Community Wealth and work with multi-lingual literate histories, I analyze core participants' articulation of their motherhood and literate identities, looking for the sources of wealth they draw on as they navigate a new culture. I offer $\mathrm{CCW}$ as a new model through which to see women like our participants, and imagine re-listening to focus groups' needs through such a model.

The fourth chapter argues that the longevity of a community literacy program is in how it can revise current models in programming. Mamas Together was what Paula Mathieu has referred to as a "tactical program," in that it filled a community-defined need using only the resources at hand, and was assumed to be short-term, at least in this iteration (17). Nevertheless, it was meant to make bottom-up changes to the larger landscape of programmatic structures at Americana. While it was well-liked and achieved 
its goals, changes to Americana's funding structures dictated deep cuts, and Mamas Together did not have a second run. The fourth chapter argues that in order for a good but short-lived program to have lasting impact, it needs a way to speak back to larger programs. End-of-program documents, analyzed through an institutional critique lens, can help us imagine a point of intervention.

Over the course of these chapters, I contribute a robust listening methodology specifically for community and/or literacy programs seeking to use participant input to craft more equitable structures that resist deficit, marginalizing discourses while helping participants get what they need. My chapters not only theorize such a methodology, but work through how it might 1) help situate and evaluate current listening practices, 2) locate new models for organizers to "stand under," and 3) offer a concrete way to use such a methodology to "speak back" to partner and funding organizations using programmatic documents, thus giving programs potentially greater longevity. 
CHAPTER TWO

LISTENING TOWARD ACTING:

WHAT (ELSE) WE HEAR WHEN WE ASK FOR COMMUNITY VOICES

\section{Introduction}

"Every day if I don't come home and have a question about whether or not something was right, like, 'was that opening the conversation or was it closing the conversation for that person?' [...] then I'm probably not acting in a way that is gracious and with cultural humility," Julie tells me over coffee. We're sitting in a neighborhood roastery two blocks from Americana World Community Center, where she serves as program director. Julie is describing a "personal litmus test" for her work with the large immigrant and refugee community in Louisville's Southside. Central to her work is a belief that those in power should be willing to reflect critically on their interactions with marginalized communities. This belief informs her staff trainings and workshops for institutional representatives serving immigrant populations. What I hear in her articulation of cultural humility is a goal toward forging deep listening relationships, not just on a personal level, but for the purpose of creating change.

As discussed in the introduction, calls for listening in community literacy are both necessary and popular. Their focus, however, trends toward the results of listening (or not listening) in community partnerships, and an outline of listening principles rather than practices. Rowan and Cavallaro sum up these principles as "the call to learn about and listen to community concerns and voices, the value of starting before we feel entirely 
ready, and the importance of doing our homework by engaging in community listening first" (24). A methodology accounting for the listening process is much less common. My dissertation outlines how we might listen, and what we might do with what we hear, focusing especially on community literacy programs. This chapter begins with my belief that the listening process starts long before a face-to-face discussion between organizers and community members. I propose that before asking how we should listen, we must examine our current processes, asking "how do we listen?" and "to what do we listen?" This chapter examines the preparatory stages of Mamas Together, my central case study, asking what else facilitators listened to, in addition to formal focus groups, which informed how we heard community members. Teasing out the "what" is necessary to get to the "how."

My analysis focuses centrally on the perspectives of program organizers as we prepared and ran Mamas Together, a seven-week family literacy pilot program for refugee and immigrant mothers of toddlers that was half playgroup, half mother-support group. As outlined in the introduction, the program was held at Americana World Community Center during spring 2019 and developed to serve mothers of children 0-2 while collecting data on this underserved groups' goals and needs for Americana's executive board, which makes funding and grant-writing decisions. From the beginning, using participant perspectives in design and implementation was central to Mamas Together. Before beginning planning, Leah, a full-time staff member, and I invited Americana participants to share their experiences with pregnancy and child-rearing in the United States during a series of focus groups. Young mothers related the physical, emotional, mental, and spiritual supports they relied on, as well as those they lacked, and 
brainstormed how a new program could meet felt needs. The conversations, analyzed later in this chapter, were intimate, emotional, and powerful. We, as organizers, began from a place of believing the women we invited, and framing them as experts on their experiences. We made a point to ask questions and only give advice when women asked about accessing community resources. During planning, we drew directly from focus group findings and aligned our plans with Americana's organizational philosophy, discussed at length later. Within Mamas Together sessions, we continued aligning our actions with Americana's core values, a legacy of practices within well-established programs, and the needs we heard in focus groups.

In many ways, the program was a great success - an energetic launching point toward meeting needs for an underserved population at Americana. As with all community programs, however, when organizers responded to what we heard using the resources we had, we felt the strain between our intentions and practices. In some cases, material realities, which are rarely accounted for in the call to listen and act, forced readjustment. In other cases, organizers understood goals differently, and had to negotiate diverse expectations. One reason for different expectations, though we voiced concordant values, listened to the same women, and agreed on program goals, is that organizers were listening long before focus groups were scheduled. We especially listened to our respective institutions' values, to dominant discourses about immigrant families and mothering work, and to institutional narratives about literacy practices woven through both values and discourses. We also listened to how both value-sets and discourses animated practices in existing programs. In this way, layers of unacknowledged voices spoke into focus groups and planning sessions. Sometimes this 
soundtrack of values, discourses and practices enabled us to hear participants more clearly. Sometimes, they limited what we could hear and enact. In this chapter, I want to do the tricky work of tracing three intertwining strands of voices that spoke into planning: core organizational values, past program practices, and focus groups. Attending to these voices, I argue that 1) we hear participants and one another through other things we have listened to, and 2) we invite people to identify rhetorically through what we listen to.

The listening methodology employed in this chapter is meant to address gaps between intentions and on-the-ground practices, which are often revealed in patterns of tension or discomfort within a program. I see these trends as places of productive unease, and starting points for a process I call "listening back," or attending to the factors other than participants' perspectives, that informed particular structural and practical decisions. The methodology operates by first noting a point of tension and articulating how it aligns with participants' stated needs. It thus assumes that organizers have intentionally listened to community members and can trace their implemented practices back to intentional conversations, such as the focus groups Mamas Together employed. The methodology then looks for antecedent genres, or legacies of practice that organizers drew on as they shaped the practices of the current programs, looking for mismatch between past and current programs' goals and material realities. Material realities might include partnerships, funding constraints, limitations in space, supplies and staff, etc. Continuing to listen backward, organizers then ask what organizational values or beliefs were taken up in practices, as well as what larger circulating discourses informed how participants were figured. Where did participants express local, situated needs, for instance, but organizers might have heard cultural deficits because of the power of deficit-model 
thinking surrounding immigrant families? Or where were situated community needs both expressed and understood, but organizers drew on a model that assumed deficit despite having different program goals? Listening back aims to identify misalignment between values and practices - intentions and consequences — so that organizers can more clearly see deficit discourses, recognize the material realities of individual programs rather than carrying them over from one program to another, and seek out new models for practice that better align with their intentions.

While this may seem like merely a thought exercise, and a messy one at that, I think there's exigence for it. Community-based research is invested in creating deep relationships with reciprocal partners, and reversing, where it can, the silencing of unheard voices (Alvarez, Cushman, Flower, Moss, Mathieu, Parks). It's committed to both reflection and action - to critically examining current models of partnership and seeking develop new ones (Flower, Grabill, Feigenbaum, Mathieu, Rousculp). Many grassroots organizations, like Americana, are committed to the same. Again, though, listening literature often lacks details on methodology, and I do not think we can productively answer "how should we" until we answer "how did we"? What we hear impacts what we offer to participants, so that without attending to how we listen, and what we listen to, it's impossible to adjust our models or incorporate new discourses. To be ready to listen, we need to be aware of what else we hear. This conclusion informs my methodological contribution to listening scholarship: developing ways to hear how unacknowledged dominant discourses shape on-the-ground practices and create a legacy for future programs and partnerships. 
Given the work in rhetorical and community listening that I outlined in the introduction, my literature review explores two sets of discourses always present in family literacy programs: mothering discourse, and deficit-model thinking, especially as it applies to immigrant families. These are important to understand because they operate invisibly, so that even when a program does good work, the legacy of these ways of imagining participants can continue to influence organizers' choices. Having established these discourses as powerful, especially when unmarked, I turn to the three most direct things that organizers drew on as they planned Mamas Together: Americana's core organizational values, the programs that created models for enacting both organizational values and discourses about immigrant mothers, and finally the focus groups in which participants detailed their experiences and concerns. The chapter concludes by looking for the consequences of listening and enacting: two moments of tension, during which we stood under conflicting voices, made good-faith decisions, and wrestled with the implications of those choices in practice. My hope is that in attending to organizer's intentions, processes, and consequences, we can re-examine how we listen, attending particularly to the soundtracks of unacknowledged discourses, and thus create better space for listening to participants.

\section{Literature Review: Operating Discourses and "Rhetorics of Literacy"}

To establish the power of discourses, I draw from (transnational) feminist scholarship that critiques and extends the work of Michel Foucault. Foucault's influential work on discourses' regulatory power views language as not merely descriptive, but rather as a force that "constructs, regulates, and controls knowledge about the world" (Smythe and Isserlis 24). Given that his work emphasizes the power of large institutional 
structures on individuals and groups, Foucault acknowledges that power scales up and down, but is centrally interested in studying top-down movements of power through disciplinary, regulating discourses. Sociologists Stuart Hall and Dorothy Smith both draw on Foucault to point out the ways that discourses “'rule in' certain ways of talking about a topic," and thus "regulat[e] how people's subjectivities are coordinated, what can be uttered, what must be excluded, what is simply not made present," (Hall 72; Smith 18). Because of his top-down focus, some Western feminist work critiques his scholarship as over-emphasizing the ways institutional power orders individual lives, and underemphasizing subjects' ability to resist and reimagine powerful discourses (Fraser, Hartsock). While transnational feminists have used Foucault's work to study colonialism's pervasive "ruling relations," (Mohanty, Grewal) they have also critiqued some of the theorist's blind spots, including a Euro-centric focus on institutionality and race relations (Stoler, Hostettler) and silence on Western intellectuals' historical complicity in "(post) colonial global power relations" (Spivak, paraphrased in Hostettler 80). Drawing on both Foucault and on Spivak's critique of Foucault, Raka Shome argues that "instead of merely uncovering hegemony in Western discourses," the work of the Western transnational feminist critic "also needs to examine the power relations that structure her or his own discourses" (48, emphasis mine). Taking up Shome's call, then, I employ Foucault as he's been taken up in more recent work like Smith's and Shome's, both for their standpoint and because they share discourses about mothering and literacy programs that are relevant to my project.

My interest in discourses begins with the perspective of individuals and programs, scaling up to attend to the unacknowledged power of dominant institutional discourses. 
Dorothy Smith serves as a useful model here: her work begins explicitly with women as the standpoint from which her projects originate, while also acknowledging controlling discourses' power to homogenize populations at the institutional level. In her work on the standard North American family (SNAF) as an ideological code, Smith sees herself as extending Foucault's definition of discourse "as a conversation mediated by texts" to include "how actual people take them up, the practices and courses of actions ordered by them, how they coordinate the activities of one with those of another or others" "'SNAF" 51). Smith's definition reveals the great degree to which discourses order relationships, inviting people to find their place in relation to others within an institution and/or community, and even in relationship to the institution itself, organizing what kinds of relationships can exist through the created models that people take up and use. Given that institutional discourses organize people's activities and given the "recurring emphasis on relationships" in community-based research and writing, I posit that studying the uptake of discourses in community and family literacy programs involves looking at the relationships between the institutions housing the program and the individuals invited into it (House, Myers, and Carter 3).

Within literacy studies, John Duffy employs a similar kind of "invitational” language in his work on Hmong and Hmong-American literacy practices. Studying the relationship between institutions and literacy learning in Hmong communities, he argues that literacy instruction, formal and informal, is a rhetorical practice by which an institution invites individuals to take up certain places within the discourses it employs. Duffy defines rhetoric as "the ways of using language and other symbols by institutions, groups, or individuals for the purpose of shaping conceptions of reality" extending 
Burke's argument that rhetorical work is not merely persuasive, but "socializing" (15). That is, rhetorics of literacy ask people to understand their identities through the sponsoring institutions' values, taken up through literacy practices. Churches caring for Hmong refugees, for instance, employed a "rhetoric of Christian sponsorship," using Biblical instruction and hymnbooks to teach reading and Christian ideals (126). Public schools, through the use of literate practices such as teaching American history and reciting the Pledge of Allegiance, invited schoolchildren to "think American" as one participant phrased it, or imagine themselves as American citizens (144). The idea that literacy sponsors necessarily invite participants to align their identities with institutional values is important, since, outside of schools and universities, community literacy programs are one of the most central orchestrators of direct literacy instruction. Thus, programs must carefully consider how they use literacies rhetorically and what they invite participants $t o$.

The link between Smith's work on discourses and Duffy's "rhetorics of literacy" is in how an institution invites individuals to identify with its values, made clear through speech and written texts, and recognize themselves within those values. Often, those invited to take up discourses and adjust their identities are not invited to "stand under" them, in the way Ratcliffe means it. For Ratcliffe, standing under "swirling" discourses (208) means attending to the ways language "constructs, regulates, and controls knowledge about the world," and fits into invisibly operating cultural logics (Smythe and Isserlis 24). Since institutional discourses inform how individuals interpret the world around them, and their place within it, both participants and organizers risk adopting views that further marginalize vulnerable communities. An invitation to take an active, 
interrogative stance toward discourses, rather than merely adopting them, would benefit both participants and organizers in community literacy programs.

The following sections spend some time "standing under" two groups of centrally operating discourses at work (and/or being worked against) within any family literacy program: mothering discourses and deficit-model thinking, especially as it pertains to immigrant family literacies. In looking at mothering discourses, especially, I also draw on Duffy to outline a rhetoric of American parenting, which will be key to examining how immigrant mothers were invited to identify as a particular kind of parent during Mamas Together. At the outset, it must be noted that the two sets of discourses outlined here necessarily intertwine, and even inform each other; I have created an artificial teasing out to give myself space to explore them, but even within these sections, overlap is evident.

\section{Mothering Discourse and a Rhetoric of American Parenting}

Family literacy programs, as several scholars in education and literacy studies have pointed out, rhetorically position themselves to invite families—-particularly mothers - to identify with the program's values, and even to treat those values as an extension of "natural" parenting tasks (Smythe and Isserlis, Auerbach). Understandingor standing under-mothering discourses helps explicate a rhetoric of American parenting, with which institutionalized family programs invite participants to identify in the ways they teach and regulate literacy use. This section explores what mothers are invited to, and the ways they are asked to adjust their identities and mothering work to take up institutionalized family values and literacy practices. Just as there is no single "rhetoric of public schooling" or "rhetoric of workplace literacies," so there is no homogenous rhetoric of American parenting across family literacy programs. Rather, a 
look at literature on mothering discourses in family-centric texts reveals patterns of central, socializing rhetorics that family literacy programs take up, to set the scene for programs at Americana. In pairing research on mothering discourses with Duffy's work with the invitational work of rhetoric, we can ask how a "rhetoric of American parenting" invites transnational mothers to identify as a particular type of mother, taking up the values of institutionalized mothering discourse.

Mothering discourse, according to Griffith and Smith, orders what mothers can and should do for their children, articulating the emotional labor and organized work of mothering, as two parts of a bio-social connection between mother and child (87). Smith's work further explores the roots of mothering discourse in what she terms the standard North American family (SNAF) ideological code, which pictures the normal family as a male-headed household with two married, heterosexual adult parents; the father's employment provides for financial needs, while the mother's chief concern is home and family care (52). As a "schema that replicates its organization in multiple and various sites," SNAF informs a wide array of text-mediated discourses, including bureaucratic forms, popular media, educational reports, even research interviews (51). SNAF is powerful because "it infiltrates and shapes the ways in which individuals and communities act and understand their world to the extent that these actions and beliefs seem normal, natural, and thus, invisible" (Smythe and Isserlis 26). SNAF, and the mothering discourses it informs, is central to articulating a rhetoric of American parenting because of its power to order what institutions, individuals, and communities think of as "natural" and "deficient" within family functions. 
In their analysis of family literacy texts in four Western English-speaking nations, Smythe and Isserlis outline three intertwined mothering discourses employed across texts that "invite" mothers to partner in their children's education, sometimes through guilt: 1) "normal family" discourse 2) "mothering as pedagogy" discourse and 3) "maternal responsibility" discourse. "Normal family" discourse draws from Smith's analysis of SNAF, extending the language of nurturing and care to educational tasks. It assumes that mothers have the time, space, and mental and emotional capacities to oversee their children's education, starting long before children enter a classroom. The other two discourses proceed from "normal family" discourse. "Mothering as pedagogy" discourse employs the logic that "you [the mother] are your child's first and best educator," a seemingly positive commentary on parents' ability to pass their knowledge and passions to their children. Rather than recognizing parents' capabilities and knowledge stores, however, "mothering as pedagogy" discourse is used in family literacy texts (and programs) to point out deficits in mothers' abilities and to teach mothers to support and augment the work of the school (28). Finally, "maternal responsibility" discourse holds that "a child's success $[\ldots]$ is proof of a woman's success as a mother, while a child's problems $[\ldots]$ demonstrate mother's deficiencies" (Dudley-Marling 192, quoted in Smythe and Isserlis 30). Here, blame is more overt than in the other two discoursesrather than an invitation to "partner," the "first and most important teacher" is called to account for the ways in which she has not measured up to the institution's standards (or imagined standards in a program for younger children) and to adjust her work accordingly. 
Mothering discourses aimed at mothers of infants, toddlers and pre-school aged children employ many of the same discursive logics discussed above, in and out of family literacy programs. For instance, a playgroup or moms-group style program might focus on emotional and social literacy, teaching mothers to take up "therapist" and "emotion coach" roles as young children learn to process in relationship (Hoffman). While not explicitly educational, family programs connect emotional and social literacy to being equipped for school, as well as to the critical thinking and processing skills attached to educational attainment. Other mom-and-tot groups focus on health literacy-encouraging songs and poems coupled with active play. Here, an early version of "mothering as pedagogy" functions as moms are encouraged to exercise with their children, modeling healthy habits. "Mothering as responsibility" is also at work: creating healthy habits in toddlerhood is associated with lower health risks, including childhood obesity.

Even before a child can speak, mothering discourses operate in the form of giving them "the best intellectual start." In groups focused on infants, maternal bonding discourses often couple breastfeeding with "good mother" discourses (Barton, Wolf). In Western European countries, "breast is best" proponents link breastfeeding with more than early nutrition and biosocial connection. The mothering work of breastfeeding has been argued to decrease the likelihood of childhood obesity and asthma and increase IQ (Rito, et al., Kanazawa). Despite numerous studies working to de-link breastfeeding and IQ, specifically, the belief that breast milk gives an intellectual headstart is still firmly rooted in popular imagination. Again, mothering as responsibility discourse plays a role-if a mother can increase her child's future intelligence and health, shouldn't she? Jess Restaino has argued that a rhetoric of fear helps spread these early-life mothering 
discourses. Such rhetoric may be the precursor to the shame tactics Smythe and Isserlis found in family literacy texts. Of course, as with other SNAF-ordered discourses, this assumes the time and space to feed on command, and the income to either be able to stay home or pump at work. American-born minority and low-income mothers are less likely to breastfeed for this reason among others. Immigrant mothers, on the other hand, are as much as $85 \%$ more likely to breastfeed their children, though "each additional year of US residency decrease[s] the odds of breastfeeding by 4\%" (Gibson-Davis and Brooks-Gunn 641). This exemplifies a persistent contradiction within mothering discourses: while mothering is treated as a bio-social action, this research suggests other forces at play, such as limiting socio-economic structures that keep immigrant mothers in low-wage, hourly jobs and wear down their ability or willingness to nurse.

In addition to regulatory discourses that assume white motherhood, family literacy rhetorics aimed at transnational mothers also take up global motherhood discourse, which positions white women as "global mothers," able to rescue the world's children, and in contrast presents brown mothers as necessarily failing to care for their children (Shome 397). Global mothering discourses enable white savior rhetorics in international adoption, white celebrity "poverty tours" through UN ambassadorships, and popular media like Born into Brothels, and as such are often aimed at white Western audiences (Shome, Hesford). I explore global motherhood discourse in detail in chapter four, when I explore how grant narratives draw on these ideas, but they also rate a mention here, given the frequency with which family literacy programs are staffed by white women and aimed at minority and multi-lingual women. In community literacy programs, global motherhood discourses function when white organizers or speakers 
assume that immigrant mothers need their help learning parenting tasks — nursing and sleeping arrangements for infants, or the importance of literacy for school-aged children—rather than assuming, as research indicates, that women draw from cultural knowledge that may not align with American parenting styles. It is crucial that those planning family-centered community literacy programs knowingly stand under the intertwining "normal family," "maternal responsibility," "mothering as pedagogy," and "global mother" discourses and listen to the ways they inform what we invite participants to. The following section shifts focus from discourses that regulate the home to the deepseated belief in the deficiency of immigrant students and family's literacy practices.

\section{Immigrants and Literacy Education: The Legacy of Deficit-Model Thinking}

Literacy scholarship concerning Western-based (US and European) organizations' interests in foreign countries_-including schools, NGO and government-sponsored literacy programs, missionary efforts, and refugee resettlement programs within campshave noted the frequency with which the sponsoring organizations or governments' interests are made forefront, "inviting" participants to think of themselves as members of the institution, sometimes in ways that ask them to sacrifice identifying with their community of origin (Christoph, Duffy, MacDonald, Powell). Likewise, scholarship focused on immigrants and refugees in American literacy programs - including government-sponsored re-education programs, community and church programs, and K12 classrooms - has often noted the push to assimilate new immigrants into majoritarian culture through English language learning (Vieira, Duffy, Lam and Warriner). Kate Vieira, for instance, argues that "literacy's association with cultural assimilation [...] has haunted immigrant education for over a century," from Americanization campaigns in the 
early twentieth century to modern English-only campaigns (25). Aptitude in particular national literacies is tied to images of "model immigrants" and even "good citizens," as evidenced by national citizenship tests. Educational spaces, including programs sponsored by the National Center for Family Learning (NCFL; formerly National Center for Family Literacy), frequently participate in the "good citizen" myth by inscribing transnational learners as "deficient" or "lacking appropriate tools for competence." Rarely do such institutions examine the unequal structures that keep immigrants from traditional models of success, nor do they consider the potential wealth of cultural knowledges and literacy practices (Roy and Roxas, Yosso, Gedalof, DePouw).

Commonly, the terms "deficit model" or "deficit thinking" are applied to educational programs that work from an assumption that participants of a particular cultural or class background require additional tools and teaching to reach satisfactory levels of educational attainment. While immigrant families do draw benefits from learning English and cultural navigation, these goals are often framed as if immigrants themselves are inherently deficient. Such programs ignore both the structural obstacles to these learning goals, and the wealth of knowledge that immigrant communities bring with them about topics like education and mothering. Tracing deficit thinking's history in American education, Valencia notes the pattern of blaming minority students for what the school views as inadequacies:

The deficit thinking model is, at its core, an endogenous theory_positing that the student who fails does so because of his/her internal deficits or deficiencies. Such deficits manifest, adherents allege, in limited intellectual abilities, linguistic shortcomings, lack of motivation to learn, and immoral behaviour. (6-7)

Studies of deficit thinking within minority groups have exposed some of the specific harms that come from a core belief in their intellectual and moral failings. Roy and 
Roxas, studying Somali Bantu families resettling in the US, found that teachers and administrators frequently named "lack of motivation," and a culture that did not "value education" as reasons for students' difficulty with adjustment. Few, however, acknowledged "what the school was lacking in terms of knowledge and resources," including teacher training for helping students with war-related trauma, and avenues that allowed families to work with teachers to find compromise (528). In contrast, interviews with parents highlighted their emphasis on hard work and educational attainment, and students expressed frustration over the difficulty accommodating both school norms and cultural beliefs. Because the school system believed that Somali Bantu students were illsuited for mainstream school, they did not provide training or resources, resulting in the removal of all Somali Bantu students to an alternative school in the year following the study. While others studying the harm of deficit thinking to minority communities' attainment have noted frictions that keep them from success and make it harder to identify as "good student" within a particular context, Roy and Roxas' example indicates higher potential consequences of deficit-model thinking operating at the level of educational system.

Studies like Roy and Roxas' clearly indicate the accuracy of Valencia's conclusions - that deficit-model thinking blames victims for intellectual and moral failings, while obscuring structural faults within community institutions and perpetuating xenophobic practices. Further, the harm of deficit-model thinking is well-researched and the conclusions widespread, not just in academic scholarship, but in educational literature circulated in community organizations as well. And yet, deficit-model thinking continues to have hold in school systems and community programs, many of which claim to 
practice strengths-based models instead (Crooks). Therefore, the power of deficit-model thinking — the reason it can perpetuate—must be in its chameleon-like ideology. That is, deficit thinking is so culturally embedded that it can begin to look like empowerment rather than the perpetuation of structural inequalities.

Remedying a "cultural deficit" is often framed, for instance, as "giving tools," to minority cultures, or "providing an equal start." This language sounds like creating a more equitable system for marginalized populations, but obscures the need to question the educational and community systems that require a particular set of "tools," instead forwarding practices that have allowed white, middle-class students to succeed. Literacy "tools" are taught as though literacy is stable across cultural experiences and socioeconomic backgrounds - as though writers can gain and then call on skills as needed, and predict their successes based solely on how well they utilize literacy "tools" (Lorimer Leonard 8). Further, deficit-model programming often treats minority populations like blank slates, ready to be filled with the so-called "common" knowledge of majority cultures, rather than acknowledging existing cultural knowledge and literacy practices that have may have been used with success for generations (Street; Janes and Kermani). As Janes and Kermani, among others, have pointed out,

People from nonmainstream backgrounds do not come tabula rasa to the educational system, but rather have deep and powerful attachments to their own local knowledge and its transmission, and that is frequently why they have difficulty 'seeing' elements of classroom culture that mainstream teachers and students take for granted. (465)

In other words, even if the idea of developing a multi-lingual writer's "toolkit" were only based in altruism, "adding tools" is never as simple as effectively teaching the literacy practices that have been successful in majority cultures, such as reading before bedtime 
(Janes and Kermani) or learning thesis based organizational practices (DePouw).

Structural inequalities, cultural understandings of communication practices, and even the results of past experiences with particular types of writing all inform an individual's willingness and ability to implement particular "tools" (Lorimer Leonard, Lu and Horner, Williams).

Implicit, and sometimes explicit, in both the "good citizen" and the "equal start" narratives is an idea that educational attainment starts at home, and thus that the familyits parenting practices and its literacy practices - must be transformed. Proponents of the "good parent" myth believe in the ability, and duty, of family literacy programming to instill parenting and literacy values that "break the cycle of intergenerational undereducation and poverty, one family at a time, by changing the 'messages' communicated at home....about education and the expectation of success" (NCFL 1994 mission statement, quoted in Auerbach 102). As Auerbach points out, family literacy organizations often do not think of themselves as deficit-minded, using keywords like "empowerment" and "drawing on strengths" as they describe their approaches to "eradicate poverty through education solutions for families" (NCFL, 2020, "Mission Statement"). However, in practice, "teaching parenting" through read-at-home programs and parenting classes "often invoke a strengths rhetoric for intervening in the internal workings of family life. Parents are taught specific middle-class ways of disciplining their children, talking to them and playing with them" (103). The mothering discourses discussed above are clearly at play here; in teaching ways of "disciplining, talking, and playing" with children, the mother as "first and best educator" is invoked, but in a remedial space. Families are invited to see themselves through the lens of the family 
literacy program — as currently lacking, but able, through the work and values of organizations like NCFL — to be empowered. Thus, deficit-model discourse can also contribute to a rhetoric of American parenting through the way it orders literacy values.

The intertwining of these narratives about literacy — that literacy enables and signifies good citizenship, intelligence, and familial success—is crucial to understanding the dominant narratives that Americana, and thus organizers in Mamas Together, wrestled with as they listened to focus group and program participants describe service gaps. Again, the discourses that figure immigrant mothers as deficient are powerful for literacy sponsors hoping to do good work because they circulate using "empowerment" and "tool-giving" language. While, as Goldblatt points out, we should not think of sponsors as only negative, we should proceed with caution given their power to shape, enable, and withhold (Brandt). We should examine the rhetorics of motherhood that circulate in any "parenting program," and particularly given the uneven power dynamics at play with racial and linguistic minorities.

It may seem that I am establishing a binary between "American parenthood as the ideal" and "listening and acting ethically." The reality is less clear-cut. While community-based scholarship does want to redress the harm of deficit-model thinking through a different type of community relationship, standing under the values, discourses, and institutional practices that help shape a program model reveals not a dichotomy between "ethical" and "harmful" practices, but— to further the hearing metaphor—a dichotic of blending and competing narratives that become more complex as organizational values and histories and material realities become practices. 
In the next section, I pivot momentarily from discourses to study organizational values closely. My goal is to look at intentions in listening, before studying how discourses and values combine in practice, to create the layers of voices organizers heard in focus groups.

\section{Values, Program Legacies, and Focus Groups: The Voices We Heard}

In articulating the importance of "stance" for community-based researchers, Jeff Grabill defines it as "a position or a set of beliefs and obligations that shape how one acts" as they approach community-based work. Stance, he argues, is for the communitybased researcher "the single most important issue to consider when researching in or with communities and needs to be better understood in any conversation about research methodology" (211). Stance is informed by our positions - the discourses researchers listen to and the beliefs they enact as a result. The concept is similarly useful in this conversation, because of its connection to organizational philosophy, voiced in staff members' articulations of values at work, as they become trainings, programs, and practices. In articulating a methodology for listening, we must begin by paying closer attention to the beliefs and obligations that shaped our early choices.

Here, I'm interested in the voices organizers attend to as ethical commitments become practice, knowing that enacting values based on intentional listening is never straightforward. Arguably the clearest place to listen back to is the focus group findings and resulting brainstorming sessions. Focus groups directly impacted the structures we created in Mamas Together. Further, when advocating for better listening in communitybased research, the emphasis is often on crucial face-to-face conversations between community members and the researcher/organizer. I discuss focus groups last, however, 
suggesting that some of the tensions we found in program implementation resulted from other "voices" we listened to. While organization may seem top-down, examples clarify that my listening methodology begins with noting a moment of tension within enactment and then working backward — a bottom-up approach that begins with a participant/organizer interaction.

To locate the power of these other speakers, I listen backward to the commitments that Americana has made to the community in previous programs. Namely, I map out the organization's four core macro-values because staff members understand them as central to Americana's work at every level of practice. Because values are always negotiated as they become practices, I then locate them in the two programs that most directly impacted choices we made Mamas Together: Family Education and Community Engagements. These programs, I argue, took up both core values and operating discourses in particular ways that, while they may have supported participant goals, also colored organizers' listening and enactment in Mamas Together. I then look at focus groups, with the soundtrack of values, discourses, and past practices playing as organizers attend to participants' spoken needs.

\section{Americana's Core Values}

When Leah and Julie, as full-time Americana staff, talk about their goals in program development, they both turn to Americana's motto "bridging the gap between surviving and thriving." Then, they explain that motto through the organizations' core principles: social justice, holistic development and human dignity. To this set, Julie adds cultural humility. I see these four principles as a set of macro-values that operate at every level of practice at Americana. Throughout their descriptions of programs and practices, 
both women return to these principles, indicating that they align their decisions with this macro-value set. Given how often Americana’s programs (including Mamas Together) begin by hearing participants' stated needs, I think we can take this a step further: what organizers hear is filtered through their commitments to social justice, holistic development, human dignity, and cultural humility. To understand how organizers listen, we need to start by clarifying their values in action.

In order to tune in to operating values, we need to establish three things: clear definitions, relationships between values, and values in practice at multiple levels. To come to an understanding of values' power and work at Americana, I coded Leah and Julie's interviews for beliefs, motivations, goals, and practices, looking for relationships and the presence of the four macro-values in the ways they discussed Americana's practices at multiple levels. My goal in this section is to set-up the values that organizers are committed to enacting before showing how they can be interpreted through mothering and deficit-model discourses as they become programmatic practices.

The four macro-values_-social justice, holistic development, human dignity, and cultural humility — always exist in relationship, but are also distinct. Definitions are flexible, based on different stances and situations, which becomes clear listening to Leah and Julie talk through them. Julie, speaking as a program director, defines enacting social justice as an organization using their resources_- "education and [...] social support" at Americana - to create "equal opportunity [for people] to get things that they need in a community." Leah, who helps individual families navigate community institutions in her coaching role, adds advocacy to Julie's definition. Social justice is "knowing that there will always be someone to fight for them," and "tell [outside organizations] what is 
wrong." Second, Leah defines holistic development as providing complex, multi-faceted solutions rather than a "quick fix" or "a bandaid," and keeping the focus on participants' self-identified goals, rather than those determined by an institution. Julie provides examples of how holistic development means recognizing interconnected needs: while English proficiency or job skills may be an obvious need, they are tied to social and economic systems set up without immigrant families in mind. Thus, adult immigrants need access to both individual and structural knowledge. Within family relationships, surface dysfunction often indicates past physical and emotional trauma, exacerbated by a lack of resources post-immigration. Thus, trauma counseling and access to resources work hand-in-hand to move a family forward. Development is a complicated process, requiring complex, multi-faceted solutions within programs. Third, human dignity is "see[ing] the whole individual" and not "just their abilities [...] or their capabilities" from Leah's coaching standpoint. Another way to phrase it might be seeing a person's humanity rather than their either what they lack, or what they can be used for. Julie's definition is two-fold. From a programming point of view, she says it is "understanding that it doesn't matter if someone's purple and from the moon, they deserve everything that you [as an organization] have." As an attitude, she describes recognizing a person's humanity through "building relationships over time [...] because people slowly uncover layers of themselves and [...] what's going on in their life and what's gone on in their life that really inform who they are right now." In community listening, the call to this reserve judgement in favor of deep human relationships seems aligned with this definition (Royster, Ratcliffe, Fishman and Rosenberg). Finally, cultural humility, Julie says, means a member of majority culture being willing to "not be an expert," to sit with 
discomfort rather than making quick judgments about cultures or individuals, and to "apologize often." While this description, in particular, sounds like an attitude that functions best in one-on-one interactions, all four macro-values scale up and down, as the end of this section demonstrates. These four macro-values, both distinct from and dependent on one another, make up Americana's core philosophy, animating organizers' decisions. When participants voice their needs and experiences, organizers hear them through a commitment to macro-values, which shape how they move from theory to practice.

Singling out individual values creates an artificial construct because they always exist in conversation with one another, materialized in practices. In studying how they play out in relationship, we can see values working in an organization, moving from the realm of organizational philosophy to a traceable part of the organization. One way to visualize values-relationships might be as a Mobius-strip: at different junctures, different materializations of values come to the fore, but cannot be separated from the whole. For instance, Julie's articulation of social justice as "people having equal opportunity to get things that they need in a community" incorporates holistic development, or the recognition that needs are interconnected and require complex solutions. Americana's Family Education program, detailed below as a model for Mamas Together, enacts the intersection between these two values in offering parents both English and parenting classes, and preparing children for kindergarten in a Headstart-like setting — giving access to a major community institution within the safe space of Americana's campus. Leah's definition of social justice, as advocating for "every single person who walks in these doors" and letting institutions know "what is wrong" incorporates human dignity-which 
Leah and Julie together define as treating people as worthy of "everything [an organization] ha[s]," because of their humanity rather than their "capabilities." In practice, these intersecting values may look like using a staff position and membership in majority culture to challenge racist institutional practices. Leah names specific instances of interceding, including explaining refugee status to an insurance company, and pointing out institutional racism to a university admissions department. Julie and Leah's examples are both responses to participants' spoken needs, but they emphasize values differently, demonstrating how values-relationships animate distinct practices at Americana.

Not only do values intersect in practice, but they also scale up and down, informing program development, structures and practices, and individual interactions. Here I include two lengthy examples, from Leah and Julie respectively, to show how intersecting macro-values create a soundtrack for organizers that functions at every level of programming. The first example further contextualizes Leah's definition of social justice. Her coaching work moves between helping with individual goals and navigating institutional structures. A lot of families' goals require them to work with community institutions — banks, landlords, employment offices, educational institutions, etc. —so Leah and other coaches spend a lot of time making phone calls with families:

A lot of the times people [...] feel like they can't express themselves over a phone $[\ldots]$ because they know the person can't see them and [...] doesn't really understand them. So they have someone who's here with them who can help advocate for them, so [if] something goes wrong or they feel like they can't express themselves, then the person with them can express it for them.

Families define their own goals and steps - part of a commitment to holistic development—and coaches believe that participants need what they say they need —a central tenet of human dignity. At an individual level, Leah says that she's helping people 
build confidence as they learn how to get what they need within the safety of a coaching office. She enacts social justice through committing to step in when asked, recognizing that enacting values in one-on-one relationships is not always enough to create equitable outcomes. Coaches' commitments to holistic development, human dignity and social justice scale up here, in the moments "when something goes wrong" at the level of institutional practices, using their language skills and social capital to make families' needs legible to institutional representatives.

Julie, who has a bird's eye view of programming, gives another example of enacting values at multiple levels, describing a community representatives project in which young community leaders collaborate on common problems:

All of [the participants have] this very unique knowledge about their communities, about our community, and about the way the world works [...]. We could be doing more to lift up their voices and also make sure that they have the skills necessary to advocate for bigger groups [...] You wanna listen to them, then bring them all together $[\ldots]$ and show them the ways that leadership is accepted. Not like how to be leaders, but "these are the people you have to talk to and this is the way that they listen." [...] This is about people who [...] on their day off take their friend to the food stamp office and interpret for them. Those are the people that I really want to be involved in this, because [...] they're the people doing the legwork behind it.

In Julie's desire to create space for these young leaders to talk to one another, as well as what Grabill might call, "the rhetorical ability to participate effectively," her commitment to all four macro-values operates at multiple levels (24). First, standing under cultural humility and human dignity, she recognizes that program participants have unique cultural knowledge and experience navigating institutions. They don't need someone to determine what their community needs. They also do not need help at an individual level: they have advocated for friends and neighbors on their own. They need a coalition, and 
some help learning the rhetorical strategies that enable bigger changes. Holistic development operates in helping participants gain access to structures, rather than trying to better prepare individuals to "fit into" a set of structures that was created without attending to immigrant communities' needs. Thus, Julie has built a program that enacts her vision of social justice as "people having equal opportunity to get things that they need in a community." The program's structures allow community members to own their cultural knowledge and work together for holistic change, while staff members' central role is to create space and add rhetorical and institutional knowledge where they can.

Emphasizing Americana's core values as the first thing organizers attended to when making early choices for Mamas Together, benefits the larger argument of this chapter in a couple of key ways. First, it helps to situate Mamas Together as a program within a larger institution, organized by a core philosophy. If we are searching out the soundtrack that was playing as organizers listened and planned, core values provide the steady rhythm. Second, taking the time to work through core values serves as a reminder to read practices generously first, seeing them as the negotiation between organizers' intentions and the material realities of programs. The next section spends more time examining material realities, through looking at how values are negotiated in partner relationships, and how their negotiated uptake creates antecedent genres of practice, with which new programs, like Mamas Together, must wrestle.

\section{Programs and Experiences}

In our program recap and personal interviews, Danielle, Leah and I often discuss previous trainings and program experiences to explain the practices we enacted in Mamas Together. Some of our guesses about effective practices were drawn directly from 
previous experiences with a particular type of participant, to varying degrees of effectiveness. For instance, Danielle had spent time as a camp counselor but had little experience with babies and toddlers. She initially planned to create centers for Mamas Together with coloring pages, books, and musical instruments. After spending two sessions with toddlers, she dubbed herself the "child wrangler," and kept the box of musical instruments in her office, opting for quieter, more age-appropriate activities. As I planned for the mother group, I drew on the kinds of community-building practices I found effective in first year writing courses, suggesting a time of reflection on a central question and then sharing if women felt comfortable. While we did follow a model that asked women to share their experiences surrounding the topic, my suggestion to have women write first, in order to reflect, revealed the link I see between the written word and deep personal thought. It did not, however, consider women's varying literacy levels or the differences in cultural and individual attachments to writing. We found that for our community-building purposes, a model in which we asked each woman to share her opinion verbally was more effective.

While casting back to a similar audience is a direct way of imagining a current audience, I think a focus on practices within past programs is stickier and more formative influence. Programmatic practices enact values and discourses in ways that create patterns for future programs to follow. In the two influential programs explored below, Americana's core values were always at play and in tension with other organization's values and the uptake of popular mothering and deficit-model discourses. Examining Family Education and Community Engagements, two programs that closely informed 
Mamas Together, gives us a point of tension to tease out how practices enact discourses and values and create antecedent genres, or patterns of practice, for future programs.

\section{Family Education}

Family Education is Americana's largest family literacy program and establishes a model for other programs. Mamas Together was developed as a counter-part to the Family Education program, both to emulate its strengths and to respond to challenges we saw in the model. The way Family Education enacts organizational values, as well as mothering and deficit-model discourses, created a pattern of practices that Mamas Together wrestled to navigate. My literature review frequently examines discourses in texts rather than programs, but I would argue that Family Education's practices functioned much like antecedent genres in textual creation. When we created plans based on what we heard in focus groups, we could not simply ignore past practices in favor of new practices that better fit participant needs. Rather, we had to determine whether to respond using the Family Education model or to intentionally make a break.

In this section, I briefly explain the program's set-up. Then, examining the uptake of values and discourses, I focus on one pattern in the Family Education model - the teacher/student relationship. This was an area that Leah and I worked away from in creating Mamas Together, but that created discomfort for Leah especially, as an Americana staff member experienced with the Family Education template. My aim in this section is not necessarily to critique or praise Family Education, though I do question whether there is space for participant perspectives within its model. No program can do everything, and Family Education has accomplished important work for the Americana community. My focus, ultimately, is on Mamas Together, and the legacy Family 
Education created through a particular way of enacting discourses and values. The relationship between teachers and students, in particular, created a model that we "stood under" while we listened and planned (Ratcliffe).

Americana's iteration of the Family Education program began in 2015, as an "intergenerational approach" to giving immigrant and refugee families "a leg-up in the community" (Julie, personal interview). Specifically, it is meant to provide families with access to educational and institutional resources, so that they can meet personal goals for themselves and their families. The program is housed at Americana and staffed by both Americana and Jefferson County Public Schools (JCPS) personnel, in what Julie calls a "true partnership." Funded by the National Center for Family Learning (NCFL), Family Education uses a model common to NCFL's literacy programs, especially those aimed at immigrant families. It consists of four components: ESL classes, school preparation, "parenting in the US" classes, and parent and child together (PACT) sessions. As noted above, Americana's version of Family Education also includes optional meetings with a family coach, who helps participants define and work toward goals they define in one-onone sessions.

The first three components of Family Ed are instruction and information-based, teaching both language and American culture. Sessions take place in traditional classroom settings, where students sit at tables and the teacher stands at the board or walks around the room, leading participants through the lesson. Past parenting-class topics include registering children for school and creating weekly menus from grocery store ads, so navigating community institutions, especially through texts, is clearly important. During PACT sessions, parents and children participate in a literacy activity 
together-listening to a book, listing New Year's resolutions, creating caterpillar life cycles with pasta, etc. This is meant to "reinforce traditional parent-child roles," that can become inverted as families adjust to a new culture. (Leah, personal interview). While Family Education is open to any parent with a child two to five, the majority of attendees are mothers, a pattern typical of family literacy programs.

Since its introduction, Family Education has had a waiting list every semester, in large part due to its place as a cultural and institutional embodiment of school. Family Education's sponsorship by JCPS and NCFL has speeded its establishment as an accepted educational institution within the community, which, as Foucault notes, grants it some power to regulate what counts as knowledge and who disseminates that knowledge. In addition to institutional sanction, through affiliation with JCPS and NCFL, Family Education possesses accepted structures that establish its legitimacy as an educational institution. These structures are both material—like classrooms with white boards—and institutional — like teachers and end of term program assessments. Thus, like a school or literacy foundation, it has the power to reify the creation and recognition of relevant knowledge. As a well-attended, institutionalized program, it has set a precedent for how effective educational programming proceeds at Americana. It has also become part of organizational culture - if social justice, human dignity, holistic development, and cultural humility are Americana's value set, Family Education outlines methods by which participants move "from surviving to thriving."

On the surface, there seems to be very little tension between Americana's goals and those of its partners. Julie asserts that " $99 \%$ of our partners align with our values," but vary in "how $[\ldots]$ we work around greater policies." While I think her estimate is 
optimistic, I take her point. Americana chooses partners that not only use similar language to describe their values, but who want similar outcomes. I believe that JCPS and NCFL genuinely want immigrant families to have the support they need to meet educational goals, and thus help sustain a program that provides vulnerable families with socio-educational resources, free of charge. The rub, however, comes from three factors that build on one another: 1) varying definitions of core values, 2) unmarked discourses surrounding immigrant families, especially mothers, and 3) on-the-ground practices that create a legacy for other family programs to follow.

Americana's core values are always in play in Family Education, but both material needs and the reality of power differentials impact how values play out. Partnering with other organizations means that values necessarily shift some to accommodate partners. The public school system and NCFL have been useful partners, providing staff and funds that Americana cannot provide on its own. As separate institutions, however, they bring their own set of values, defined through their own histories of organizational practices. As organizations focused on family literacy, they also function as culturally-accepted gatekeepers of "relevant knowledge." This power is regulated through their uptake of mothering and deficit-model discourses and informs how values are enacted. As the literature review above indicates, educational and paraeducational institutions often invite mothers to help fulfill institutional goals, rather than asking how the school or program might adjust to fit the community's specific needs (Roy and Roxas, Auerbach). Without recognizing the power differentials between those who disseminate and receive knowledge, it is impossible to take intentional steps to reduce them. Perhaps JCPS and NCFL have taken such steps. My limited observations 
did not suggest this. Thus, Americana must negotiate between its values and those of its partners within Family Education. One element that became particularly important for Mamas Together was the teacher/student relationship model. In examining it, we can see core values at work, as well as the negotiation of those values.

Family Education's focus on giving information and resources makes it seem natural that it operates as a top-down structure with clearly defined roles. Again, as Foucault reminds us, institutionally-sanctioned programs hold power to regulate whose knowledge counts as socially useful, not only for educational or financial success, but even to complete daily life tasks, like grocery shopping or playing with children. We see this tension between Americana's desire to enact core values through privileging participant experience, their power-here through Family Education — to regulate "official” knowledge clearly in the student/teacher relationship model. Family Education is primarily a top-down program, with clearly defined roles. The model is largely teacherled, and building community between participants or complicating the student/teacher relationship depends on the personality of the instructor; it is not built into the structures of the program. ${ }^{5}$ Leah articulates the clearly defined relationship between teachers and students:

There's lots of interaction between the student and the teachers, but as how [participants] best take in knowledge, they can write down things, and they can say "oh, who is this person? Oh this person's teacher. This person, they tell me information."

This imagined internal gives an important clue about Family Education's work as an educational program: it privileges imparting information over building on students'

\footnotetext{
${ }^{5}$ There are many definitions of community and Grabill's Community Literacy Programs and the Politics of Change includes an excellent review of the term's uptake. Here, I mean a space where participants share knowledge and rely on each other as resources within the program, rather than an instructor serving as the primary knowledge-bearer.
} 
cultural resources. Explored in depth later, Family Education's focus created tensions for organizers when we created roles in Mamas Together. My particular pedagogical training and experience in community-based research makes me wary of teacher-centered classrooms, especially involving frequently marginalized populations. On the other hand, Leah's position as family coach leads her to believe that clear roles can provide comfort for participants struggling with English. In other words, a clearly structured relationship in which participants' roles are to take in information might diminish discomfort with language or institutional structures. Being able to sit and listen may provide relief from the work of navigating other institutions - the bank, the social security office, the doctor, even the grocery store-where full participation is crucial.

Listening to Family Education's roles from this perspective, we can see both Americana's core values at work and the ways they are negotiated in practice. Social justice is at play, for instance, as staff use institutional resources to give people "equal opportunity to get things that they need in a community" (Julie, personal interview). Human dignity functions in the form of meeting participants where they are, and treating learning as a process. Holistic development ensures that English language learning is not disconnected from child-rearing or job skills: meeting goals means work in many interconnected areas of a family's life. While Auerbach criticizes NCFL's family literacy programs as "intervening in family life," neither the participants in Family Education nor the staff invested in their success necessarily see it that way (101). Recognizing the significance of these values at work is crucial: they have laid a pattern for how participants' goals are met, and thus color listening and planning. 
In examining relationships, we can also clearly see negotiation between the way school systems understand something like "social justice" and the way Americana understands it in other programs. Julie's examples of social justice advocate amplifying the work participants are already doing, and helping them learn rhetorical strategies to increase their impact. Leah's examples demonstrate using her position to call out discriminatory practices. In both cases, staff use institutional knowledge to meet the community's specific needs. In the case of Family Education, however, "granting access" means moving families toward meeting school system's goals rather than taking the work that families are already doing into account. Within parenting classes, curriculum is based on school outcomes, and preparing to enter that institution becomes a personal goal for participants. Mothering discourses invite women to partner with the school system to make sure their children meet an institutional definition of success. Texts, including sale papers, popular children's books, and school registration portals, all familiarize parents with their new community, but they also invite parents to identify with the rhetoric of "American parenting" literacy (Duffy). This socializing rhetoric is difficult to complicate without intentionally building space for participants' knowledge into a program's structures. In examining Family Education, we can hear both the comfort that Leah rightly prioritizes, and the possibility for perpetuating deficit, rather than strength, narratives. For a listening methodology to do good work, it must attend to all of these elements: the intentions, the circulating discourses, and the ways that program structures enact both.

The teacher/student relationship structure was a particular challenge that Leah and I hoped to tackle in Mamas Together, because of the way it privileges institutionally- 
approved knowledge at the expense of women's existing resources. Thus, we intentionally made participants' knowledge more central to our program. This choice was challenging in ways that I did not anticipate, however, because of the pattern of practices that Family Education created, which had consequences beyond that program. In planning Mamas Together, staff heard participant requests through Family Education's popular model. The first example, at the end of the chapter, works through this listening process and analyzes a tension between mine and Leah's understandings of values as we sought to break with the Family Education model while still creating a program that participants (and staff) recognized.

\section{Community Engagements}

Part of Family Education is a monthly program called "Community Engagements" during which outside community speakers are invited to talk to Family Education participants about community resources and topics of interest. Examples of past sessions include using the public library and enrolling children in public school. These engagements are an established enough practice at Americana that preparing for them was a major part of Danielle's Americorps Vista work. Community Engagements can be difficult however, because successful communication relies on speakers' familiarity with multi-lingual audiences and ability (or willingness) to re-work their material for their listeners. Staff members send ESL speaker guidelines and tips, but Leah notes that "some people read it; some people don't." Even those who do may not know how to use the information:

Some people just, they come in and [...] they do what they regularly do and they see how people respond $[\ldots]$ and that's when they kind of get it and they start looking to the facilitator to help guide them, so it's either had to be like we have to 
have interpreters for different language groups whenever speakers come in or you have to be like "okay, [...] let's re-say this cause it looks like not everyone's on the same page," and then the person talks and we stop again, and again. And that's always been how to go about doing it.

We can both extend generosity and attend to consequences here. When well-meaning but busy people speak to an unfamiliar audience, they often prioritize their message over their listeners' needs. They may never even consider how to incorporate participants' knowledge or experiences. ${ }^{6}$ However, invited speakers' unwillingness or inexperience with linguistic minorities creates another clear distinction between talking and listening roles. Despite this issue, connecting immigrant communities to beneficial services is important enough to Americana that they continue hosting Community Engagements, knowing that staff will serve as go-between for speakers and participants. Staff prepares much as possible to fill in the gaps between partners and participants.

Given our goal to provide access to resources while building community in Mamas Together, Danielle comments on the risk she saw of drawing on Community Engagements as a pattern. She notes surprise that we could strike any balance between our desires to build community and provide access to resources:

I was worried we weren't going to be able to have [Mamas Together] as discussion-based as we wanted it to be. [...] I knew that we had a lot of information and we were bringing in speakers and the participants were still learning English and I just wasn't sure how all of those dynamics were going to work. [...] I feel like when people are uncomfortable, it's easy to just fall into the pattern of someone was just gonna teach the class. [...] I mean sitting in on the Community Engagements, [...] there's no discussion. It's gonna be "the nice lady from [the public school system] is going to outline the process [of applying for school] and answer questions." (emphasis mine)

\footnotetext{
${ }^{6}$ In my experience, the library presentation was an exception to this rule. The presenter had clearly considered her audience: she brought books in several languages and gave women ample time to explore books together. Thus, this session became a site for enjoying one another's culture rather than teaching majority culture.
} 
Danielle's reflection nicely frames my purpose in describing Family Education and Community Engagements, which is to show the tensions between the voices that inform common practices. Americana's core values align closely with calls in community-based research that seek to dismantle deficit-model thinking through careful, thoughtful crosscultural conduct. They want participants to feel seen and have needs met. Staff's commitment to advocacy against unjust institutional practices permeates their relationship with participants, especially at an organizational and individual level. At the same time, there are competing narratives about immigrant families' needs. One clear narrative frames immigrant families' knowledge and experiences as important, and says that they need to be invited into full participation. The desire to give information stresses the importance of cultural navigation in a new community. Another narrative, that can look the same, draws from deficit-model discourse and "mothering as pedagogy." It says that immigrant families need to be "caught up" to what their English-speaking peers already know. It invites them to a narrow rhetoric of American parenting, defined and propagated by educational institutions. Neither of these narratives comes from inside Americana, nor do they originate with their partners and invited speakers. They exist in tension with one another at every level of work with immigrant families, and compete with one another to be heard.

In Family Education, the conflict between narratives stem from NCFL and the public school system - the funding and partnering organizations in Family Education, respectively. Creating programs means negotiating visions of what relationships and roles should look like, sometimes knowingly, other times unconsciously. The real material limits of creating community programs - such as the need for funding and staffing- 
necessitates this kind of negotiation, not just at Americana but at all grassroots community organizations. Community Engagements are limited by the tension between needing to connect immigrant communities with institutional resources, and not being able to control what institutional representatives understand about transnational audiences. It is okay to have programs where information is the primary goal, but Community Engagements had a different purpose for inviting speakers than Mamas Together. Listening to focus groups' goals invited us to enact Americana's values in ways privileged participants' knowledge and experience, and complicated the reproduction of knowledge (and therefore power) that institutional representatives often bring. The second example, at the end of the chapter, deeply explores moments of tension experienced by speakers invited to Mamas Together.

As programs take shape and become central to the organization's work, they create models for future programs: organizers look to what they know and align new programs with old programs, even as they recognize misalignment between crossculturally responsive ideologies and top-down, authority-based practices. Given my discussion of organizational values and past programming experiences as central shapers of Mamas Together's structure, the next section centers on how we listened to focus groups - carefully laying out our commitments and findings, while attending to the interpretive frames that prior program experiences created.

\section{Focus Group Findings}

A central goal in the creation of Mamas Together was the use of community perspectives to help design what would become a new program. While the large gap in programming for mothers with infants and toddlers was clear to Americana staff, who 
knew the frequency with which previously committed participants dropped out of programming after giving birth, the specifics of their experiences and felt needs were less clear. Thus, we decided to hold focus groups with the intention of designing a program that would serve the specific needs of this population. This decision to plan based on what we heard from participants is not unusual at Americana, but it did set Mamas Together apart from other family literacy programs, especially Family Education. Again, Family Education is staffed in partnership with the local school system and funded by NCFL (a national organization that began and remains based in Louisville). From its inception, Mamas Together was meant to be planned and staffed without outside grants, meaning that we had freer rein to implement what we heard participants asking for.

Julie and I drafted focus group questions, and I finalized them with Leah. In summer 2018, Leah and I held three focus groups on the Americana campus targeting Latina and East African women. An early target audience for the program was undocumented families, and a majority of undocumented participants at Americana emigrated from these regions ${ }^{7}$. Each focus group used a translator who had ties to Americana and to the community they were translating for. The daughter of the administrative assistant, who works with AmeriCorps, translated for the Latina groups; a liaison from Family Health Centers Americana translated for the East African group. Both women were themselves immigrants, but also held institutional roles within the organization, a trend at all levels of Americana staff. Thus, translators were both familiar with the organization and the community for whom they were translating.

\footnotetext{
${ }^{7}$ Americana staff does not ask about documentation or immigration status and instructs volunteers not to ask. Families often share such information with staff as they develop relationships, and/or when staff members advocate for families to institutions like schools and courts.
} 
Julie and Leah made lists of participants based on past participation rosters. Participants were invited and given reminders via phone calls. Typical of initiatives that rely on busy, transportation-insecure populations, far more women committed to focus groups than attended. Each of the three focus groups lasted approximately 90 minutes. The East African group had three attendees. Both of the Latina groups had only one participant; in fact, the second group was scheduled because of poor turnout during the first.

During the first group, I asked permission to record our conversation for better listening as we identified trends. Because the participant was undocumented and nervous based on previous legal experiences, she stated that she preferred not to be recorded, even without identifying information. I followed that preference with all three groups, taking notes rather than recording our conversations.

Each focus group started by inviting women to share their experiences as experts on their own stories, explaining that our goal was to create resources and programming for them and women like them. Early situating questions asked about pregnancy, birth, and experiences with child-rearing experiences in the United States. Later questions asked specifically about resources and services: who did women rely on for physical, mental, emotional, and spiritual support? What gaps in service did they experience? How might Americana programming adjust for those needs? We began with the same base questions, and tailored follow-up questions to responses. Since Latina focus groups functioned more like personal interviews, answers frequently diverged from one another. While we tracked divergent answers in our notes, we also brought up resources that other interviews had named as important. For instance, the first Latina group named a need for 
mental health and community support from other women, but the East African group focused centrally on physical resources and information about physical and social navigation. After noting the need for resources and information, we also asked about the desire for emotional support in a group setting. When organizers brought it up, group members unanimously agreed that this would be helpful, but they did not name it themselves.

Even given the low overall turnout and distinct characteristics of each group, Leah and I observed several noteworthy trends in answers that gave us the early shape of Mamas Together. First, women held anxiety about parenting in the US and wanted access to resources that would help. In two of the three groups, this was expressed as wanting a clearer understanding of what was legal for parents in disciplining their children, and a fear that children might be taken away from them. Their fears were not unfounded; one participant reported that her daughters' school had contacted CPS after the child broke her arm at an after-school program. The teacher was reticent to take responsibility, and Americana staff served as legal advocates for the mother in this case. Second, women found it difficult to meet their personal goals such as learning English or getting a job because they could not secure adequate childcare for young children. Beyond merely putting their goals on hold while they waited for their children to be old enough for Family Education, a central takeaway from the three groups was the interconnectedness of mothering struggles. Physical limitations during and after pregnancy, mobility issues like transportation and childcare access, and financial struggles due to needing to stay home with children all led to a decline in emotional health because of stress over their mothering role and disconnection from community. Third, women wanted spaces with 
increased connection to other mothers who they could rely on for emotional support. Two of the three groups talked specifically about struggling with post-partum depression after the birth of at least one child, and the severe loneliness of being pregnant and having an infant while far from family and home culture. The second Latina focus group named other difficulties as contributing to emotional distress, but agreed that having a place at Americana to talk about motherhood and get mental health support would be helpful, especially if it also included information about community resources that could meet other needs.

Across focus groups, we heard women name five distinct desires for programming:

1. A clearer understanding of practices for "parenting in the US," especially their rights as parents regarding discipline.

2. Programming directed at women in their life stage, so that they could connect with other mothers and spend time with their children.

3. Access to resources and services that could meet material needs (like diapers and groceries) and social needs (like childcare and family services).

4. Opportunities to continue pursuing personal goals such as learning English while they waited to be able to work again.

5. Emotional and mental health support either in an individual setting or with a group of other like women.

Thus, Leah and I brainstormed a program that included three components: 1) a playgroup dynamic where mothers and children could be together, 2) access to community resources and information, including local speakers, and 3) a mental health component that, at the very least, used trauma-informed care principles to create space for women to share their experiences with one another. 


\section{Creating Mamas Together: Early Visions and Choices}

In brainstorming for Mamas Together after focus groups, Leah and I compiled stated needs and talked through how we would address them in ways that paid careful attention to focus groups' concerns. I see our conversations about trends as filtered through our commitment to macro-values, but also through the ways that past programs took up values and discourses. This is a key reason that I explored Americana's central values first, programming legacies second, and focus group findings third. In tracing our practices, one must understand these three levels of informing discourse - from the macro-level philosophy to the micro-level focus groups.

Given our shared commitment to social justice - using the resources you have to create a more equitable space-we developed a plan that addressed each of the concern trends. Our dedication to cultural humility led us to acknowledge that, while the Family Education model was popular and useful for meeting some goals, it created a top-down relationship between teacher and student that limited how much women could draw on their experiences and form relationships with one another during class sessions; we wanted to create space for community listening. Given our commitments to human dignity and holistic development, we wanted to continue to use participant experiences and opinions to shape the program in day-to-day practices. That is, we imagined our participants as women who both had real needs that we could help meet, and as women whose mothering knowledge was important and could help other women. Our participants were always both of these things, but as in any program, creating practices meant balancing needs and strengths. 
Some of our initial plans had to be adjusted due to time and personnel restrictions. Original plans were for two meetings a week, so that we could spend one day focused on parenting practices and one day focused on community building and mental health counseling. Americana has a relationship with the Doctor of Psychology program at a local university, and we hoped that students could either provide individual counseling or lead group sessions. Other programming needs cut Mamas Together from two days a week to one, and the doctoral psychology students were unable to participate. Thus, we created seven two-hour group sessions.

The first hour was a playgroup-style art or movement class, led by a partner program, Mama to Mama, where mothers participated with their children. During the second hour, Danielle provided childcare, while Leah and I facilitated semi-structured conversations about parenting practices. Here, we combined focus groups' calls for information and access to resources with the stated need for community and emotional support. During these sessions, we asked open-ended questions about women's experiences and shared one by one in a seated circle. (Examples of questions include, "what's one hard thing and one sweet thing about being a mom right now?" and "what was your birth experience like?"). Women were not required to share, but nearly always did. Leah and I shared our experiences as well, inviting participants to see us as both facilitators and mothers with experiences to share. Our goal in opening sessions by sharing stories or reflections was to allow participants' experiences to inform the rest of our conversation during the session. In post-program reflections, participants named this sharing practice as a positive experience that connected them to other women. 
I lay out these practices with clear reference to focus group findings and our shared commitments to indicate the care that went into decision making, before showing the tension in our goals. As an organization, Americana is committed to prioritizing participants' needs and valuing community knowledge at every level of programming. As organizers in Mamas Together, we were committed to acting on issues that immigrant mothers "define as sites of struggle," as Flower advocates in community-engaged practices. (19). And yet, even as intentional listeners committed to giving immigrant mothers' experiences a platform, we were not always able to escape deficit-model discourses. This was especially evident in our effort to disrupt the teacher/student model of Family Education, and the "expert/non-expert" model of Community Engagements.

\section{Values in Practice, Goals in Tension}

At the beginning of this chapter, I asked "how should we listen?" calling for a robust listening methodology in community programs. I argued that a way to answer how should we was to intentionally look for complexities in a past listening process. Drawing from rhetorical listening primarily, I "stood under" two sets of discourses that trouble family literacy programs, before presenting the organizational values, tracing both discourses and values through program practices, and laying out focus group findings. I argued that our practices were not only a result of our commitment to listening to participants. They were also a result of the other things we listened to. The examples below, I think, are particularly rich because of their messiness. They don't detail successes or failures. They detail listening enacted. As above, I quote at length from our reflections on practices, to invite the reader to listen with me. 


\section{Example 1: Listening Relationships}

Again, a hope for Mamas Together was that it would become a "younger sister" to Family Education. We imagined that some of our participants would have attended Family Education with their older children, and would expect something like a substitute for the program they had left behind. This made deciding where and when to break with the Family Education model all the more challenging. A number of our choices were based on a desire to ease transition from one program to the other; like Family Education, Mamas Together centered on parenting in the US, and provided access to local institutions to solve common parenting problems in the immigrant community. In early brainstorms, Leah and I also discussed issues we had with the Family Education model, and outlined ways to intentionally diverge from it. Primary among our concerns was the fixed teacher/student relationship that made it clear whose knowledge mattered. We wanted to give participants' experiences more space, and thus more power, to outline a model for other programs, including Family Education. (The extent to which this happened, or can happen, is chapter four's central concern).

When I talked with Leah mid-way through Mamas Together, however, she expressed concern that our shifted power dynamics were too uncomfortable for participants used to a top-down classroom model:

I imagined it more [like] Family Education, with [the] teacher/student kind of thing but almost having the same feel. [...] I wasn't really sure how to go about doing [parent time] as a mental health session, [because] the parents are more used to the teacher/student role. [...] And this is very different in the fact that you're actually just talking about your experiences and you're learning about things, and for them they're just - [pause] — I can tell from their faces they're kind of like "what is happening?" So I haven't really been able to tell [...] if that's something that works, or if it needs to switch to more of a teacher/student role but still kind of have that play off. 
Here Leah tries to sum up the tensions she's feeling three weeks into the program as we figure out how to restructure core relationships in Mamas Together. In another three weeks, during our program recap, she will praise the practice as creating a comfortable atmosphere where mothers and their children could begin rich relationships. At this moment, however, the program is still feeling its way. We've chosen to break from a previously accepted norm, shifting how we ask participants to identify in the rhetorical space of Americana's family literacy programs. Leah, who values participants' comfort and meeting expectations, is anxious about the break from expected roles and looking for participant feedback in expressions and responses.

I admit to feeling confused at this point in our interview; I had been in the same sessions, but I felt excited over our early, imperfect attempts to create community. One way to unpack this moment is to listen back to the voices that Leah and I attended to, and how. Americana's core values were important to both Leah and I, but the sedimented practices we drew from were different. I saw social justice, cultural humility, and human dignity working when participants were heavily involved in shaping discussion, so I prioritized participants' direct input over accounting for potential communication difficulties. Leah, on the other hand, understood those same values as Family Education practices them. As an institutionally sanctioned educational agent with JCPS and NCFL backing, the Family Education model looks like education to both staff and participants. Leah was used to taking up discourses and values as they had been modeled in this established program, and re-interpreting them to form different practices felt risky.

While we were both pleased with the outcome of our decisions, honing in on the tensions of this moment enables studying listening as a process. Employing the 
"listening back" methodology outlined in the intro, we can hear at least three things from Leah's listening practices. First, we can hear Leah employing an eavesdropping practice, rooted in her position as family coach (Ratcliffe, Fishman and Rosenberg). Based on what she knows of participants in other contexts, she imagines what their faces might be telling her, trying to hear group discussions from their perspectives. Following Dreher, her agreed-upon role as facilitator has granted her permission to eavesdrop- her job is to create safe space, and she's listening to participants' silence and facial expressions. Second, we can hear her listening to Americana's macro-values, and some competing discourses, as Family Education takes them up. My enactment of human dignitymodeled from composition pedagogy—emphasizes giving participants space and time to learn from one another, while Leah's emphasizes meeting participants where they are. Further, she draws from the ways Family Education incorporates "human dignity" into its top-down teaching practices. In Family Education, teachers do most of the talking, so a mother can participate no matter her English level. The program also starts with an assumption of need, rather than strength, and thus, the instructor is in the position of passing down knowledge, while mothers, through worksheets and repeated phrases, are encouraged to receive knowledge. I want to be clear: both a commitment to human dignity and an assumption of deficit can function here. The result of entangled macrovalues and deficit discourses is that as organizers act toward "that which we deem fair and just" in one way during a program, practices become sedimented, and create antecedent genres that we may try to import into a similar program. These antecedent genres of practice make it harder to "question that which we deem fair and just" (Ratcliffe, "A Trope" 203). Not only that—because programs create expectations for the 
ways immigrant literacy and mothering discourses have been taken up, they speak into the way organizers interpret participant responses.

It would be too simplistic to point to discourses and values in tension and say that we must acknowledge what we hear and choose to listen to the right thing. On the ground organizing is never so straightforward, a key reason that we must leave space for "commonalities and differences" as we listen (Ratcliffe). Rather, there is no purely right or wrong enactment of values here, and there was something to be lost and gained in both possible models. ${ }^{8}$ While my commitments to community knowledge made me long for participant voices in whatever program we created, Leah's similar but distinct commitments told her that something recognizable was the best choice for the community she loves. Further, Leah's role as family coach and Family Ed instructor has given her valuable experience and good instincts: her guess about participant discomfort was right in some cases. The open conversation dynamic was difficult for more than one participant with low English levels, as interviews confirmed. One committed attender called the practice "weird, but good." While some continued participating because they liked the relationships and the opportunity to practice English, others dropped out, likely due to language difficulties. This indicates that "making space" does not look the same for all audiences, and flexibility in design is necessary if we want the broadest range of voices possible. It also indicates that, as with Family Education, no program can do everything or listen to everyone; doing good work means making choices. If those choices go unmarked, it may be harder to make different choices later, when another practice fits

\footnotetext{
${ }^{8}$ Scholarship has demonstrated unequivocally that both composition classrooms and para-educational literacy programs continue to struggle with reproducing institutionally-sanctioned knowledge in the name of "giving tools," especially with Black and transnational audiences. (Fernandes, Lu and Horner, Young, Williams)
} 
better. Thus, organizations need avenues for reflection and ways of assessing that make values overt and include participant perspectives at different levels, from program creation to structures to individual relationships.

\section{Example 2: Guest Speakers}

Because of focus groups' interest in information and access to community resources, a central feature of our "parenting practices" sessions were invited speakers from community organizations. Our goal was to draw on speakers' knowledge as experts and give participants a face-to-face connection to local resources. Speakers led two out of the six weeks, speaking on breastfeeding and children's healthcare during separate sessions, and once again their presence in the group revealed an interesting, unanticipated tension in what we prioritized as we listened.

Both of our speakers came from likeminded organizations, and we chose them both because they were knowledgeable and they shared our vision for communitybuilding. Whether or not Mamas Together continued past its initial run, we wanted mothers to have connections to community organizations that shared our values. The first, a lactation consultant, is a native English speaker who leads "New Mama" classes at a local parenting co-op. She was unknown to our specific community but used to partnering with moms. The second speaker is well-known at Americana and in the community: she works for a health center on Americana's campus, translated for our East African focus group, and is herself an immigrant mother. Her connection to the health center provided immediate (and free) access to resources that our program could not provide on its own, but we specifically invited her because of her intimate knowledge of 
the immigrant mother experience; we knew that she could partner with us in treating our participants' experiences as strengths rather than deficits.

What surprised us, however, was that in both cases the presence of speakers made it more difficult to balance our goals of sharing information and building community. I want to listen to the experiences of both speakers, and ask questions of them as a set. The health center representative brought extensive notes with her that functioned similar to a checklist. Attendance was unexpectedly low that day, with one participant, and the speaker referred several times to information she would have given women, if there were more present. In spite of being an immigrant mother herself, she took up the role of health representative to talk to our attendee.

While the lactation consultant attended on our fullest day — about eight participants - she experienced similar discomfort in navigating her role. After our session, she confessed uncertainty over whether she'd been helpful. She had imagined women who didn't know much about lactation and had brought a host of teaching resources, including a breast-shaped pillow and a baby doll. Instead, she found that participants had a wide range of knowledge to share. A few mothers asked personal questions about nursing, but many more forwarded their own expertise. East African women, participants noted, often strap their infants to them and sleep with their children beside them, so their bodies learn to respond to feeding cues. These mothers openly dissented from what they saw as a sanitized, American view of sleeping and feeding arrangements, offering their own cultural traditions and experiences as a substitute. They agreed with what our speaker advocated because her views of nursing aligned with their experiences. Yet, in adding their voice to hers, these mothers gently resisted her expert 
role, and thus the narrative that held up American parenting practices as something they should emulate. Leah and I were excited at the exchange of knowledge taking place. Listening back from the edge of my own perspective though, I can imagine our speaker's discomfort. She assumed that her role was to fill a knowledge gap, rather than to invite women to share their parenting expertise. It was difficult, and perhaps unnerving, to reimagine herself as having one of several types of expertise, instead of being the central expert. It was difficult to re-imagine herself as a listener.

Taken individually, we might empathize with each speaker's discomfort. Taken together, however, we can move past empathetic understanding and listen to the trends. Why did both women, practiced in partnering with mothers and immigrants, struggle with disrupted roles? In part, Leah and I set it up that way. In focus groups, we heard a clear request for information on parenting in the US. Specifically, mothers wanted to know about health and discipline: How could they make sure their children were safe and healthy? What were they legally required to do or not do? By inviting speakers who knew more than us about these topics, we gave participants asked-for resources. We were careful with who we invited, too. I discussed discipline during a conversation on "managing multiples" rather than, say, inviting someone from CPS to talk about legal disciplinary measures. As we listened carefully to focus groups, though, (where) did we also hear deficit narratives about immigrant mothers? If we had consciously resisted deficit-thinking, we might have spent more time recognizing the ways that American structures have been set up without immigrant families in mind and tuned our conversations accordingly. We might have prepared speakers differently, encouraging them to ask participants to share knowledge, even as they gave desired information. 
As with the teacher/student role, however, I think the central tension stems from practiced uptake of values and discourses. Listening to speakers' discomfort, we hear echoes from Community Engagements. As Leah and Danielle noted, guest speakers frequently come in as "experts," but their knowledge-sharing is a mismatch with the community. The legacy of deficit-model thinking in mothering and educational programs means that speakers draw on an expectation of deficit as they prepare, and bring unspoken assumptions about the relationship between instructors and mothers. In our program follow-up, Leah noted the importance of communicating to future speakers that "the point of this is, $[\ldots]$ yes, to impart the information, but moreso getting the group comfortable talking about these topics.” Further, we need upfront work that helps guests take up a listening stance. Naming the ways power is maintained when some knowledge and some ignored can help speakers move beyond empathetic knowledge-sharing and toward seeing themselves as topical experts speaking to experts on immigrant mothering.

I celebrate that, given the space to speak openly, so many participants in the lactation conversation had no problem owning their experiences. This group did not see themselves as deficient mothers, or white facilitators as "experts," in contrast to global mothering discourse. Even though they drew similar conclusions about child health, they stood under different cultural discourses about mothering practices, and their insight added depth to our conversation. That tells me that, even in information-heavy portions, we had built space for complexity into our structures, and participants eagerly took it up. If we had more intentionally approached their knowledge from a place of listening, rather than emphasizing information, we could have more explicitly acknowledged the rhetoric of American parenting from which we drew, inviting participants to a rich dialogue on 
contrasting cultures of parenting. In final surveys, one participant suggested that she would have liked to have time to directly talk about mothering in home countries. "Of course!" we said, "Why didn't we include that?" Because seven weeks is short. Because remembering to make space for difference is a process. Because "trying and trying again with empathy" means attending to the consequences of the last attempt and adjusting accordingly (Fishman and Rosenberg).

\section{Conclusion}

As I prepared to write this chapter, I revisited Royster's constructive, imaginative questions in the opening of my introduction. I noted the many ways that Americana, as an organization, already works to answer them. Thus, my question in this chapter has been "how did we listen, as organizers of a single program within a larger landscape?" To get to that question, I have worked through what else we listened to, as we heard participants, and what the structures in place in other programs enabled us to listen to.

In articulating a listening methodology, I argue that looking at how we listened is important to outlining suggested practices. Listening back to tensions is more than a messy thought exercise. I see it as a way of moving forward carefully and in humility. It's also a way to ground idealistic commitments in material realities, a way to study values and discourses as they become further complicated in practice. Not enough scholarship interrogates values negotiations and material realities for community partners. This chapter, then, seeks to outline a past listening process, teasing out the ways that discourses and values mingle and histories of practice influence what and how we hear.

While my analysis focused on tensions and discomfort - the most productive moments for studying listening-I primarily count Mamas Together as a success. Focus 
group questions asked about existing resources and community networks along with gaps in service-confirmation of needs that we could run a program off of. We were then, looking for community-defined "sites of struggle" and committing to "ethical action" based on what we had and what we heard (Flower, Ratcliffe). During the program, we built in ways of "staying open and curious" through weekly discussion questions, beginning, midpoint, and end assessments, and weekly reflection questions for staff about what we heard during sessions and how we should adjust for future weeks or next program runs. Participants said that they felt like their knowledge was recognized and as organizers, we celebrated the implementation of a changing teacher/student dynamic. Our commitment to listening and action paid off, despite the tensions in goals I've noted as we re-imagined relationships and roles.

I also think that once we recognize the possibility of standing under deficit-model discourses, we need to begin looking for alternate models. As the section on programmatic lineages indicates, sometimes organizers take up practices that do not align with their values because of the discourses they've seen modeled. Thus, rather than working to simply make existing models better, we need different discourses and different models for operating. The next chapter, which looks at how participants employ literacy practices in their mothering work, uses a cultural community wealth model to hear them from a dominantly strengths-focused perspective. 


\section{CHAPTER THREE}

\section{LISTENING FOR CULTURAL COMMUNITY WEALTH: LITERACY HISTORY INTERVIEWS AS DEFICIT-COUNTERING NARRATIVES}

\section{Introduction}

The previous chapter set up a methodology for "listening back" to the flow of local organizational values and larger circulating discourses, especially as they were taken up in legacies of practice. I argued that when we heard from focus groups and put practices into place, we were also listening to a soundtrack of other voices-including organizational values and deficit-model discourses about immigrant families - especially as they had been enacted in previous programs. Like antecedent genres, which create expectations for future iterations of a text, existing programs create legacies of practice, requiring careful interrogation and re-adjustment for new programs wanting to make a change. Listening back demonstrates where organizers take up discourses in ways they have seen modeled, but that do not align with their values or intentions. As such, it holds space for a generous, empathetic read of listening practices while also attending to the gaps between intentions and consequences.

Recognizing mismatch in this way is crucial for creating the kinds of programs, and ultimately community institutions, that increase equity and empathy. When organizers are attuned to the presence of discourses that assume cultural and individual 
deficit, they can better align practices with discourses that assume cultural wealth and resilience instead. The goal is to cultivate what Feigenbaum calls a "collaborative imagination," or the "capacities to imagine alternative worlds - more just, more tolerant, more compassionate, more sustainable - $[\ldots]$ and then to employ mutually derived, rigorous methods for realizing these worlds" (5-6). This chapter begins imagining an "alternative world" by attending to refugee and immigrant women's literate life histories and analyzing them through a cultural community wealth lens, a framework that emerges from critical race theory's application in educational scholarship. Cultural community wealth has been fruitful in demonstrating Black and transnational students' ability to draw on cultural and familial resources in K-12 and university settings, but also has clear application in community literacy programs (Yosso; Pérez Huber; Jayakumar, Vue, and Allen; DeNicolo, et. al.; Rowan and Cavallaro). By listening to women's voiced perspectives on their own literacies and mothering through this kind of explicitly antiracist, feminist frame, program organizers can hear the ways that women understand their goals and needs (in contrast to our assumptions). We can thus begin counter-acting deficit discourse models and systems of injustice through the programs we create. The rest of this section lays out the theoretical frame, data and analysis for the chapter.

The literature review in this chapter further demonstrates the advantages of examining literate history interviews through critical race theory (CRT) and transnational feminist concerns. Within family and community literacy studies there is already a history of analyzing marginalized communities' literate histories and repertoires for the sake of countering deficit discourses. Literacy scholars such as Kate Vieira and Rebecca Lorimer Leonard have studied immigrant communities' for drawing on literate resources 
as they meet goals and navigate institutions. These studies of immigrant families' literate histories demonstrate participants' resilience as they adapt practiced literacies to navigate historically (and presently) marginalizing institutions. Implicit in literacy studies is a belief that having access to different kinds of literacy stories can counter existing narratives about marginalized groups' educational deficiencies and clarify inequities in educational institutions. In education studies, scholars including Louis Moll, Daniel Solórzano, and Tara Yosso advocate for schools and universities to expand their definitions of educational success to include the wealth of knowledge and experience within racially and linguistically marginalized communities. Bringing critical race work, like Solórzano and Yosso's, into conversation with literacy scholarship makes this goal more explicit, directing attention to the ways immigrant and refugee families counter racist, immobilizing structures in everyday literacy practices.

Because immigrant and refugee women experience marginalization in similar, but distinct, ways from other communities of color, I draw on transnational feminist scholarship in the examples I use to show critical race theory's application for this population, both in familial and educational settings. The following paragraph overviews how these secondary research areas—-literate history methodology and critical race theory, with an emphasis on transnational feminist concerns - informed my primary research and analysis methods for this portion of the study.

The data used in this chapter is drawn from literate life history interviews that I conducted with the three core participants in Mamas Together. I conducted these interviews to hear more complete accounts of women's cross-border literate practices and community navigation practices than I could get during the six weeks the program ran. 
As regular program attendees, these women became comfortable revealing some of their life experiences and future hopes during the six-week program, but we only heard about fragments of their identities, based on the weekly theme, the discussion questions chosen, and the group dynamic during that hour. Varied English proficiency also impacted what we and other members of the group understood. Thus, one-on-one interviews built on what had been shared previously and asked for greater context, uncovering trends that connected to or diverged from weekly discussions.

Post-program, I conducted 90-120 minute interviews with core participants focused on three central topics: Participants' perceptions of themselves as mothers, mothering practices in home country as compared to the US, and their perceptions of and suggestions for Mamas Together. Within those broad categories, I asked questions about the communication and literacy practices that supported their work across the roles they held, and the experiences that both helped them develop literacies and ascribe meaning or importance to them. After looking broadly at the intersections between mothering and literacy work across borders, I analyze them through a community cultural wealth lens, drawn from critical race theory and detailed at the end of the literature review below. Community cultural wealth describes six types of "cultural capital," listened for after thematically coding interviews. Using a lens drawn from cultural race theory, which explicitly treats stories from communities of color as spaces for resistance, re-frames women's literate life histories as narratives with the power to counter the kinds of stock stories educational programs employ (Delgado, Martinez). Further, listening for these types of capital helped me hear the ways that women's stories countered particular pieces of the deficit-model narrative about immigrant families, and my analysis section is 
organized into four themes animated by participants' stories of literate capital. The end of the chapter demonstrates how a program like Mamas Together might use this model as an alternative discourse to "stand under," as organizers revise their listening practices.

\section{Literature Review}

Current community literacy scholarship understands literacy as a set of socially, culturally, and historically situated interpretive practices that make sense of a variety of texts for the purpose of getting work done and establishing identities within communities. This basic definition owes a debt to New Literacy Studies, which "argue[s] that literacy [is] something people [do] in the world and in society, not just inside their heads" and thus "should be studied in an integrated way in its full range of contexts and practices, not just cognitive but social, cultural, historical, and institutional as well" (Gee 35). The literature review for this chapter brings together a rich and well-established method in literacy studies — literate history interviews — and an emergent methodology from critical race studies - community cultural wealth analysis. Pairing these two within a transnational feminist frame allows us to consider how immigrant and refugee women's understandings of their literate identities and practices might create an alternate set of discourses for organizers to intentionally seek out when asking for participant input to create programs.

\section{Literate Histories: Constructing Worlds Around Literacy Practices}

Literacy history interviews (LHIs) are a rich and increasingly common research method for contextualizing individuals' and communities' literate practices, because they are at once highly local and highly connected: individuals' practices that are socially, culturally, historically, and even institutionally situated (Vieira, Brandt, Duffy). Kate 
Vieira, who uses the methodology in research with immigrant communities, points out that while other methods might give better insight into a particular writing moment, LHIs give context to a writerly identity by "untangl[ing] the knotted threads of literacy and history" ("Doing Transnational Writing Studies," 139). That is, they uncover links between individual literacies and the economic, political and social forces surrounding literate learning and use. This section discusses literate histories as a methodology, ultimately arguing that because of LHIs' attention to wide contextualization and complex life-worlds surrounding writing, they are well-suited for combatting deficit-model thinking without creating the false dichotomy between "success" and "struggle."

Early, oft-cited work using the methodology establishes literac(ies) as something people do in daily life, combatting the idea of literacy as a tool people acquire and can make equal use of across situations and social positions (Barton and Hamilton, Pahl, Gregory and Williams). Their focus takes up New Literacy Studies' reaction against earlier "autonomous model" theories that "treat literacy as a decontextualized and decontextualing technology," occurring primarily inside the mind (Brandt and Clinton 337). Work in New Literacy Studies also reacts against educational practices that treat literacy as a widely transferrable tool—a kind of currency that communicators develop through similar processes and transfer from secondary schools to higher education to work-places. Barton and Hamilton demonstrate the localized, active nature of working class literacies in Lancaster, England, arguing that practitioners' literacy use is both particular to their needs and historically situated within a locale. Kate Pahl focuses on literacy's materiality, accounting for "the lived, the sensible, as well as the sensory and embodied forms [of textual meaning making] within the world" (6). Seeking to "dispel 
deep-seated myths" about "the teaching and learning of reading in urban, multi-cultural areas," Gregory and Williams trace intergenerational cross-cultural literacy practices of a Bangladeshi immigrant community in the City of London (xvi). Using LHIs to resist a definition of literacy as singular, skill-based and universally useful is crucial for understanding barriers to socially normed literacies as a systemic issue, rather than a moral or intellectual failing within a minority culture. While less explicit about the connections between individuals and institutions, locally focused scholarship still hints at the ways institutional agendas act as conduits of literacy learning, affirming some types of literate experience and discounting others.

In their "loving critique" of New Literacy Studies scholarship—sometimes termed the social-practice perspective—-Brandt and Clinton argue that NLS "assumes separations between the local and the global, agency and social structure, and literacy and its technology" (338). While "we must always study local literacies," they argue, "what appears to be a local event can also be understood as a far-flung tendril in a much more elaborate vine" (347). That is, what we observe from literate acts and actors are single, situated moments in a chain of larger, even globalizing, literate practices. By tracing, for instance, the technologies that enable textual creation and delivery, or the institutional human and non-human actors whose practices direct and respond to writing acts, we more accurately contextualize literate processes and reveal places where readers and writers may be less autonomous than an examination of a single context suggests. Literacy history interviews have thus been a key way to begin the work of tracing literacy's “transcontextualizing” work, since stories of people's literate lives reveal connections between local situations through literacy "apparatuses" (347). 
Over the past two decades, LHIs have been used to reveal thick relationships between institutions and literate practices (Brandt, Grabill). The methodology has been particularly fruitful in documenting how literacy is bound up in institutional power, especially as it crosses borders (Duffy, Vieira, Lorimer Leonard, Lagman). In Writing on the Move, Lorimer Leonard conducts LHIs with educated women writing across national and linguistic borders, arguing that literate practices are mobilized at different speeds often based on institutional "valuations" of women's literate repertoires. As literacy moves - across situations, institutions, national borders, etc. - it is "revalued" by the people and institutional structures who recognize or disregard it (12). The term "literate repertoire," describes the "dynamic sets of literate practices learned in specific, lived social contexts," which people (here, immigrants) call on in daily life. Lorimer Leonard notes the fluidity with which some literacy practices move, as women mix languages in their writing or the classes they teach, and the friction that greets other practices, as women struggle to make their literate identities legible in workplaces or worry about losing linguistic skills as they practice English. In some cases, they even seem "stuck" or "stalled" as other factors like childcare or certification preclude women from drawing on their literate repertoires. Listening to LHIs in studies like Lorimer Leonard's demonstrates the complexity of border-crossing literacy — the riches, frustrations, and pieces that seem not to fit the larger literacy puzzle. Moreover, they use individuals' voices as a starting point for creating literacy theory, combatting a focus on institutional expectations and grounding scholarship in the lives of readers and writers.

Focusing more heavily on the institutional texts that preclude or enable particular uses of literacy, Kate Vieira uses literate history interviews to develop a socio-material 
theory of literacy. Her study of Azorean and Brazilian immigrants reveals the role of bureaucratic papers in documented and undocumented migrants' use of literate capital, arguing that we cannot understand literacy as a social force without understanding it as a material force. As do many institutionally-situated studies of literacy, Vieira draws on Brandt's theory of sponsorship, which makes institutional structures visible, exposing gaps between individuals' needs and institutional agendas. At the same time, sponsorship also highlights individual agency, as people use learned literacies for their own purposes, transforming sponsors' purposes to meet their own needs across contexts. Vieira points out that documentation papers — visas, green cards, passports—are "strong texts, because subjects and state engage in everyday activities, including reading, writing, and deporting, which contribute to and reify the social belief in texts' power" (American by Paper, loc. 386). In a documentary society, like the modern US, literacy acts can still certainly be subversive, and even transgressive, as people find ways to resist and recast literate uses set forth by regulatory institutions. However, literate repertoires are more often made invisible or deemed inadequate by these same institutions, making them difficult to draw from without securing the right certifications.

Locating LHIs within the frames I laid out at the beginning of this section, I find it important to clarify how listening for complexity and context, rather than merely gain, is necessary to combat deficit discourse models. As Lagman notes, there is a temptation toward using LHIs to only show a community's or individual's literate wealth rather than also demonstrating loss, so that "transnational experience can appear to equal multiplicity" and "mobility across borders can seamlessly lead to gain" (28). Lorimer Leonard, also, notes that "sometimes in enthusiasm for supporting multilingual writers, 
scholars miss the fixity inherent in any literate movement" (12). This makes sense, given the pervasive nature of deficit-model discourses across educational and para-educational institutions and the desire to correct institutional assumptions about groups considered to have low literacy skills, including racial and linguistic minorities. However, as many scholars have demonstrated, literacy histories reveal fixity and friction as often as they reveal multiplicity and strength. Brandt, for instance, shows how literate skills can become obsolete as technologies change, so that once literate subjects seem illiterate in a new context. Vieira, again, shows how controlling texts, given power by the bureaucracies that create and maintain them, create a reality for undocumented migrants whereby “everything you want to do depends on a document you don't have" (loc. 365). Paying attention to loss and friction alongside gain and mobility is essential to undoing the kind of deficit thinking often taken up in well-meaning educational programs - the kind that promises "tools" to succeed in a literate, English-speaking world.

This work makes it clear that drawing on literate repertoires is never as easy as "giving tools" or "filling in gaps" in knowledge; as a socio-material force, literacy's usefulness shifts across borders, roles, and institutions, which are themselves unstable. Deficit discourse assumes institutional neutrality and durability—-that the systems requiring and regulating literacy are either unflawed or unchangeable or both. It also assumes literate stability — that once the right kind of literate benchmarks have been met—English proficiency, a college degree or citizenship papers, for instance- then success depends on the hard work of the literate individual, rather than on institutional valuation of skilled, literate identities. Because transnational women's literate identities exceed their current local context, however, studying their literate wealth reveals these 
benchmarks to be moving targets. Women can possess a college degree, and not be able to "transfer" their education because of visa status, for instance. The reality of friction in spite of deep and varied literate practices is important to keep in mind as we look toward a community cultural wealth model of analysis, which by its very name may seem to focus singularly on gain.

\section{Cultural Community Wealth as a Heuristic for Listening}

Literacy history interviews provide rich data with the potential to interrupt majoritarian discourses about historically marginalized groups and offer a set of stories that community literacy programs could benefit from, but rarely ask for. Listening to participants describe their wealth of current and past literacy practices offers something different than listening to descriptions of needs or suggestions for new programs. I would argue that both are needed, but that the former is often ignored because it seems less relevant than the latter. After all, a central purpose of community programs is to help participants fill gaps and meet goals. And yet, stories about how life experiences have shaped literate resources complicates stereotypical assumptions about refugee and immigrant families, and mothers in particular, giving organizations insight into how they can partner with participants as they offer resources. Further, since literate histories always exist within the context of institutions, attending to the role of institutions also gives organizations a way to interrogate trace systemic injustices within their own and their partners' efforts, and reimagine systems that are crafted with refugee and immigrant interests in mind. Literate life histories, then, contextualize current needs and goals, so that organizers can look for institutional as well as individual solutions. 
This section introduces a methodology for listening to literate histories that can "cultivate expansive capacities to imagine alternative worlds" in which community organizations draw on the wealth of their participants' experiences, even as they recognize structural inequities (Feigenbaum 5-6). By listening to participants' literate histories as counterstories — challenges to the "stock stories" about immigrant families' literate practices discussed in the previous chapter-and analyzing them through a cultural community wealth framework, organizers can do more than imagine an abstract alternative world. They can begin implementing changes that amplify the disruptive potential of literacy counterstories in institutional settings. This section discusses literature on counterstory, demonstrating the disruptive potential of literate histories. It then introduces cultural community wealth as a methodology for listening to and using counterstories in ways that disrupt deficit-model thinking about refugee and immigrant mothers' literacy practices (Yosso).

\section{Counterstory: A Methodology for Combatting Deficit Narratives}

Counterstory, a methodology from Critical Race Studies, has become a popular means of calling out harmful majoritarian narratives in major social institutions, including judicial proceedings (Crenshaw, Delgado and Stefanic, Weinstein and Wolfson), university departments (Delgado, Martinez, Solórzano and Yosso) and K-12 schools (Kelly; Karsli-Calamak; Kinloch, Penn and Burkhard). Solórzano and Yosso explain it as both "a method of telling stories of those people whose experiences are not often told," and "a tool for exposing, analyzing, and challenging the majoritarian stories of racial privilege" (32). Counterstory methodology does not assume that dominant narratives, or "stock stories," are misguided but well-intentioned, but rather that "the 
stories or narratives told by the ingroup [...] provide it with a form of shared reality in which its own superior position is seen as natural" (Delgado 2412). Stock stories are insidious because they protect dominant groups from culpability and maintain the status quo.

Literature on counterstorytelling pictures a direct confrontation to such narratives that undermine majoritarian cultures' "shared reality" in two related ways: they create and secure counter-realities, revealing new possibilities for how the world could work, but they also serve a destructive function (Delgado, Solórzano and Yosso, Martinez, Kelly). As Delgado writes, "they can show that what we believe is ridiculous, selfserving or cruel. They can show us the way out of the trap of unjustified exclusion. They can help us understand when it is time to relocate power" (2414-5).

Counterstory has been especially productive in pointing out the hypocrisies of educational institutions and revealing possibilities for listening to different narratives. Many such stories about educational structures take the form of imagined conversations to confront patterns of stock storytelling that justify dismissing students and faculty of color as "not a good fit" to avoid asking hard questions about departmental culture (Delgado, Solórzano and Yosso, Martinez). This kind of direct, intentional approach tells a stock story through imagined dialogue between majoritarian department members, and then retells the event through dialogue between the student or faculty member in question and another minority speaker. These collective counterstories point out hypocrisy in "progressive" academic departments that purport meritocracy but uphold institutionally racist policies. 
Counterstories are not always so detailed, however. Two examples from K-12 schools analyze counterstory-telling in conversation—its potential to "jar $[\ldots]$ comfortable dominant complacency" and to create new opportunities for coalition, postdisruption. Laura Kelly relates two moments in which elementary school students in her literacy classroom provided counterstories in their reactions to classroom texts. Their single-sentence comments related shared community knowledge about longstanding racism within institutions, redefining the texts with which they interacted. Kelly's analysis lingers on her felt discomfort, even defensiveness, as a white teacher, and her struggle not to belittle her students' perspectives. She uses these moments to expose and challenge her racialized view of the institutions she represents. Post-reflection, she reimagines how she might have used students' counterstories to build bridges between their home and school lives, especially in conversations with their families. In this instance, counterstory is represented as a brief, jarring moment that reveals fissures between majority and minority understandings of educational institutions.

The examples so far picture counterstory as confrontations to majoritarian groups' beliefs about themselves. It can also be used to make direct change, when multiple groups are invested in amending institutional practices. Writing about Syrian refugee families within a Turkish public school, Karsli-Calamak focuses demonstrates counterstory's potential to facilitate coalitions between schools and families. In her study, five Syrian mothers provide counterstories during targeted focus groups with teachers and administrators. Teachers respond to mothers' counterstories by implementing structural changes that better meet refugee children's needs, indicating that seeking out alternate discourses has potential to change our actions as well as our attitudes. Some include 
simple administrative solutions, such as ensuring that each Syrian student has another Syrian classmate when possible. Others are more complex initiatives, such as offering Turkish language classes for mothers - and thus organizing transportation, teacher schedules, and childcare for younger siblings. Once it understands community interests, the school is willing to use its limited resources toward such initiatives. Counterstory's role in this instance is to interrupt assumptions about Syrian families - that mothers are uncomfortable speaking with male teachers or administrators, that they are uninterested in learning the language, etc. In this case, counterstories subtly resist majoritarian narratives by simply providing a fuller, more accurate perspective.

Surprisingly, while literacy history interviews have been used to combat marginalizing tropes about immigrant and minority identities, their use as counterstories has not been explored. This may be due to explicitly activist element usually present in this type of storying (Delgado; Kinloch, Penn and Burkhard). While not necessarily told "to resist and counter white, middle-class practices, actions, and ways of being," literacy history interviews can act as counterstories as they "allow us to tell different stories" about the wealth of minority (including immigrant) literacy uses practices (Kinloch, Penn and Burkhard 384). LHIs deep exploration of literacy as it interacts with institutions and informs identity construction grants them the potential to serve both the creative and destructive functions of counterstories. Specifically, they counter the types of deficit narratives about immigrant mothers and families that inform the educational policies enacted by school systems and community literacy institutions. Whether conducted during lengthy research studies (Vieira, Lorimer Leonard), or asked for in weekly reflection questions - as might be more common in a community literacy program- 
fragments of literacy histories have the power to contextualize immigrant family's knowledge-making practices, supplementing and shifting the discourses community organizers "stand under" (Ratcliffe).

\section{Interpreting Counterstory through Cultural Community Wealth}

In the previous chapter, I detailed ways that deficit-model thinking can reproduce by using "strengths" language while continuing to obscure structural inequities and xenophobic practices. The deficit-model of literacy instruction frequently replicates through an uptake of Bourdieu's "cultural capital" framework. Bourdieu argues that in a hierarchical society, upper and middle-class knowledge could be considered valuable capital. Formal education could offer access to such knowledge for those born into families whose knowledge is not already "deemed valuable" (Yosso 70). By pointing out that non-majoritarian cultures are less likely to draw on the same educational backgrounds or opportunities for literate enrichment that benefit their white, middle-class peers, literacy educators and policy-makers can place blame on "deficient" home lives and cultural practices not set-up to grant educational success. Such arguments may even acknowledge the "oversight" in instructional structures, but the solution remains individually or culturally focused. The result is often remedial literacy instruction based in white, middle-class literacy practices, to grant the missing "cultural capital," but not educational institution's expansion to include minority students' community knowledge.

Tara Yosso disrupts this oversimplified reading of Bourdieu, by looking for cultural capital in Chicanx students' educational counterstories. Using trends in interviews, Yosso compiles six forms of "community cultural wealth" found in her interviews: aspirational capital, linguistic capital, familial capital, social capital, 
navigational capital, and resistant capital (77-80). These categories of cultural community wealth represent six ways that a community understands, shares, and uses its resources. All these forms except "resistance" exist apart from "in-group" narratives, though they also acknowledge the reality of structures that assume the community's deficit. Here I define those categories briefly and place them in a literacy context so that I can draw on them as I examine participant literacy histories. The italicized and quoted portions are Yosso's language, while the plain text applies categories to a community literacy context like Mamas Together.

1. Familial Capital: "cultural knowledges nurtured among kin" (including extended family, close friends, and even religious or social groups) "that carry a sense of community history, memory, and cultural intuition.” Familial capital includes work with “communal bonds," (Foley, Morris) "funds of knowledge” (Moll, et. al), and "pedagogies of the home" (Delgado Bernal). It is at play when women's literate acts draw on practices observed at home, or share literate practices with their own children. Drawing on shared educational and child-rearing experiences to give homework help, nurturing religious practices as part of extending home culture, and mimicking parents' experiences with workplace literacies as one applies for a job are all examples of drawing on familial capital. Kinship groups provide physical and emotional support for literate acts, such as friends in refugee camps attending English classes together. Family capital is also at play as family members use literacy skills to connect to one another, such as emails and video chats with distant family members. 
2. Social Capital: using "peer and other social contacts" to provide "instrumental and emotional support to navigate through society's institutions. " Social capital connects family and navigational capital, using kinship networks to enable navigation. For instance, neighbors or church members who watch children during ESL classes draw on a kinship group to navigate a social institution. Women also use their forms of capital to help others in their kinship group navigate socially, such as looking over a child's college application materials, or bringing a friend to a community center.

3. Navigational Capital: skills of "maneuvering through social institutions," especially those created "without Communities of Color in mind" (capitalization in original). Intimately integrated with other forms of capital, navigational capital describes the resources people draw on as they get what they need in a community, especially within social institutions. Within literate histories, navigational capital may show up as women draw on past experiences with similar institutions to maneuver in new contexts: using study skills learned in college to pass a language exam, for instance, or finding a pediatrician through a combination of internet research and asking friends.

\section{Linguistic Capital: "intellectual and social skills attained through} communication experiences in more than one language and/or style." Within literate histories, literate capital obviously involves reading, writing, and communicating in multiple languages, but it also involves being able to draw on multiple styles of communication for a variety of audiences. For instance, an immigrant mother might use professional communication practices gained in her 
workplace to advocate for her child's educational needs, or an instructor might communicate with an overwhelmed multi-lingual student using a shared home language. These examples require both linguistic skills and knowledge of the social position a particular type of language occupies.

5. Aspirational Capital: "the ability to maintain hopes and dreams for the future even in the face of real and perceived barriers. " To possess aspirational capital, people need not have concrete plans for achieving goals, but simply be able to imagine a different life for themselves and/or their children. Within literate lives, this may take the form of meeting goals that require literacy, such as earning a college degree or passing a citizenship test. In other cases, people may use reading and writing as a medium for imagining a different reality—such as keeping a dream journal, or reading magazines that picture their idea of a "better" life.

6. Resistant Capital: "knowledges and skills fostered through oppositional behavior that challenges inequality." Along with aspirational capital, resistant capital is the form most clearly tied to counterstories, as it recognizes inequality and nurtures identities that act against majoritarian narratives. Resistant capital shows up when women use writing transgressively, or when they tell stories about their reading and writing practices that explicit diverge from what they know to be stock stories about immigrant education. While often discussed as an intentional counter to white, Western culture, immigrant and refugee women also use literacy tools to resist past narratives about themselves or their culture. Taking English classes or 
gaining computer skills, for instance, might resist a history of being denied education in a home country or refugee camp.

These six forms of capital have been previously employed in listening scholarship. Rowan and Cavallaro demonstrate the uses of a community cultural wealth framework to listening scholarship, drawing on both rhetorical listening and community listening scholarship. As insider/outsider members of San Bernadino, California (academics who live and teach in the city, but moved from elsewhere) Rowan and Cavallaro use these six forms of capital to better understand the community resources in a city often described by its deficits alone. Their goal, similar to mine, is to add to the sparse literature on listening methodology by establishing a "preparatory framework" for listening that examines and complicates deficit narratives. They are examining the discourses the city itself stands under by enacting community listening. At Town Hall meetings, in responses to articles, and on community program websites, they hear a community's cultural wealth "not in response to but in light of majoritarian deficit narratives" (24). Standing under only deficit discourses, they point out, reveals a broken, destitute city, rather than a city capable of tackling its own problems in spite of real obstacles. Similar to acknowledging loss and friction in LHIs, Rowan and Cavallaro caution that an asset-based approach to listening must still acknowledge the presence and power of deficit-discourses in their community. Listeners standing under community cultural wealth shift their listening stance, however, to hear a community's strength and perseverance primarily.

\section{Listening for Wealth in Participants' Literate Life Histories}

Knowing that community programs draw on small pieces of participants' identities, I began interviewing our participants shortly after Mamas Together wrapped to 
ask about their goals and identities, literacy practices, and experiences with the program. As an organizer revising the program for its next run, I hoped that having a sense of our core participants' larger goals and identities, the obstacles they faced, and the resources they employed as they overcame these obstacles could add to what we had gained during focus groups. Asking about Mamas Together as part of this conversation, I hoped, could give us a sense of where participants felt seen, and where we might adjust the program in the future. As a researcher, I was interested in 1) the ways women's literate and mothering identities did and did not intersect, and 2) how they use the resources at their disposal, Mamas Together among them, to meet personal and familial goals. In 90-120 minute interviews, I asked each of our core participants about the following things:

1. Their mothering work pre- and post-immigration

2. Their personal and familial goals

3. Their access to and use of resources, including educational, emotional, spiritual, and physical resources

4. Their past and present experience with written texts and communication-based media

5. Their experiences with family/literacy programs, including Mamas Together. These five topics gave me a rich sense of participants' literate life histories as they intersected with current goals, mothering identities, and daily navigation of community institutions. Thus, the analysis employed in this section draws on these parts of women's literate histories, listening to them through a Community cultural wealth framework. The goal is to demonstrate how a strengths model, aligned with Americana's values, might 
help organizers listen to participants' stated needs differently, in light of an expanded understanding of their identities, goals, and navigational tactics.

Mamas Together's core participants had very diverse life experiences from one another prior to immigration. Post-immigration, however, their goals and needs are quite similar, due to similar current life stages, socio-economic levels, and institutional navigation needs. In order to give their individual literate repertoires and histories space, and to demonstrate listening through community cultural wealth, the first part of this section discusses individual literacy histories and trends in use post-immigration. The second half of the section examines types of community and cultural capital at work in their past and present literacies, and how they create a different narrative to "stand under" as organizers adjust plans for future community literacy programs.

\section{Snapshots of Participants' Literacy Practices}

My purpose in using literate history interviews is to suggest ways that a community literacy program can listen for wealth even among a small number of diverse participants. Because of my sample size and commitment to hearing from participants, I overview individual literate repertoires before discussing trends. The diversity of the experiences detailed below should come as no surprise given the sample size and the deep complexity of women's lives revealed through literate practices. What's more surprising, I think, is that such diverse experiences pre-immigration result in such similar literacy uses post-immigration, a trend that requires further interrogation in the final analysis section. The chart below overviews identifying information for ease of understanding. The sections that follow provide snapshots of women's literate repertoires as they cross borders and roles. Though each section hits on similar themes, I have 
worked to let women's priorities during interviews guide organization as a way of helping readers "listen" to each participant on her own terms. Each section therefore begins with the participants' description of herself and her goals, and is organized based on trends in our conversation. After snapshot sections, I examine trends through a community cultural wealth lens and imagine what programming might look like using such a model. The following chart also provides a quick overviews of identifying information (fig. 1). 
Figure 1: Overview of Participant Information

\begin{tabular}{|c|c|c|c|c|c|c|c|}
\hline Participant & \begin{tabular}{|l|} 
Ethnic \\
Identity
\end{tabular} & $\begin{array}{l}\text { Year } \\
\text { Immigrated }\end{array}$ & $\begin{array}{l}\text { Immigration } \\
\text { Status }\end{array}$ & $\begin{array}{l}\text { Family Status } \\
\text { (during interview) }\end{array}$ & Education & Work History & $\begin{array}{l}\text { Languages } \\
\text { (Spoken and } \\
\text { Read) }\end{array}$ \\
\hline Win & $\begin{array}{l}\text { Chin Falam } \\
\text { (Burma) }\end{array}$ & 2017 & $\begin{array}{l}\text { Refugee } \\
\text { (Malaysia) }\end{array}$ & $\begin{array}{l}\text { Three children }(6,3 \text {, } \\
\text { and } 1)\end{array}$ & $\begin{array}{l}\text { BS, Statistics } \\
\text { (Burma) }\end{array}$ & $\begin{array}{l}\text { Reports no past } \\
\text { paid } \\
\text { employment }\end{array}$ & $\begin{array}{l}\text { Chin Falam, } \\
\text { Burmese, } \\
\text { English } \\
\text { (reports } \\
\text { reading better } \\
\text { than speaking }\end{array}$ \\
\hline
\end{tabular}




\section{Laila: Work gives Women Strength and Confidence}

Laila was a 30-year-old Egyptian woman who had lived in the United States for six months when she began attending Mamas Together. She lives with her husband and two daughters, ages seven and three at the time of our interview. Her family moved to Louisville so that her husband could get his $\mathrm{PhD}$ in biomedical engineering with plans to move to Germany when he's finished. When asked to describe herself at the beginning of our interview, Laila begins with her career as a civil engineer in Egypt, which she sacrificed when the family moved. The loss of this career and of familial closeness has been emotionally difficult. In Egypt, her mother lived nearby, and Laila depended on her for emotional support as well as occasional childcare. Because of visa restrictions and childcare expenses, Laila now stays at home with her younger daughter. Throughout our interview, Laila returned to the importance of meaningful work in her life, and to the idea that she's "frozen" right now, having traded a busy, goal-oriented life she took pride in for "this house with walls" — what she sees as a "boring," basic existence and far fewer

choices. Short-term, her goal is enough English proficiency to take TOEFL or IELTS and apply for a graduate degree. Long-term, a Master's in civil engineering would allow her to return to work either in the US or in Germany.

While this moment in her life reveals deep loss, examining Laila's literate repertoire and current uses suggests something interesting about the women's literate processes as they cross borders. The specific knowledge she used in engineering projects might not be applicable to her life now, but Laila learned how to study and make use of academic resources in college, and she practiced workplace communication with 
managers and teammates. Having a long-term career is important to her, so she uses free internet guides to study for TOEFL and IELTS, language exams required for entrance to graduate school. Her knowledge of educational institutions and the academic and workplace communication patterns she built in Egypt are useful for this task, and can at least help with this first hurdle toward graduate education. Going from a fulfilling career to preparing for an exam to apply for graduate school is certainly a step backward for Laila, but her ability to fall back on the literate patterns that have given her success in the past is considerable.

In addition to geographical borders, Laila's literacies also cross roles. Laila uses the types of literate capital she practiced as a student and worker to meet her immediate family's needs and to stay involved in her extended family's lives in Egypt. When her sister-in-law was in an Egyptian hospital, Laila emailed the director to express concern about the quality of food, using her experience with professional communication. She credits her advocacy with the change in her sister-in-law's care, and her eventual recovery. As a mother, Laila believes that her job is to raise "strong," hard-working, loving children, and that her habits in and out of work play a role in their development:

The kids is all the time [watching] yours. If you're doing anything the kids is "oh mommy's doing that, I will do that." Now I am trying to study English, [and my oldest daughter says] "Mommy I need to study, so please focus with me and please see that if that's true or false." So why she does that? Cause she saw Mommy doing that and also her father $[\ldots]$ has to do good on his exams.

For Laila, being fulfilled in a career is in chorus, not competition, with mothering. Excelling is an individual and familial task, as family members support one another's excellence. For instance, Laila's oldest daughter attended a German language school 
while in Egypt because their endpoint is Germany. To support her, Laila took German language classes at night, drawing on and building some of the same skills she now uses to study for graduate language exams. She sees the progress she makes toward goals as intertwined with her familial work, arguing that children reflect their parents' attitudes and work habits, and that spouses, too, work harder when they see their partner succeeding.

\section{Khadra: Learning is Important}

Khadra, a Somali woman in her early thirties, has lived in the United States for seven years. Her three youngest children and the father of her infant daughter live with her. Her youngest children (4 years old and 5 months old at the time of our interview) were born in the United States. Her oldest daughter was born in a refugee camp in Uganda. Her oldest son lives with his father in Kenya. When asked to describe herself, Khadra says she is a "humble, patient mom" in that she takes care of her own needs early in the day to be available to other family members. She often uses navigational literacies to meet familial needs with clear goals in mind, as many of the examples in this section indicate. Her self-description indicates upholding a traditional position as household manager and balancing the mental and physical load that accompanies such a role. Khadra's literate repertoire both supports and complicates her definition of her role, however.

Much of Khadra's literate repertoire is based in practices from her family of origin. Her father is a community organizer and teaches kitab classes, in which children practice reading and writing Q'uran, in the local mosque. Her mother aids an obstetrician 
in addition to running a neighborhood market. Khadra, the oldest daughter in her family, grew up caring for siblings, attending her father's kitab classes, helping her mother in the market, and sometimes attending formal school. Her background has not only given her specific religious, workplace, and home-management literacies; it has also provided her with administrative knowledge about religious, social, medical, and economic institutions. Some of this institutional and literate knowledge she draws on in current roles as mother, learner, and teacher. When she needed a driver's license in case of an emergency at her daughter's school, she asked family members in Ohio, who taught her to drive. In Louisville, Khadra has created a hierarchy of resources including family, neighbors, and public institutions like the library, for homework help and childcare while she attends ESL classes. While she is digitally literate - using messaging apps and video chat to communicate with family members in Somalia and Ohio-Khadra relies on this resource network to navigate community institutions.

Other knowledge in her repertoire balances between reproducing cultural practices for her children and reaching future goals. Believing that "learning is important," Khadra takes her children to weekly kitab classes, and often attends an adult class at the same time, drawing on practiced study patterns. At home, she enforces twenty minutes of daily Q'uran study, prioritizing it before free time:

You know kids don't like every day, "learn, learn, come here, listen to me!” Ack, no, sometimes I'm say, "Okay, this time go play, go watch tv. But remember, don't forget, my twenty minutes. Today, tomorrow, twenty minutes. Don't forget."

In this parent/child negotiation, Khadra recognizes her children's desires to make their own choices, but also sees the discipline of daily study as essential to their religious, 
cultural, and literate growth. Kitab and at-home study involves copying, reading aloud, and memorization. It not only builds religious literacy, but also aids in close reading of other texts (Clifton, Williams). For Khadra, these practices benefit English study and practice for citizenship tests. These literate practices will enable Khadra to get a part-time job and to make more regular trips home.

Another consistent trend in Khadra's stories, across borders, is her need to order her own priorities. As a teenager in Somalia, she reports that she preferred working with her mother or caring for siblings to attending high school. She frames this as a choice rather than a hardship, which resists a vision of African girls as "barred" from education because of responsibilities at home. At 19, she moved with an aunt to a refugee camp in Uganda, leaving her parents and her oldest son. Her aunt returned to Somalia after a year because of the difficulties of camp life, but Khadra stayed another two years in hopes of immigrating to the US. Again she clarifies these as intentional choices, resisting a vision of refugees as always, only helpless victims. While Khadra describes life in the camp as frequently unsafe, she also describes community service involvement and opportunities for English and Q'uran study during that period, indicating that she was building on her literate practices during what might seem like a stagnant period.

Post-immigration, she continues to draw on the classroom literacies she practiced in Somalia and Uganda, but she also draws on a practiced patience. As the mother of an infant, she currently attends English and Family Education classes sporadically, when she has childcare from a downstairs neighbor or her daughter's father. Still, because she orders her priorities and takes care of her own needs first, she maintains regular language 
and citizenship practice, using networks of friends and community services to work toward goals.

\section{Win: I Want Them to Have a Choice}

Win is a 30-year-old woman from the Chin Falam region of Burma. She immigrated to the US from a Malaysian refugee camp in May 2017 with her husband and oldest two children. She was pregnant with her youngest daughter when she arrived and gave birth soon after. Motherhood is an identity Win says she feels born for: "When I have children, I said 'this is a blessing from God. As a woman, I feel like [...] I was born to go through [motherhood] with my life. [...] It may be a hard job, but it's what I like the most." As with Khadra, Win's description of her may seem at first to uphold traditional gender roles, but border-crossing identities are never so straightforward. Furthermore, while motherhood is a major motivator in furthering her literate practicesan interesting observation in and of itself - a snapshot of Win's past literate practices reveals a deep literate history that is difficult to draw on.

Of the three participants, Win has the most limited English and the least work experience. In fact, she has never worked outside of her home. She is also a member of an ethnic and religious minority that has been historically mistreated in both Burma, where she was born, and Malaysia, where she lived in a refugee camp. Given a likely history of trauma, the intensity of mothering young children, and no work history outside of the home, it is easy to assume, as Americana staff did, that Win has the most limited literate repertoire. In fact, Win reads, writes and speaks fluently in Chin Falam and Burmese, and can read and write enough English to communicate with her son's school. 
The daughter of manual laborers, she and her siblings learned to read and write in Falam at their local church during summer breaks. Presumably, she learned Burmese in primary and secondary school. She has a degree in statistics from a Burmese university, and learned some English from a Burmese instructor. Thus, her academic and potential work literacies use mostly Burmese, making them difficult to draw on in a context where English is needed instead. Chin Falam, on the other hand, continues to be useful for building kinship ties and navigating locally. Win and her family are members of a large Chin church in the city that they attend weekly, so their social group and religious study continue to be conducted in their first language.

While other participants draw comparisons between home cultures and life in the US, Win seems eager to move on from her time in Malaysia. She resists critiquing life in the US generally, reporting that "everything is better here because there's lots of laws." Those laws ensured her access to medical care and respectful treatment when she delivered her youngest child in a hospital shortly after arriving in the US, "even though I don't speak English." Still, she admits that it is "really hard to live without the language skills." She insists that there are no cultural traditions that she wants to pass on to her children other than her desire for them to be Christians (the Chin state is the only region in Burma with a Christian majority). Instead, she emphasizes her desire for them to attend college and to make their own choices about their futures. Her daughter, she says, is "strong and active" so she may like sports. Her son loves to dance. She is happy for them to have those choices, so long as they also have the social mobility that she believes an American education affords. 
As an educated woman who cannot put her own repertoire to use, Win says the hurdles sometimes seem too great to imagine a long-term career that uses her degree. What she can imagine is short-term goals that move her family forward: learning enough English to get a driver's license and enough computer literacy for a part-time job when her youngest child goes to school. She also imagines something beyond household management and future-creating goals, though. During our conversation Win talked about the need for new experiences for both children and mothers, arguing that "when we get out from our homes, we see more things. [...] We gain some sort of courage not only [from] what we learn, but [as] we learn through what we see [...] with other people, in a new environment." I find this statement about courage and curiosity not only a compelling argument for community literacy programs, but also a clear look into the driving forces behind all three participants' continued literacy learning.

While they acknowledge the friction between new contexts and the literate repertoires they possess, all three women express something beyond resolve. They demonstrate a deep curiosity and love for learning — for their family's sakes, but also for their own sakes. This indicates that cultural community wealth is not only beneficial for meeting needs, but also a source of personal pleasure and pride. The following section listens for the community cultural wealth in our group as a whole, noting trends, and asking how community literacy organizers might use cultural wealth narratives, rather than cultural need narratives, as a starting place for program planning. 


\section{Listening through Cultural Community Wealth Lens}

Employing a cultural community wealth $(\mathrm{CCW})$ model is useful because it creates a distinctly different stance from which to listen, while still attending to the complex processes involved in literate use and institutional navigation. Because of its focus on “cultural capital," a shallow employment of CCW risks making literate activity only seem like gain, something Lagman warns of when analyzing literate histories to spite deficit discourse narratives. Even though the goal is to examine resources, unbalanced positivity need not be the case. Countering deficit discourses is as much about examining the loss or friction caused by institutions' narrow definitions of "useful literacy" as it is about seeing the deep literate resources immigrant mothers draw on.

Having presented snapshots of individual literate histories in the previous section, this section examines for their potential as counterstories. I listen to participants' literate histories through the six types of cultural community wealth explored in the literature review: aspirational, familial, linguistic, social, navigational, and resistant. I have organized them into four themes that directly challenge specific majoritarian beliefs about immigrant mothers' identities and needs within literacy programs. Each theme includes two or more types of capital, acknowledging that the six categories outlined above are distinct but interact with one another in compelling ways. Specifically, I look for 1) capital gained and used in past literacy practices to combat a stereotype of transnational mothers as undereducated home-keepers 2) capital transferred, especially across national borders, to address beliefs that pre-immigration literacy practices are irrelevant in current contexts, 3) the relationship between literate capital and loss or 
friction to complicate a belief that teaching literacy gives "tools" that transfer easily from one context to another (Street, Barton and Hamilton) and 4) the role of aspirations and resistance in shaping how communities understand themselves in opposition to majoritarian stories. I categorize "literacy practices" broadly, attending to the ways in which participants draw on cultural wealth as they use reading, writing, and communication practices for their own gain, for family support, and in interactions with literacy-sponsoring institutions. ${ }^{9}$

\section{Theme 1: Women's Past Literate Practices Enable Diverse Lives in Pre-Immigration} Contexts

Majoritarian stories hold that immigrant and refugee women are taught to be mothers, wives, and reproducers of home and culture. Thus, any previous experiences with literacy are too limited to be useful in post-immigration contexts, such as educational and workplace settings (Gedalof, Lorimer Leonard, Vieira). There are two distinct but entangled parts to this stock story. First, it argues that women neither build nor use deep literate repertoires in home countries, which homogenizes both women's experiences and their countries of origin. Second, because women lack literate wealth, they are underprepared for the literate requirements of post-immigration lives. Listening to this particular stock story leads organizers to conclude that women arrive underprepared, or even as Janes and Kermani argue, "tabula rasa," to community and

\footnotetext{
${ }^{9}$ My use of the term "literacy practices" (or sometimes "literate practices") is in-line with Barton and Hamilton, who explain that while "in the simplest sense, literacy practices are what people $d o$ with literacy $[\ldots]$ at the same time practices are the social processes which connect people with one another, and they include shared cognitions represented in ideologies and social identities" (7-8).
} 
family literacy programs, ready for American women to teach them how to parent and educate their children (465; Auerbach; Moll, et. al.).

This section answers the first half of the "immigrant women lack literate capital" stock story — the argument that immigrant women lack literate experience- by listening to participants' descriptions of building and using their literate repertoires before they immigrated to the United States. It starts with examples of literacy learned in families of origin (Khadra and Win), and then looks at uses of familial and linguistic capital in preimmigration adult lives (Laila). While the stories I present include intertwined forms of capital, I specifically name familial and linguistic capital here, because those are the two categories that the stock story most clearly denies.

Women's counterstories about literate practices learned in families of origin highlight the intersections between familial and linguistic capital. Familial capital stresses the "cultural knowledges nurtured among kin [including family, close friends, and identity-shaping social groups] that carry a sense of community history, memory and cultural intuition," while linguistic capital includes the "intellectual and social skills gained" through both different languages and different styles of communication (Yosso 77). Looking at the overlap of these two forms of capital complicates dominant narratives about how transnational families share and shape literacy practices for their daughters. In contrast to deficit-model discourses about immigrant women, participants described learning a broad array of literacy practices within their kinship groups, demonstrating important links familial and linguistic capital. 
First, participants' stories highlighted the ways they had learned to move between linguistic styles as they participated in community life with their families of origin. Khadra, for instance, did learn to care for younger siblings, but she also learned business literacy skills as she helped her mother stock and run the neighborhood market. From her father's Kitab teaching and work in public service, she learned both religious literacy practices and community organizing. Thus, she participated in four spheres central to community life: homelife, local economy, religious practices, and community infrastructure. The "cultural knowledges" learned from participating in her particular family's life gave Khadra daily practice moving between styles of communication. Khadra drew on familial literate capital daily in her life in Somalia, interacting with customers, working in the community, and developing faith habits. As she moved into the Ugandan refugee camp, she continued drawing on and building familial capital through creating new kinship networks that joined her in learning English, studying Q'uran, and working on in-camp community projects. The intersection between Khadra's familial and linguistic capital is reminiscent of Louis Moll's "funds of knowledge" concept which looks outside of traditional K-12 literacy outcomes to discover other learning experiences in students' lifeworlds. Moll, et. al. write "Each exchange with kinsmen, friends, neighbors $[\ldots]$ constantly provides contexts in which learning can occur-contexts $[\ldots]$ where children have ample opportunities to participate in activities with people they trust" (447). As a participant in family and community life, Khadra learned the literate practices of her lifeworld, and how to move between languages and styles to get what she needed. 
In other cases, the relationship between familial and linguistic capital was more clearly separated, and participants learned to identify deeply with some sponsoring institutions, and to understand others as a means to an end. Win describes less organic movement between kinship spheres and literacy, but no less diversity in the literacy practices she developed in the Chin Falam region of Burma. Win's parents are manual laborers; they lack formal education but are active in their church community. Win and her siblings learned to read and write in Falam at church, which she describes as an extended kinship network. Through this process, they also learned the religious literacies that were important to their family and community. The relationship she describes between familial capital and linguistic capital can best be examined through John Duffy's "rhetorics of literacy" in which community institutions invite identification through the literacies they enable. In Duffy's language, these literacy practices developed both familial and linguistic capital by inviting Win to identify as a Falam Christian. In contrast, she learned to read and write in Burmese, practicing the dominant language and rhetorical traditions she would later use in university. While she may have been invited to identify as a Burmese citizen in this way, Win does not see the government schools she attended as an extension of her kinship network. Thus, she learned to move between the languages and styles of her home culture and public life separately. This is an important feature of Win's counterstory and the study of cultural community wealth. Contrary to the belief that family education programs function to teach "deficit" immigrant mothers to parent in the US, Win's counterstory demonstrates that women not only build literate capital pre- 
immigration, but that they also make choices about which literacy sponsors are important to their identities and which they can draw from but resist identifying with.

In addition to illustrating the relationships between familial and linguistic capital, participants also described ways in which kinship networks made linguistic development possible in pre-immigration contexts. Laila, for instance, details a close emotional relationship with her mother, a school principal who now works for the ministry of education. From her mother, Laila says she learned gentle parenting practices and a habit of leading by example, which shaped her attitudes toward both mothering and work. In addition to providing an example of a "productive" home and work life, Laila's mother provided physical and emotional support for Laila's literate development. Her mother provided physical support through childcare while Laila was at work. When Laila's oldest daughter enrolled in a German immersion school in Egypt, Laila began German lessons to help with homework. Her mother provided childcare for her younger daughter during these sessions, supporting both Laila and her daughter's linguistic development. The ways that familial capital supports literate practices emotionally is a little harder to trace but comparing Laila's descriptions of her relationship as a daughter to her relationship as a mother indicates that friendship with her own mother gave her space to try out her mothering and work practices: "my mother is $[\ldots]$ my sister, she is my friend, she is everything for me. That's [why] I'm talking about [how what you show your child] reflects back with you." Here, Laila uses the same kind of language to describe emotional reciprocity as she does when she talks about children emulating their parents' work ethic in the literate snapshot above. This indicates that she sees her mother's emotional, not 
just physical, support as a central animating force behind her ability to draw on literate capital. Although she mourns the loss of that support, she also seeks to replicate it in her relationship with her own daughters. In this third articulation of a relationship between familial and linguistic capital, being able to rely on a familial network for emotional and physical support makes space for linguistic development.

Women's stories about their pre-immigration literate lives indicate that they develop and employ a wealth of literate resources inside and outside their homes. In contrast to stock stories about "homemaking" traditions that inhibit girls' education, participants indicated diverse ways in which their familial relationships encouraged and animated a range of linguistic practices. Listening for counterstories that address the relationship between familial and linguistic capital prior to immigration provides history and context for women's literate repertoires and current knowledge-making practices. It asks family and community literacy organizers to re-consider participants as women with rich familial and linguistic resources prior to immigration, rather than as homogenous victims of undereducation. The next theme examines the social and navigational capital that women draw from post-migration as an extension of the patterns explored in this section.

\section{Theme 2: Women Draw on Community Resources as They Cross Borders and Roles}

The second part of the "immigrant women are undereducated" stock story makes assumptions about what they can achieve post-immigration. It assumes that because women lack literate experience, especially outside the home, they are underprepared for educational and employment contexts. In keeping with the belief that intervening in 
family life solves undereducation and poverty issues, this majoritarian narrative also pictures immigrant and refugee mothers as deficient in their homes (Gedalof, Shome). Transnational feminist scholar Irene Gedalof argues that within this stock story, immigrant women serve to reproduce home cultures. Drawing a line between public and private life, immigrant women are pictured as static "home and culture keepers," rather than full members of community life within this narrative. They are thus unable or unwilling to assimilate to American culture, and thus unable to help their children succeed within American education. The present theme draws on the wealth and experiences that participants noted in home cultures to examine the ways women develop social and navigational capital across borders. In answer to the belief that immigrant mothers' function as static "cultural reproducers,"- and thus must be re-taught parenting practices for the sake of their children-I look at the complex work of adapting cultural literacies within new contexts.

Social capital, in Yosso's definition, links the socio-emotional connection of familial bonds to the socio-material processes of community navigation (79). It connects women to resources within their network and reminds them they are not alone in the struggle. Closely linked to social capital, navigational capital refers to the skills needed as a woman maneuvers through social institutions - especially those designed "without Communities of Color in mind" (Yosso). In stories about drawing on social and navigational capital, women demonstrated tactics that increased familial bonds along with their ability to navigate in the community. I sometimes collapse these as "socionavigational capital" because of how closely linked they are. 
As women cross national borders, they draw on practices they developed in home countries to form social networks and to maneuver through institutions. While they often turn to community organizations like Americana, they also find resources within the kinship groups both here and abroad. Further, maneuvering across geographical and linguistic borders to meet needs seems to become easier with practice - in contrast to the picture of "static" immigrant woman Gedalof lays out. Khadra's frequent use of navigational capital offers a key example. When she is unfamiliar with a particular literacy, Khadra routinely uses her practiced networking skills_-formed in her family of origin and practiced in the refugee camp — to meet her and her family's needs. When she needed a driver's license so that she could pick up her daughter from school, she asked her family in Ohio for driving lessons and study help. By calling on a kinship network, she circumvented hiring an instructor and learning to operate a machine in an unfamiliar language. Simultaneously, she bolstered kinship bonds across state lines (social capital) and met a practical navigational need for herself and her daughter (navigational capital). While she may not have understood this particular type of bureaucratic literacynamely, getting a driver's license — she certainly had the navigational and networking skills necessary to accessing it. Similarly, when her daughter needs homework help, Khadra takes her to the library or visits a downstairs neighbor who attended university. She may not have enough experience with English language or educational practices in the US to help her daughter along, but experience using community resourcesincluding, but not limited to social programs - means her daughter has the help she needs. Khadra's experiences refute the stock story that immigrant women's involvement 
in the cultural communities indicates discomfort with immigration (Gedalof). She also counters the belief that women's lack of experience with particular institutions (such as local government bureaus and schools), render them helpless. Instead, she demonstrates creativity and tactical resilience as she navigates institutions that, at best, were created without considering her needs.

The belief that women are underprepared for post-immigration contexts may be most often considered in school and other institutional contexts, but it also confirms a suspicion that "under-educated" immigrant women serve as cultural preservers - that they are immobilized by low educational skills and thus unable to help their children adapt to Western ideals. Gedalof argues that as immigrant and refugee women cross geographic borders, their identities are often measured through their home-work, as cultural "reproducers" for their families. Dorothy Smith notes the pervasion of Standard North American Family (SNAF) ideology in family instutions, which pictures mothers as the "primary teacher," responsible for overseeing school-approved literacy practices. When "cultural reproduction" discourses are ordered under SNAF ideology, immigrant mothers appear deficient both as caregivers and as instructors. Although the next chapter spends time arguing against this vision of immigrant families within family literacy texts, in this chapter I want to tease out participants' resistance to these discourses in their literate history interviews.

A central tenet of this belief is that maintaining cultural ties is prohibitive to social integration. Instead, women's stories reveal the continuation of rich, complex literacy practices that connect new contexts to home cultures, and provide multiple generations 
with a sense of identity and connection. Within their current contexts in the US, Khadra and Win both discussed kinship ties as supporting their current literacy practices and mothering work. Both are part of a large community of refugees from the same region or home country. The Chin Falam congregation where Win attends church provides regular Bible teaching for both parents and children as well as the many benefits of a consistent friend group. She and her family attend together, giving them at least a weekly connection to a group of like-minded Falam speakers who share in communal literate practices, including reading Scripture, congregational singing, and listening to a sermon in their native language.

Khadra, similarly, uses weekly kitab classes at the mosque as a tie to home culture and a chance to sharpen literacy skills. She can attend adult classes during her children's lessons, reading and writing in Arabic and getting teacher feedback. These lessons continue in her "twenty minutes" of daily Q' uran study with her children, not only tying the home to the local mosque, but also reproducing practices that were an intimate part of family life in Somalia. Far from re-creating sameness, however, as discourses about immigrant mothers often suggest, we can see the complexity of Win and Khadra's transformation of culture across borders. As Gedalof points out, "[cultural] reproduction in the context of migration is about a complex and dynamic process of identity constitution, in which moving and settling are inextricably entangled" (96). By reproducing literate practices that connect her children to Somalia, to other Somalis in Louisville, even to the Q'uran classes she attended as a refugee in Uganda, Khadra reconstitutes her own identity as Muslim mother and connects her children to a family they 
have never met, in a place they have never visited. In Khadra and Win's examples, I see many types of capital at work - familial, social, linguistic, even resistant capital as women help their children inhabit identities distinct from dominant American culture. Listening to these stories of dynamic capital at work is an important counter to the belief that women's lives are static apart from programs that teach them how to parent and educate their children. By attending to these types of examples, program facilitators hear women as experienced cultural navigators and as knowledge-makers in their homes and communities. We can thus look for ways to make programs a more integral part of the cultural navigation processes that women are already undertaking.

\section{Theme 3: Women Experience Loss and Friction as They Draw on Literate Resources}

Within majoritarian stories about immigrant and refugee families, literacy functions to fill educational gaps and save families from undereducation and poverty (Auerbach; Moll, et al.; Yosso). Family literacy programs, therefore, function as heroes in this narrative, imparting the resources—namely literate skills and social capital — that rescues otherwise deficient families. Within this stock story, transferring literacy instruction from literacy classes to community institutions depends on people's dedication, not the structures that render them illegible. This theme transitions from arguing for the complex processes involved in building and enacting literate capital to examining the loss and friction inherent in cross-border literate transfer (Lagman, Lorimer Leonard, Vieira). I return to linguistic and socio-navigational capital, focusing on Win and Laila's struggles to draw on their deep literate repertoires. Their experiences act as counters to the stock belief in literate transfer, and instead reveal the marginalizing 
structures that inhibit immigrant and refugee women's ability to put their literate repertoires to work.

Examining Win's literate repertoire, and especially her linguistic diversity, highlights the friction women experience as they transfer literate practices to new contexts. Win speaks, reads and writes Chin Falam, Burmese, and English, and each language has a distinct role in her literate life. While most English-speaking institutions recognize Falam as little more than a burden to translate for, the most beloved parts of Win's life are Falam. Falam connects her to family, both in Burma and the US, and provides kinships ties to other Chin refugees. It's also her spiritual language: she learned to read it at church, and still worships in Falam. Burmese, on the other hand, was Win's academic and institutional language pre-immigration. The dominant language of her home country, she learned to speak and read it in primary school and carried it into a bachelor's degree in statistics. While it was useful in Burma, Win does not identify as Burmese and has little use for it in her current context. Win has the least experience with English, but it has taken the place of Burmese as the language of "institutional communication." While she studied English during university, she points out that learning it from a non-native speaker makes it difficult to draw on. In a Burmese workplace, being able to draw on both languages may have been advantageous, but Win has found English-speaking in the United States difficult. Furthermore, her difficulty speaking causes people to assume she cannot read or write English either.

Win was perhaps the most linguistically diverse participant, but had the greatest difficulty participating in conversation. Thus, what could be productive literate capital in 
another context is hindered because her linguistic skills are not legible to many of the institutions she encounters daily. Listening to Win's experiences through a linguistic capital lens highlights literate loss, combatting the parts of deficit-discourse narrative that picture immigrant families as linguistically deficient because of their disinterest in education, rather than because the mismatch between institutional structures and transnational women's rich linguistic capacities.

In contrast to Win, Laila has the kinds of capital that facilitate easy cultural navigation, but the wrong kinds of documentation to enable its long-term use. Her linguistic capital is fairly fluid: she speaks accented British-English, fluent Arabic, and some German. In day-to-day life, Laila is highly mobile. As she in Egypt, she uses a combination of internet research and conversational ease to connect with community resources. Using search engines, she figured out her daughter's school bus route and connected to the Family Health Center on Americana's campus for physicals. Her confidence in new situations, built through career and frequent international travel, helped her use conversation with a Family Health Center doctor to find Mamas Together. She also navigates institutions cross-culturally, as when she used her experiences sending "official" emails to project managers to advocate for her hospitalized sister-in-law.

Laila experiences friction as she works toward long-term goals, however. Laila and her husband are nearly the picture of ideal, cosmopolitan immigrants, if such a thing exists. Her social mobility in Egypt, granted in large part by her experiences with university and career, should have given her deep resources to draw on as she navigates American institutions. However, Laila's immigrant visa forbids her from hourly-wage 
jobs, so she needs to pass the TOEFL, enroll in university classes, and get a Master's degree before she can use her professional experience in a new career. Khadra and Win's refugee status, on the other hand, grants them greater ease of navigation. Language skills, access to transport, and adequate childcare may keep Khadra and Win from hourly wage jobs, but on paper, they can work. This is a prime example of the fixity-or "stalled literate movement"- that Lorimer Leonard describes (66). Laila describes it as being "frozen." Her skills and literate practices are certainly sufficient for a service job and are likely sufficient for a career, but without permission-granting documents, she cannot employ them.

Both Win and Laila immigrated to the United States with college degrees and trilingual experience. Upon arrival, however, they found that their literate resources did not transfer-either because of the languages they spoke or because of the types of documentation they possessed. Listening to frustrated attempts to draw on capital provides a better understanding of the kinds of resources immigrant women need to access, as well as revealing how a devaluation of cross-cultural literacy keeps them from fuller social participation.

\section{Theme 4: Women Combat Fixity Through Aspirations and Resistance}

Finally, majoritarian stories make family literacy programs heroes, saving women through literacy and parenting education. Thus, women's perseverance and successes can also be credited to interventionist programs rather than their own resilience and the cultural wealth of their communities. And yet, the other themes I have explored indicate the depth and breadth of shared community knowledge that shaped women's literacy 
practices both here and abroad. Further, as Delgado reminds us, institutional use of dominant narratives is not merely "misguided"; it functions to protect dominant groups and exclude the already marginalized (Delgado). Thus stories of community cultural wealth act as direct challenges to the status quo. As we listen to them, we must note the "agency and sustenance" within communities of color "apart from and in response to oppressive forces" (Morris 102).

Thus far, themes have focused on the experiences and institutions (including family and community) within participants' environments that have affected their literate development and use. Aspirational and resistant capital, however, describe the attitudes cultivated in a community as people imagine better futures in the face of real and perceived barriers. This section overviews the ways women built and drew on aspirational capital, before re-examining to Laila's experience with navigational friction. I then examine resistance as a refusal to accept present situations as determinants of future realities, demonstrating aspiration and resistance as closely related mindsets that drive literate gain.

In all three cases, women's imagined futures were drawn from the literate practices and skills they had built pre-immigration. Further, each woman had short and long-term plans for achieving goals in light of their understandings of barriers. Aspirational capital motivated the choices women made about pursuing particular literate practices during a period of limited mobility. The importance of listening to aspirational capital in combatting deficit narratives is simple: while particular structural, economic, 
and lifestage barriers may create similar challenges for young immigrant mothers, their goals are not identical. Rather, they are based in women's histories and experiences.

Laila's current feelings of being "frozen" are interesting to interrogate through an aspirational capital frame. Eager to work again, Laila spends late nights studying English online for her TOEFL exam. While the language, spaces, and technologies that enable language learning are different, she has practiced these same kinds of mental processes before. Learning German while in Egypt was more than a tactic for helping her daughter in school. It was also an aspirational move: her husband hopes to move to Germany because "he liked so much the people there and [said] 'they are so strong; I need my daughters so strong." Both Laila and her husband consider it a gift to their daughters to have wide cultural and linguistic exposure, believing that it provides "strength and confidence" and gives them an edge in potential careers. While Laila would rather have stayed in Egypt, with family and career, her current "fixity" is not, as it would seem, a period without movement. She continues to build on current skills, planning for her own next step. Listening to Laila's experiences as they reveal aspirational capital combats both views of immigrant women and families as "under-prepared," and views of immigrant women as "stuck."

While it was fairly easy to listen for women's aspirations and the specific ways that their experiences with literacy informed the goals they made for themselves and their children, I found it harder to locate resistance in their stories. Resistance is often talked about as central to counterstories, because of the clear break they make with majoritarian narratives, so I want to take a step back here to show my process for locating it. During 
early coding, it seemed that women had not spoken about their literate practices in terms of resistance, because I was listening for examples of "oppositional behavior" and speech that counter and aim to transform "structures of racism" (Yosso 80-81). I expected some push back on American or institutional visions of immigrant women and families, perhaps expressed through cultural pride, as in the Mamas Together's breastfeeding session. Several interview questions made room for pushback, in the hopes that I could hear about our good faith "misses" as organizers. Participants unanimously avoided that kind of critique. As I re-listened to interviews, however, I began to hear resistance differently. In many cases, women's resistance was tied up with their aspirational capital. An example from each woman's interview demonstrates what I mean. Laila and her husband's desire to move to Germany is rooted in his desire for "strong" daughters, suggesting possible resistance to gender systems in Egypt. ${ }^{10}$ The US serves as a means to that end. Laila and her husband persevere through a difficult season out of a desire to raise daughters who resist marginalization. Win's resistance was a little harder to locate: she made a point to tell me she was happy with American systems-both social programs in which she participated and American life as a whole. In part, that may have been the complex power differentials between us, but I also think that her support of American institutions is a form of resistance against the Malaysian refugee camp she had left two years prior, and perhaps the Burmese state as well. Win's comments that the US is better "because there's lots of laws" indicate that she sees it as a safe place, where she can be

\footnotetext{
${ }^{10}$ This is not meant to reduce Egypt to an oppressive, patriarchal state. Clearly, given Laila and her mothers' fruitful careers, Egyptian social structures are more complex than that. Rather, I'm drawing on Laila's and her husband's stated motivations and desires for their daughters' lives.
} 
protected even as an ethnic minority. She understands the importance of an education for social mobility, and in wanting her children to successfully integrate American and Chin cultures, she resists her own history of marginalization. Khadra's forms of resistance capital are also related to her experiences in the refugee camp, but could be coded as resilience, or even stubbornness; she chose to wait three years in an often unsafe place and chose to bring an infant daughter to the US. She clearly had a different vision for herself than what she saw either in Somalia or Uganda. That's not to say that participants do not face marginalization or racism here; previous sections soundly rebut that. Rather, the point of listening for resistance capital is to hear women as more than victims of structural racism. Participants clearly use programs, even those that employ deficitmodels, as vehicles for resistance, imagining different futures for themselves and their children.

\section{“Standing Under" a Community Cultural Wealth Discourse during Planning}

Listening to community cultural wealth reveals the depth of literacy practices and experiences that women carry with them into community programs, specifically in ways that resist their pigeonholing by marginalizing discourses such as those combatted in the previous section. Further, these stories of wealth better align with the values that an organization like Americana already holds. They demonstrate the need for human dignity and holistic care, two of Americana's core values, not out of charity, but because accounting for women's knowledge and experience in circumventing great institutional barriers creates better, richer programs with expanded definitions of "mother" and "learner." 
While the opportunity to conduct lengthy literate history conversations with each participant was both delightful and highly beneficial to understanding our participants, having the time, space, and resources for individual interviews is not the reality for most pilot programs. Organizers in Mamas Together were deeply committed to participant input and careful reflection, but without this study, we only would have had focus groups, post-program participant surveys and discussion notes, and our own weekly and postprogram reflection to draw from. Each of those ways of garnering feedback came with its own set of with its own set of benefits and, as I explore below, limitations, based on material realities and power dynamics. Focus groups, as I have noted previously, were small and difficult to schedule, with two out of three functioning as individual interviews in spite of careful planning. Establishing trends required careful notes and some guesswork based on Leah's knowledge of families in this community. Further, Mamas Together had no overlap between focus groups and participants, so that relying on the specifics of community cultural wealth findings in focus groups would not have necessarily been beneficial to the participants we did have. I highlight this example to demonstrate the difference between the ways we imagine program planning working out, and the material realities of organizing. Lives, and therefore programs, are messy so specifying a model for program planning must account for that mess.

While the specific methods I used to tie literate life histories to our identitycentered community program may not work for other programs trying to shift away from deficit-discourse models, these limitations do not excuse community organizers from working to solicit strengths-based stories. In fact, they make it all the more important to 
implement listening practices that are attuned to examples of cultural community wealth; once we know that a set of stories exists to challenge our established narratives, organizers are responsible to listen for them. If a program aims to build participants' literate repertoires through "holistic" means, it must be willing to let participants' literate histories complicate a majoritarian view of literacy. Returning to Danielle's astute observation in the last chapter that people fall back on familiar practices without a clear plan, I want to provide two short-term ways that cultural community wealth discourses can alter what community literacy programs listen for and implement. I then conclude the chapter by suggesting a lingering problem in tactical community programs, which the next chapter tackles.

First, community literacy programs can listen for community cultural wealth through counterstories, since these have potential to create a dispositional shift in how organizers listen during focus groups and planning sessions. To return to Rowan and Cavallaro's use of rhetorical listening, we might think of the choice to let counterstories critique our assumptions as "shifting what we stand under." While, as Rowan and Cavallaro remind, dominant narratives about whiteness, immigrant mothering, and transnational literacy will never be completely erased, creating habits of questioning our assumptions leads to eliciting discussions with potential to disrupt them. Further, by asking how our beliefs about participants shape the decisions we make in programs, organizers begin to make their stances clearer for one another and themselves. This is important at an ideological level in that it provides a more complex vision of "immigrant mother," slowing down assumptions about under-education and deficit. It also leads to 
practices that recognize the diversity of the women in our program, rather than programming for a generalized "immigrant" or "Middle-Eastern" woman.

During Mamas Together, for instance, we often implemented practices based on Leah's extensive experiences with immigrant families. Knowing that many immigrant cultures have a different relationship to texts, or that reading levels are often lower than speaking levels, we limited how many things we wrote down and used images for every line of text. That knowledge was essential for many situations, but if we had been asking about women's literacy and education histories, we would have known that Win struggled with spoken English but had learned to read it in university. That would have opened new ways to communicate with her that would have drawn on her literate skills, and might have benefitted others as well. Instead, we worried about how infrequently she seemed involved in conversation, not realizing that we had options.

Second, soliciting and listening to counterstories leads us to re-consider why women have particular goals. All of our program participants and many of our focus group participants named the types of long-term goals and barriers that organizers expected. It should not be surprising to anyone working with immigrant mothers that finding financial security is a common central goal, nor that learning English is a conduit, nor that finding reliable, inexpensive childcare is an obstacle. For the sake of demonstrating a service gap, a central goal of the pilot, it may be enough to have data that shows clear, consistent needs. As Julie, the programs director, pointed out, "everybody really knew that we needed [...] more services for women who had smaller children [and] we have the data now" to demonstrate need for current and future funders. For the 
sake of creating the program, however, it is not enough to simply know goals at a surface level, since the way organizers imagine participants contributes to program structures. Since cultural community wealth narratives encourage us to hear the ways women resist and work around structural inequities, the practices we implement when we listen to such narratives are better suited to acknowledge structural inequities rather than assuming institutional neutrality and "building literate toolboxes" to close deficits.

Ultimately, we may make the same broad structural choices, but change our practices and attitudes. For example, participants and organizers both hoped that a second run of Mamas Together could add an ESL or computer class component before our conversation sessions - two classic, "tool-giving" types of literacy instruction. However, analyzing women's stories through community cultural wealth makes a difference in how we implement practices, and why we assume women want them. Women talked about ESL classes and studying at home as moments of personal pleasure- - a time to slow down and enjoy what they were doing while working toward their goals. Since we know that women both want to meet goals, and want time to themselves, ESL and Mamas Together could be built with a similarly comfortable feeling, even though their structures and purposes are different. Through a CCW framework, we also know that women draw on specific literate histories to help them develop aspirations and get what they need in a community. Thus, in coupling computer or ESL classes with Mamas Together, instructors should listen for the ways people's existing skills can be built upon and have direct conversations about how language or digital literacy can meet their goals. 


\section{Conclusion}

This chapter demonstrates the potential for shifting what we listen to and through, not just as an ideological exercise, but for the purpose of creating more just, equitable programs. In my analysis of women's literacy histories through a community cultural wealth framework, I demonstrated that women's stories about their reading and writing practices can directly combat marginalizing stock-stories about them. In the previous section, I suggested that soliciting and listening for cultural community wealth could intervene in community programs like Mamas Together in two ways: 1) creating a dispositional shift that helps organizers question their assumptions about family literacy programs' role and immigrant communities' resources, and 2) re-framing why women seek out community literacy programs, so that community literacy organizations can better suit their holistic needs. Whether in lengthy literate history interviews or brief program sessions, a CCW framework has the potential to transform small stories of cultural wealth into significant changes in organizer stance and program practice. As we interrogate our assumptions, by asking women about their mothering and literacy as connected parts of their identity, we create new trends in the discourses we use to design programs. A cultural wealth framework changes the soundtrack we listen to, however slowly, because it inserts new voices in a way that forefronts both their resilience and their intersectional marginalization.

This chapter demonstrates how noting moments of mismatch can re-frame single sessions or programs but shifted understandings of women's literate capital also has the potential to impact larger organizations. The ultimate goal of more responsive listening 
practices is to create "more just, more tolerant, more compassionate, more sustainable" networks of community organizations (Feigenbaum 5-6). Such a goal requires program longevity and the means to make a different set of stories visible to outside organizations. Thus, it changes the conversations and texts we produce: how we talk to partners as we make lesson plans, how we write end-of-program reports, how we describe needs when we apply for funding, etc. The next chapter unpacks how this might happen in partnership with a large family literacy institution, when an organization requires institutional support, but values participant design and strengths-based programs. It also highlights a CCW framework's potential to increase the longevity and impact of short-lived, tactical programs (as Mamas Together turned out to be), by using end-of-program texts to offer institutional critique, giving short-term programs longer-term impact. 
CHAPTER FOUR

THE LONGEVITY OF SHORT-LIVED PROGRAMS:

END-OF-PROGRAM DOCUMENTS AS INSTITUTIONAL CRITIQUE

\section{Introduction}

Thus far, this dissertation has taken an "inward-facing" approach to re-thinking organizer values and participant perspectives. The two previous chapters call for closer attention to the discourses that community literacy facilitators stand under and articulate a model of listening that begins by looking for strengths rather than needs. My focus has been triangular, tracing the relationships between transnational women, the organizers who serve them, and the prevailing discourses that surround both groups. My goal is to call those of us doing community literacy work away from an unproductive (but common) rhetoric of blame, and toward the need for reframing our listening altogether as we take responsibility for our places within our communities.

While the focus on relationships within individual programs is important, however, it would be a grave mistake to stop there. Suggesting shifts just at the program level, or even within a local organization, ignores the real issue of needing partners and funders who may not share a commitment to re-examining the rhetorics that inform their 
initiatives. As Porter, et al. point out, "to change the meaning and values associated with literacy in a community literacy program demands change at the institutional levelbecause significant decisions are made about classroom [and program] practices at those levels" (626). Without looking for places within larger systems where resistance and change might be possible, shifting the discourses that inform an individual program's practices makes little difference outside of that program - not to the larger organization, and certainly not to the landscape of institutions engaging with immigrant families' literacy practices. So, while the previous chapters are inward-facing-focused on "listening" and "re-listening" — this one begins to face outward, using transnational feminist theory and institutional critique methodology to imagine ways of using participant's cultural community wealth, such as those expressed in their literate history interviews, to "speak up" (to continue listening language) to funders and organizational partners within the limits of a materially and locally-situated program.

The work that we did in Mamas Together was never meant to remain inwardfacing. Leah and Julie had two outward-facing aims in creating the program: first, to collect data establishing access needs for mothers of infants and toddlers, and second, to try out a shifted facilitator/participant relationship. The purpose of the first goal was to establish a long-term program based on participants' stated needs for access and emotional support. The purpose of the second goal was to — in time- - begin shifting roles in Family Education, demonstrating for JCPS, as partner, and NCFL, as funder, that immigrant families could access what they needed with shifted relationship dynamics in place. Thus, this chapter is outward-facing, holding that while individual programs are important, part of their importance comes in their rhetorical power to speak back to the 
institutions they're in relationship with. I see this chapter-and this dissertation—as a practice in imagining ways of building relationships and using rhetoric differently. I hope that it will be helpful to organizations that sponsor community literacy, like Americana, because of what it might inspire within the good work they already do, rather than acting as some kind of corrective tool. I also hope that in building on the good happening within a real organization, I can offer community literacy scholarship an example of working away from idealism and imagined possibilities, and toward making good plans grounded in material realities.

The balance between imagined possibilities and material realities has proven to be important as I consider the longevity of Mamas Together. Because of my partners' desires to use our program to establish participant needs and adjust some current relationship models, I imagined early on that this chapter would use institutional critique as a methodology. In fact, it's the kind of project that institutional critique was imagined for in many ways. Mamas Together was a rich site that recognized and worked to navigate a lot of the tensions family literacy scholarship identifies. It worked between forwarding American parenting practices and inviting participants to share their experiences as fellow parents. It provided access to resources while answering a request for community through flexible rather than firm teacher roles. Finally, it existed as part of an established family literacy program, Family Education, but without formal ties to partners or funders. This last was particularly exciting for me, because it meant that Mamas Together was ideally positioned to make the kinds of shifts in practice that my partners were seeking. It was a great first draft: nimble, flexible and easy to run. Both staff and participants were pleased with its accomplishments, and our belief in what could 
happen next is reflected in texts like participant surveys, post-session reflections, the staff re-cap conversation, and the final program report. As it wrapped, I could already imagine both its future growth as a program, and its potential as a new family literacy model to expand the work happening at Americana.

And then, due to a series of unfortunate events at Americana and in the larger metro non-profit landscape, it ended. We wrapped in April, ready to re-vamp for a fall run, and by June it had become obvious that Mamas Together would not run again in the foreseeable future. The files we had created with longevity in mind moved to a folder in the Family Education drive for a hopeful someday. The End-of-Program report, which so carefully detailed program goals and participant perspectives, became just a document outlining what we did, rather than a plan for we could do next. The planned chapter on partner-driven institutional critique now must wrestle with a new set of questions: What is the longevity of a good program that cannot continue? What changes in vision-casting and practices can community partners realistically make — not just to individual programs, but at an institutional level—given the realities of grassroots programming? Community literacy scholars frequently wrestle with these questions because the plot of this story is so common; for every perfect model to study, three more programs meet untimely ends, often due to forces outside of our control. While there are many entangled issues in the questions above, I want to focus on two that directly impact the longevity of short-term programs: the issue of unsustainability, and the sticky relationship that community writing programs have with larger institutions. Inherent in these issues is an anxiety over wanting to do good and lasting work without sacrificing our values. 
To pursue these questions, the following literature review begins with a transnational feminist analysis of two discourses that commonly operate in appeals to funders and partners: empathy rhetoric, and global motherhood discourse. This move mirrors the literature review in chapter one, which named circulating discourses that impact organizers' listening and interpretation when programming for immigrant families. "Mothering as pedagogy" discourses and deficit-model thinking are certainly still in play, but in this chapter my focus shifts to examine the ways that organizers speak to groups with greater institutional power on behalf of their participants. Working through "empathy discourse," especially, highlights some of the difficulties of making marginalized communities visible to partners and funders who are used to stock narratives. Thus, the second portion of my literature review discusses the anxiety of unsustainability for small, grassroots programs and some of the sticking points in community/institution relationships.

I end my literature review with a discussion of institutional critique, offering it as a productive methodology for giving end-of-program documents new vitality. Institutional critique, informed by transnational feminist concerns, can help organizers advocate for different models that are more rooted in participants' expertise and everyday literacy practices, rather than forwarding a deficit-model discourse about transnational families that does not recognize the complexities of families' lived literacies.

Using Mamas Together as a case study in extending the longevity of a thoughtful, but short-lived program, I use a central document, the end-of-program report to critique NCFL's "Defining Our Work" document. I demonstrate how future program proposals or grant narratives could easily take up empathy rhetoric and global motherhood language 
that reinforces deficit-model thinking, or it could counter those narratives using the findings recorded in our End-of-Program report.

\section{Literature Review}

Funders and partners understand structurally marginalized populations, like immigrant and refugee mothers, in part, through global discourses that inform local actions. As Dorothy Smith reminds us, these global discourses are not untraceable or homogenous. "Global" does not mean uniform from situation to situation, institution to institution, but it does imply a prevailing logic that holds even as it adjusts to fit local understandings. Thus, this literature review begins by working through two discourses that haunt Western understandings of two-thirds world families, and refugees in particular: global motherhood discourse and empathy rhetoric. These discourses especially function across texts advocate for refugee and immigrant aid, and having set up these discourses as homogenizing and marginalizing, the chapter argues for organizers shifting the ways they talk about participants to partners and funders. In both cases, I begin by looking at these discourses functioning in popular texts which inform Western imaginations at a cultural level, and then examine their impact in community literacy programming.

In order to critique global discourses at the ground level, however, these concerns must be contextualized within understandings of situated, local practices. Otherwise, calls for change are too easily dismissed as impossible to enact given local material realities and/or they become unimaginable to the people doing on-the-ground work (Porter, et. al.). Thus, having laid out transnational feminist concerns over global discourses, and connected them with community literacy scholarship, I examine the sticky relationship 
between institutions and grass-roots organizations. Specifically, I look at community literacy programs' commonly expressed anxiety over unsustainability, and the negotiations between preserving values and establishing longevity in a funding landscape where those doing the work seem to have less power over their futures than those funding the work. I then turn to institutional critique a methodology which argues for effecting change from within existing structures, through rhetorical adjustments in language and spatial design.

\section{“Global” Mothers and Western Empathy: Transnational Feminist Critique}

To understand how transnational families are constructed and understood by funding organizations like NCFL, and how local organizations often position their participants to make them visible to funding institutions, we must situate family literacy narratives in surrounding discourses about global motherhood and Western organizations' role in "aiding" transnational women and children. This section uses a transnational feminist lens to work through two operating discourses at play in texts about immigrant and refugee families: empathy narratives and global motherhood discourse. Popular texts—documentaries, bestselling books, pop journalism articles—are pervasive places that empathy and global motherhood narratives gain power in the public imagination, and thus among the most common culprits for transnational feminists to analyze. Examinations of both sets of discourses begin by showing them clearly in popular texts—which I believe inform and reflect popular imaginations—-before looking at how they have been taken up in the texts created by community literacy programs, specifically. As in the first chapter, I see variations of these discourses always circulating in non-profit and community literacy programs aimed at immigrant and refugee families. 
The goal, then, is to present clearly operating discourses so that grassroots organizers can better attend to their operating power in institutional texts and relationships. In learning to listen to them, my hope is that grassroots organizers will intentionally shift the ways they construct texts to "speak back" to such discourses.

\section{Empathy Rhetoric and White Feminism}

Empathy — the act of emotionally identifying with another's suffering — is frequently employed in texts about two-thirds world women and families that target a one-third world audience. As human rights discourse has moved "beyond campaigns for civil liberties and political rights to embody in everyday language what seemed just and morally right," empathy rhetoric has helped connect it to public narratives about humanitarian crises (Grewal 121). Empathy has been a key motivator in fund- and awareness-raising campaigns, but transnational feminist scholars frequently point out the ways that white neoliberal feminism has used it to "reinforc[e] a global hierarchical system in which one-third world U.S. feminists act as 'saviors' of two-thirds world women imprisoned within oppressive, violent, traditional/fundamentalist patriarchal structure of underdeveloped nations" (Queen 472; Mohanty, Kulbaga, Hesford, Shome). Deploying empathy as a rhetorical practice requires both identifying with and separating oneself from "the Other Woman," (Queen, Kulbaga). When deployed rhetorically by NGOs and white Western feminist organizations, empathy — the desire to imagine and relate to another's suffering — couples identification with difference (Burke, cited in Kulbaga). Empathy rhetoric functions by divorcing two-thirds world women from their unique historical and cultural contexts and painting an image of their suffering as unimaginable in the so-called "first world." In this way, it homogenizes the lives and 
struggles of two-thirds world families and defines suffering using the frames and language already developed for Western imaginations. It can thus be conscripted by neoliberal, neocolonial frameworks that uses "human rights" as a regulatory measure that justifies military and economic intervention.

Arguing that widely circulated cultural texts teach their readers to relate to "othered" subjects, Theresa Kulbaga examines the process of "empathy pedagogy" as empathy rhetoric is employed in popular feminist texts. Specifically, she analyzes its use in Azar Nafisi's New York Times bestseller, Reading Lolita in Tehran, a memoir detailing the authors' experience leading a secret book club for middle-class Iranian women. Through reading classic British and American literature dealing with gendered and racial social structures - including Huckleberry Finn, Pride and Prejudice and Lolita-Nafisi says that "her girls" felt free to discuss the patriarchal structures that inhibited their daily lives. While Kulbaga does not dismiss the transformative potential of literature, she does question Reading Lolita's pop-feminism approach to portraying Iranian women, which undoubtedly played a role in the book's wide uptake in American culture, from Oprah Winfrey's book club to university book-in-common lists. Empathetic pedagogy—the process of teaching a dominant group to sympathize with less powerful group-relies on stereotypical images of Muslim culture, including child marriages, burkahs and abusive husbands, and a picture of momentary freedom afforded by Western literature. Here "third world"11 and "first world" are juxtaposed, synonymous with "oppressed" and "free," "helpless victim" and "empathetic savior." In interviews, Nafisi stresses a

\footnotetext{
${ }^{11}$ A note on terms: I use terms like "third world" and "developing" to refer to a place that exists in cultural imaginations, as the imagined opposite "first world" or "developed" nation. When talking about the geographical regions often labeled in these ways, I use the terms "two-thirds world" and "one-third world" because these are geographically descriptive phrases. I also use the term "Western" fairly frequently, to describe ideas that can trace their origins to European Enlightenment ideals.
} 
difference between Bush-era "us/them" rhetoric and the "magic of imagination" in reading that "link[s] individuals to each other despite their vast differences. Kulbaga, however, points out that the book's popularity at the height of the "war on terror" suggests "the imbrication of nationalist discourses with transnationally circulating consumer and media market forces" (507). In other words, the wide spread of texts like Reading Lolita helped to solidify the reasons for intervention in the Middle East in culture-creating spaces like Oprah's bookclub, NPR's “This I Believe" podcast, and university classrooms, transforming the war from retaliatory act to a righteous fight against oppression.

Within US non-profit structures, empathy rhetoric is frequently deployed to garner support for "at risk" populations. Several community literacy scholars have noted the "uneasy" relationship that non-profits often have with fundraising structures, choosing (or feeling bound) to ignore uneven power structures as they display snapshots of participants' needs for potential partners and donors. Kathryn Johnson Gindlesparger observes that organizations employ deficit rhetorics to garner empathy and support, but at the expense of the populations they serve. A "deficit model of funding" she says, suggests that "you can help these people because they are different from you," and leads potential donors and partners to ask "what is wrong with the people who seek instruction at literacy nonprofits, and how can we fix them?" (91-2) Like the deployment of empathy rhetoric toward two-thirds world families, deficit funding models rely on narratives of helplessness. They need participants to remain "at-risk" or "in need," reifying a victim/savior dynamic rather than examining the complex power dynamics always at play in community work. Among other things, Gindlesparger suggests that an asset-based, 
rather than deficit-based, funding approach, would help community organizations move away from re-victimizing participants. She notes, however, that when subjects are rhetorically framed differently than sponsors expect, they risk the kind of confusion that leads to funding loss. While allowing a participant at a fundraiser to tell his own story, rather than describing him and others like him as "at-risk" would have "positioned him as an expert of his own experiences," she wonders, "what if the audience didn't understand the language he used? What if he called himself a 'normal kid' instead of an 'at-risk' kid?" While that would be individually empowering, she implies, it would also risk a loss of needed funds for an organization working to fill a community gap. I think the binary implied here—-between using empathy rhetoric to make subjects legible and continuing marginalizing discourse - is a common anxiety because the stakes are high on both sides. As discussion turns to global motherhood discourse, which also sets up "savior" and "victim" roles, I want to forward the possibility that an organization can acknowledge community needs and the role of partners in meeting those while also granting that people use programs to meet situated, even temporary needs.

\section{Global Motherhood Discourse}

A second discourse frequently present in funding requests, especially when working with transnational families, is global motherhood discourse. Transnational feminist scholars have often point out the ways that human rights discourses, especially those connecting to popular imaginations through empathy narratives, privilege white Western feminists as "saviors" for women in formerly colonized nations, while disguising Western-based institutions' complicity in neocolonial, neoliberal, and militaristic policies. Global motherhood achieves this by picturing white women as 
universal mothers - nurturing, knowledgeable, and able to care for the world's children. Brown women, on the other hand, occupy an "othered" position and are pictured as insufficient caretakers who lack the resources, knowledge, and sometimes even moral capacity to parent their children without outside help (Shome, Hesford, Hawkins).

Global motherhood is often visually depicted in images of world leaders, celebrities and Goodwill ambassadors "caring" for the world's children. These popular images serve to both separate "first world" and "third world" countries, and to erase difference by divorcing people from their contexts. Exemplifying the visual rhetorics of global motherhood discourse, Raka Shome analyzes popular images of celebrities caring for poor children in formerly colonized nations. Images of Princess Diana, for instance, juxtapose the princess, bathed in light and emanating calm, with the dark-complexioned children surrounding her. In one image, Diana, dressed all in white, cradles a cancerridden baby in Pakistan. This kind of intimacy pictures the princess as caregiver and nurturer. The absence of a brown caregiving body — a mother or nurse — clarifies Diana's role as stand-in: a global mother able to rescue the world's children from neglect. Because of the tie between "good mothers" and "the imagination of a healthy civilized nation," Shome writes, "when we see images of white women caring for children of other nations $[\ldots]$ we need to recognize that $[\ldots]$ the white Western mother can stand in as the global mother only by erasing the non-white, non-Western mother, from such facile familial regimes of a global multiculturalism" (390-1).

Further examining the visual juxtapositions of a white "global mother" and brown "failed mothers," in the documentary Born into Brothels, Wendy Hesford points out that when brown mothers are pictured in Western-facing texts, they are often depicted as 
incapable, negligent, and irrational. Born into Brothels focuses on the children of prostitutes in Kolkata's red light district and the relationship they form with white filmmaker Zana Briski. The mothers are often depicted as violent and vitriolic—cursing, threatening and beating their children-while Briski is "wise" and "nurturing"—-showing them affection, teaching them to operate her camera, even advocating for their education. Hesford argues, "the film's portrayal of the mothers is indicative of the problem with spectacular human rights rhetoric and its emphasis on victimization, which doesn't account for the multiplicity of ways in which people function" (166). In Shome and Hesford's accounts, global motherhood is meant to summon empathy from its intended audience by making brown women invisible, speechless, or irrational. The mothers in Born Into Brothels are both victims and victimizers, products and producers of trauma. They have no agency except to tear down, and, without Briski's intervention, their children will continue in this cycle. Brown children, global motherhood discourse implies, can be saved from both their failed mothers and their mother countries through white women's sympathy-in-action.

Popular portrayals of global motherhood discourse are important, because they inform cultural imaginations about white women's "duty" to the world's children. Within literacy programs, both in the US and abroad, global motherhood discourse invites teachers to identify in mothering positions, teaching global mothers how to nurture their children's educational success, and seeking to rescue global children (especially girls) from becoming "Third World Women" (Shome, MacDonald). Scholars have long pointed out the imagined link between teaching and mothering, both in public perception and in teacher's own estimations (Collins, Hartsock, Grumet, James). James, for instance, finds 
in a study of pre-service elementary school teachers (all of whom were white women) that though they expressed care for their Black and Latinx students as central to their teaching styles, and used maternal language to do so, they acted out care through deficit understandings of their students' homes and communities. They frequently used phrases like "my students need $x$, because they aren't getting it at home" and sought to encourage their students to amount to "more than their mothers have" (171, emphasis added). James writes, "Because the experiences of students and families are scripted differently than those of the teachers with whom they work, they are deemed lacking in important ways" (172). As Smythe and Isserlis have established, family literacy intervention goes one step further, by teaching mothers to be their children's "first and best teachers," but through the language and outcomes of white, Western understandings of school, rather than by building on their own cultural community wealth.

As is evident from this discussion of discourses, the kinds of victimizing, deficitassuming language often used when white organizers or teachers talk about their participants and students to other white people in powerful institutions-funders, partners, administrators, etc. - maintain stock stories that keep marginalizing structures in place. In the long run, I would argue, that when organizations seeking to create antiracist spaces settle for the global motherhood language and empathy rhetoric in program documents, they make their work more difficult. And yet, as the next section indicates, there is more at play than merely choosing not to use marginalizing discourses and choosing instead to draw from cultural community wealth. 


\section{Defining “Sustainability": Success, Longevity, and Funding}

Funding and staffing realities in community projects dictate the difficulty of creating sustainable, well-run programs, especially using traditional definitions of "sustainability." Typically, a sustainable program has been understood as one that has the material resources it needs to grow over time - space, funding, staff, supplies, etc. Securing success has therefore often meant being part of an institution that could provide for longevity (Restaino and Cella, Mathieu, Sheridan). Of course, as the first chapter demonstrates, institutional partnership often means re-interpreting organizational values and even participant perspectives through deficit-model stock stories. Knowing this, community literacy scholarship has interrogated "sustainability" as a term and value. Paula Mathieu critiques the "logic [that] if a project continues for a long time and is repeatable, it's a success," as dangerously narrow, reiterating how often this definition of sustainability has meant tying into institutional visions for communities ("After Tactics," 24).

Thus, community literacy scholars often re-define "sustainable projects" as responsive, reciprocal partnerships that enact intentional listening practices, negotiate between involved communities' needs, and prioritize participant perspectives over topdown institutional agendas (Sheridan, Restaino and Cella, Matheiu, Parks, Isaacs and Kolba). Restaino and Cella use the essays in their edited collection, Unsustainable, to further expand the definition of a sustainable program as something inherently flexible that "can and should shift depending on community needs," that "resists closure," and that recognizes the enduring value of even "short-lived" programs ("Introduction," 8). At the same time, however, each of the sources cited in this paragraph are discussing 
grassroots community programs that are no more, while the larger institutions and funders that they might have tied into remain. If part of "success" and "longevity" includes influencing the structures that surrounded a program during its run, then community literacy scholarship should interrogate the ways that grassroots programs within larger institutions are (and are not) able to speak back to sponsoring and funding institutions, even after they end. We need to see the relationship more clearly between programs that end and the institutions whose support/lack thereof enabled and ultimately closed them.

A notable trend in stories of unsustainability is a lack of sufficient funding, stemming from a mismatch between institutional and organizational values. ${ }^{12}$ Scholarship on community program labor makes it clear that funders and program facilitators are rarely the same people, and that there is an unequal power balance between the two groups. Without a common vision or value set, the grassroots organization-as the more dependent party_must struggle to make itself visible or risk losing funding. Two telling cases — fifteen years apart—come from Mary P. Sheridan's work with a grassroots girlcentered organization, GirlZone, and Isaacs and Kolba's analysis after the close of a popular university/public school writing partnership. I set up these examples before diving into the ways community literacy scholarship has argued for negotiating between values and longevity, because these two cases represent key tensions that have been at play in community literacy programs for more than two decades.

\footnotetext{
${ }^{12}$ Grabill, paraphrasing Dorothy Smith, defines institutions as "a local manifestation of more general social relations, a nodal point in what I would call a rhetorical relationship between general social processes and local practices." Thus, I use the term "institutions" to talk about school systems, funding organizations, government bureaus, family literacy organizations, etc. "Organizations" describe small, local organizations - like Americana, GirlZone, and The Writers' Room — that look to larger institutions for funding or staffing.
} 
Sheridan examines the mismatch between GirlZone's values and the funders that it needed to continue its work. GirlZone, which ran from 1996-2003, aimed to give girls in the community a space to explore new interests and facets of themselves, outside of the pigeonholed identities funders saw for tween and teen girls in popular culture. Among other things, workshops and festivals taught girls how to work on bikes, run radio programs, and organize justice campaigns. GirlZone was created as an explicitly feminist space and organizers worked to keep it accessible to any girl wanting to participate. They were wary of either running it like a business - excluding girls who could not afford workshop fees — or marketing it to potential funders as a means of reducing "teen pregnancy"-marking girls as "at-risk." Even so, after six years of piecemeal funds and paying out of their own pockets, organizers recognized the need to tap into dominant narratives about girlhood to obtain stable, long-term funding. In a grant application for United Way, a conservative foundation with interests in girls' education, a co-founder emphasized the organization as a space for girls to see their talents and potential, using empowerment language rather challenging the status quo. Despite her shift in rhetoric, however, United Way denied the grant after a meeting with the co-founder, reading her as angry, aggressive, even delinquent —a common conservative narrative about feminist organizers. Sheridan writes, “[E]ven when using empowerment frames, [she] could neither mask the constitutive feminist elements of her activism, nor could she control how "feminist" gets coded as "angry" (139).

One of GirlZone's strengths, as well as the reason it closed, seems to have been a firm commitment to core values. By employing "empowerment" narratives that encouraged girls to explore their interests, rather than discouraging "risky behavior," the 
organization gave girls space to develop their voices and talents as whole individuals, not future counterparts to boys. On the other hand, when GirlZone needed funding to continue programming, organizers discovered that they had set up a financially an unsustainable model and that their vision of girls' empowerment was misread by those with the money to sustain it. If GirlZone had taken up dominant narratives about reducing pregnancy risks, they might have survived, but they would certainly have had to negotiate their values even to write such a grant. The only way to be successful in such a context, writes Sheridan, is to "both understand how [organizational] texts are read in the current funding climate and alter this climate to make it friendlier to their agendas" (140). In other words, a program has to be both legible, and able to shift the narrative about its participants - either by creating new sponsors or introducing small, meaningful changes within existing sponsors.

Writing fifteen years later, Isaacs and Kolba describe a different relationship with a dominant institution, but similar underlying concerns and conclusions. The Writers' Room $^{\text {TM }}$ Program used a writing-center style approach to teaching revision strategies to K-12 writers. The program was housed and funded by the public school system, but run by university partners, paid staff-members, and a team of parent and faculty volunteers. Documenting its 18-year run before eventually losing funding, Isaacs and Kolba point to the ways that The Writers' Room met partners' outcomes by employing writing studies pedagogy in the K12 classroom and collaborating with classroom teachers to present a holistic writing curriculum. Despite being "incredibly low in cost, following best practice, [and] assessed as effective and valued by students, parents, and faculty," the program lost funding during anxieties over recession budget cuts and needing a "return to 
basics." Reflecting on "what went wrong," Isaacs sums up the programs' place as useful, but never "fully integrated into the most powerful stakeholders" understanding of what is requisite to teach writing" (81). Ultimately, it was an outside program, and thus deemed a "nonessential" instructional aid, unlike Internet access or classroom laptops. Full sustainability, she says, would have meant that a full integration into the curriculum, and thus into the school board's definition of "essential" writing instruction:

Ironically, the Writers' Room would only have been fully sustainable if it had ceased to be a separate entity and instead had had its instructional practices to support growing writers integrated into the curriculum. Full sustainability would mean that the district stops funding the Writers' Room [...] as a line item each year, but rather creates a writing curriculum that develops rhetorical awareness and revision skills $[\ldots]$. The district would also hire, train, and support teachers in best practices $[\ldots]$ for responding to and evaluating writing that maximizes students' abilities to grow as writers and to grow in their knowledge of themselves as writers. (81-2)

I find Kolba's analysis of what sustainability would take particularly compelling in light of questions of longevity and a clear need to speak back to funders. Sustainability, in this case, does not necessitate the continued existence of a program in its original form. Rather, a sustainable model can make changes within the programs around it, and affect stakeholders' vision of the work to be done.

Despite the clear differences between these two cases, their commonalities indicate a need to re-examine how and to what degree tactical programs' values can influence the institutions they depend on. GirlZone found that shifting its rhetoric was not enough to combat United Way's understanding of "angry feminist types." Potential funders neither understood the work to be done nor their methods for pursuing those ends. Isaacs and Kolba, though they came with their university's institutional backing and won the approval of directly impacted stakeholders, also found that this was not enough 
for long-term change. Without shifting the most powerful stakeholders' understanding of what writing requires, and who student writers are, The Writers' Room remained likeable but expendable. Building from the visions of "sustainability" voiced in these two texts, the next section explores how tensions between values and longevity have been dealt with by community literacy scholars and partners, before arguing for institutional critique as a methodology for change in long-term partner relationships.

\section{Relationships with Institutions: Negotiating Values and Longevity}

The relationship between institutions and community writing programs is tricky, and thus scholars have proposed a variety of solutions. Linda Flower frames this tension nicely:

One of the enduring sources of controversy in community engagement $[\ldots]$ is this relationship to the problematic power of larger institutions. How does one weigh their tendency to co-opt and control against their potential for wider social change? (27-8)

In other words, being partnered with large institutions provides longevity and security that grassroots organizations and individual programs often cannot provide on their own, but their bigger wallets and community presence often mean sacrifice for the community organization. Institutions co-opt through narrating community needs, creating top-down structures and practices, and making demands about assessment and data collection. As Brandt points out, institutions sponsor the literacies that move their purposes forward; they "enable, support, teach, model, as well as recruit, regulate, suppress, or withhold literacy" for their own advantage, often expecting grassroots community partners to meet their requirements for program goals and assessment (166). Duffy, as explained in the first chapter, takes this a step further: institutions do not merely forward their purposes 
through literacy regulation, they invite those they sponsor to re-make their values in light of the institutions' values and see themselves as workers, or students, or deficient parents striving for better.

Given institutions' self-interest and power to co-opt, some scholars have suggested avoiding formal institutional relationships altogether. Paula Mathieu, in Tactics of Hope, offers a "tactical" approach for service-learning courses and grassroots organizations, extending de Certeau's definition of "tactics" as "a calculated action determined by the absence of a proper locus" that "takes advantage of 'opportunities' and depends on them, being without any base where it could [...] build up its own position [...]." Tactical community projects, which operate outside of an institutional "locus," are relationship-based and created to fill a community-defined need. Because they operate outside of institutions for specific purposes, they are often short-term. Tactical programs exist in contrast to strategic programs, which are top-down and meant to be long-term. Strategic programs begin within an institutional agenda and solve institutionally-defined problems. Defying the anxiety over unsustainability, Mathieu re-casts the "short-term" nature of tactical programs as a strength, rather than a hindrance. Better to partner with a nimble, community-designed tactical project, than a long-term, unwieldy strategic program with institutional goals. She points out the ways that community voices take second place to institutional agendas — if they're heard at all—as institutional involvement grows. Community perspectives become homogenized, their deficits emphasized, their experiences ignored in favor of the narrative that an institution crafts.

Space to operate tactical programs is important for these reasons. In imagining creating only programs independent of large institutions, however, I see at least two 
unavoidable issues. First, large institutions - universities, NGOs, granting foundationshave a vested interest in the community for a variety of reasons, and will continue crafting programs that meet the needs they believe a community has. Community literacy scholars refusing to work within a university structure or to partner with an institution like NCFL does not keep universities or NGOs from doing their work, it merely removes a thoughtful advocate from a position where they might re-focus goals and build in better structures for listening (Feigenbaum, Wetherbee Phelps). Second, the short-term nature of tactical programs means that they do good work for a specific purpose and then often end. They do not, however, serve to change the larger landscape of programs. Speaking back to larger institutions is not the goal of every program, nor should it be. If creating space for larger change is a goal, however, tactical programs may not be able to deliver.

Community literacy studies, and CLR more broadly, is often tempted to buy into the myth that individual programs can make lasting systemic changes merely by acting at an interpersonal level (Feigenbaum, Porter et al, Cushman). Paul Feigenbaum refers to this belief as the myth of the "starfish savior," drawing from the well-known modern parable about a man throwing beach-stranded starfish back into the ocean one at a time (9). I do not mean to imply that the impact on individual lives - whether students or program participants - should be wholly discounted. Rather, the issue is in using individual solutions to address issues with the larger system. The danger of exalting narratives like the starfish story, Feigenbaum writes, is that while the "parable depicts the starfish savior as a Good Samaritan," he "fail[s] to enlist aid in resolving the macroproblem," so that there is little chance of lasting change. I think the "myth of the individual program" can carry a similar danger. It propagates the belief that if we just 
keep at it long enough, we can change the structure from the bottom up: perhaps someone with more power and money will notice our hard work, or our participants will become change-makers who demand different kinds of programs. It's a lovely romance, except that it increases the risk of facilitator burn-out and trades the hope of institutional change for a focus on "changing the "victims"” (Street 215). As Cushman, et al. argue, a focus on individual classrooms and programs "actually might be damaging for members of communities that are served by autonomous, detached institutions that legitimize and marginalize certain literacies" (208). Feigenbaum argues that a focus on the individual keeps us from looking for more systemic solutions, and using our power as scholars, administrators, and partners to effect change outside the individual classroom or programs.

As Jeff Grabill points out, defining "communities" as positive, and institutions as negative creates a problematic false binary, whereby we believe we can have "community," at its most authentic, without attending to shaping institutional forces. Communities exist within institutions, and rely on those institutions for livelihood, education, entertainment, etc. As Duffy demonstrates, institutions function within communities as identity shapers, especially through the literacies they enable, regulate, or withhold. Schools grant participants a "student" identity; churches, the identity of "worshiper," (and alternately, non-worshipper); city government bureaus, the identity of "citizen," and the responsibilities that come with it. Seeking to work within communities separately from institutions is impossible, which means that those programs seeking to shift deficit narratives must interact with the powerful institutional sponsors that employ them. 
Institutional Critique as a Methodology for Speaking Back

Acknowledging that institutions cannot be ignored, composition and community literacy scholars have wrestled, sometimes heatedly, over the most productive way to change institutional culture. Porter, Sullivan, Blythe, Grabill and Miles' institutional critique methodology is among the most popular within CLR. Its most basic premise is that "institutions $[\ldots]$ are not monoliths; they are rhetorically constructed human designs (whose power is reinforced by buildings, laws, traditions and knowledge-making practices) and so are changeable" (611). Porter, et. al. argue that because institutions operate textually and rhetorically, critique can occur through intentional rhetorical action - in the language, documents, and spaces where institutions exert power. As an "action plan" for critique, institutional critique operates in the nexus between theory and practice, and where global institutions (e.g., the state, national family learning initiatives) connect to individual programs or organizations (e.g. a family literacy playgroup, a grassroots organization). Global critiques, they argue, are too easily dismissed "for local reasons," while seeking change at merely the local level, to return to Feigenbaum's and Street's points, does not address macro-issues and instead places the impetus for change on the individual instructor and participant- - the "victims" of institutional harm. Speaking specifically of composition departments, Porter, et. al. argue that writing program administrators - who oversee courses but also meet with deans and other department heads - are in a prime position to shift the university's understanding of writing studies, using rhetoric that the larger college understands to accurately represent writing instruction. 
One of the central criticisms of institutional critique has been its hope in shortterm changes over time. Marc Bousquet, whose heated response to Porter, et al. has come to represent this oppositional view—argues that while institutional critique's basic premises are true, it presupposes an insider who, in using the language of the institution, sacrifices the possibility of real change in favor of "pleasing the prince" (512). While Bousquet uses a labor frame to reexamine the program administrator's position, my interest is in his comments on language and positionality. There are twin dangers for Bousquet in assuming that one can use the language and logic of an institution to change it: first, it casts the institution as an "all powerful auditor," that can only understand and be moved by its own logic, so that those seeking change must use its language and logic, continuing to be complicit in "domination." (509). Second, it assumes that those outside of the institution cannot make changes - that their voices will be discounted, though large cultural shifts have been made by those who have consolidated power apart from and in response to dominant institutions. People like program administrators, Bousquet argues, operate within and are beholden to institutional logic and frames. They may be able to see the needs of those with less power — staff and participants, for instance, and imagine what needs to happen at an institutional level, but as long as they use institutional tools, they will not make the kinds of robust changes to institutional structure that Porter, et. al. want.

These two seemingly oppositional stances—Porter, et. al's claim that those within institutions must use rhetoric to make "small changes over time," and Bousquet's argument that real change must come from advocacy work that operates outside the institution's logic - again voice the ongoing struggle for visibility and the power to create 
change when you cannot acquire the funds or structures you need independent of a large institution. Taking institutional critique outside of the composition department, I think, helps demonstrate its use for more than departmental establishment, however. It also clarifies the stakes of using or choosing not to use the "prince's" language. In Community Literacy Programs and the Politics of Change, Jeff Grabill argues for "participatory institutional design"-in which institutional policies are critiqued and re-written using the input of those most affected by their policies. Grabill writes "design is a process of creating a reality, and those interests more powerful - often because of their ability to construct more persuasive knowledge — get to create their reality" (130). In programs that speak "up" the chain of power, then, using unrecognizable is costly. On the other hand, using recognizable language to describe the ways that participants are included in design can continue to build a relationship, while shifting the narrative to better reflect populations.

In a sense, it's the argument between tactical and strategic programs all over again: should a program tie into sustainability, knowing that it will have to use the language and success measures recognized by a sponsoring institution in order to continue under its umbrella? Or should it move outside of large institutional partnerships, knowing that it risks not only sustainable funding, but also the possibility of making institutional narratives more just? Can there be a third road, wherein a local institution that operates between building trust in long-term relationships with partners, on one hand, and using language and spaces rhetorically, on the other hand, to introduce change over time? 


\section{Analysis: Speaking Back to Deficit Narratives in Ways That Partners Can Hear}

There is no doubt about the difficulty of making good work legible to the people who fund it. And yet, as organizers and university partners, we cannot in good conscience continue to misrepresent the communities we serve as "helpless victims" when our research and experience confirms their intelligence, creativity, and profound capabilities. Since participants rarely interact with funders and program partners, the onus is frequently on organizers to fairly represent participants in the documents that advocate for their continued support. Once we have attended to our own listening practices and enacted richer ways of hearing and using counter-stories in program design, we then have a responsibility to speak back to the institutions that perpetuate flattening, minimizing narratives.

As I consider how end-of-program documents can shift deficit narratives, I want to turn one more time to the argument for breaking with large, deficit-based institutions over pursuing small, slow transformations and risking ideals (Bousquet, Mathieu Tactics). To be clear, I find this a reasonable argument for many programs. In some cases, it is better to have a small, seemingly "unsustainable" program built solely around community needs, rather than sacrificing ideals for institutional support. We have established the difficulty of working outside of powerful institutions as a small, tactical, grassroots program, however (Sheridan, Mathieu “After Tactics,” Isaacs and Kolba). Thus, for program organizers who consider the cost of not providing long-term services to their communities greater than the cost of negotiating values, institutional critique creates avenues for shifting the narrative about participants through building relationships 
over time, gathering data on outcomes, and using texts to "speak up" about what we know of participants beyond homogenizing deficit narratives.

Americana's relationship to the National Center for Family Learning (NCFL) is a clear example of drawing on large institutional support while working toward a more just, equitable vision of family literacy. NCFL is both a partner and funder of Family Education, Americana's largest program and the "sister" program for Mamas Together. While nationally and locally popular, NCFL's vision of family literacy has been widely critiqued as deficit-based. A review of its 2019 "Defining our Work" document, explored later in this section, demonstrates a belief in family literacy programs' power to save minority and immigrant families through intervention in homelife, and frames NCFL's work as compensatory rather than asset-based. As such, it is not fully aligned with the principles that a partner like Americana seeks to embody. On the other hand, NCFL's programs have been a staple of the community literacy landscape for at least twenty years. They have name recognition and powerful financial backing, which grants a long reach into the educational spaces that minority families must navigate. Further, as Jen Stacy points out, NCFL's deficit-model ideology has not prevented minority families from finding them useful for meeting personal goals, even if their reasons for attendance are different from those that NCFL assumes.

As the largest provider of comprehensive refugee and immigrant support in the city, Americana provides services that no other organization does, and relies on NCFL for sustainable programming. It would be short-sighted to suggest that Americana attempt to build the level of programming that they have achieved on their own. Rather than discount a powerful institutional partner, then, this section focuses on deepening 
relationships with a large institution like NCFL, whose work is deeply embedded in the community literacy landscape, but whose involvement requires negotiating the activist nature of social justice work. As a methodology, institutional critique can make longterm, sustainable changes to the discourses about immigrant mothers and their family literacy practices, targeting the points at which a literacy sponsors' uptake of discourse becomes practice.

Partnerships, I have continually argued, require compromise and lead to changes in the ways values are enacted. While chapter two's examination of the ways that values can be redefined in partnership focused on the potential cost to a grassroots organization, this chapter argues that powerful sponsors can also be affected through relationships with justice-seeking organizations. It's more difficult, to be sure. Porter, et al. were right to point out the material realities that get in the way of large-scale changes, but the alternative is for the success of small, thoughtful programs like Mamas Together to rely on the continued goodwill of large-scale funders rather than using what we learn from them to re-shape institutional discourse. To demonstrate the potential to extend tactical programs' longevity, this section uses Mamas Together as a site for institutional critique. It does so by examining places of slippage in NCFL's "Defining our Work" document and pointing out places where Mamas Together's End-of-Program document and postprogram participant interviews might intervene.

\section{Situating NCFL and the "Defining Our Work" Document}

As a national leader in family literacy programming and publications, The National Center for Families Learning (NCFL; formerly National Center for Family Literacy) is a policy-setter and model-creator for family education organizations and 
programs. It is a prime example of a long-term, strategic, institutionally-situated organization. Though it operates nationally, NCFL is made up of more than 1000 local programs within school systems and grassroots organizations like Americana. That means that opportunities for institutional critique are available to its many partners across the nation who forefront community listening and community knowledge in their programs, but who have prioritized the funding and stability that NCFL provides to the vulnerable populations they serve. To understand how to intervene in NCFL's discursive constructions, I use the following section to first provide a brief history of NCFL's growth, an overview of its values, and significant challenges to its model to situate the "Defining Our Work" document in the ongoing conversation about the institution's work.

\section{The History and Influence of NCFL}

Family literacy programs gained popularity during the 1980s and 90s because of research connecting home and school literacies and U.S. policies naming family literacy as a "potential solution to economic and social disparities" and have continued to grow as calls for student testing put pressure on teachers and parents alike (Taylor; ComptonLilly, Rogers, and Lewis 34). Early family literacy models were shaped within the context of the Clinton and George W. Bush administration's neoliberal social and economic policies, which limited government support for social programs, emphasized personal responsibility in the home (for mothers) and education (for classroom teachers), and pushed for educational assessments through increased standardized testing (Compton-Lilly, Rogers, and Lewis). Concurrently, as immigration rates increased following the 1990 Immigration Reform Act, the make-up of public-school classrooms also changed. Increased educational pressures, "personal responsibility" narratives, and 
long-standing beliefs about minority populations' educational deficits, then, joined with burgeoning research on the potential of diminishing poverty by intervening in home literacy practices.

Denny Taylor's dissertation, and the 1983 book that followed, are often cited as the first use of "family literacy," as a term. Taylor demonstrates the transmission of "literacy styles and values" within family units, without parents or children's awareness. Literacy, she argues — using similar language to New Literacy scholarship —is a social process taking place in everyday lives (87). Given a growing cultural and political anxiety about poor and minority families' literacy rates, and the need for standardizing education, proponents of family literacy joined Taylor's definition with discourses about parents — mothers especially—as "first and best teachers." Family literacy programs were quickly touted as a means of breaking "the intergenerational cycle of under-education and poverty," through intervention in family life, not just the classroom (NCFL, "Family Literacy Program Quality Self-Study," 3). It is against this social, political, and scholastic backdrop that family literacy organizations like NCFL emerged.

NCFL began in Louisville, Kentucky in the late 1980s and quickly became a leading provider of family literacy and education programs in the US, with programs in 39 states (familieslearning.com, "Our Network"). A search of NCFL programs in Louisville yields results from 17 organizations, including Americana and three other organizations serving the transnational community. A national leader in family education research, NCFL hosts an annual conference, publishes its own scholarship, and promotes family literacy "field research" from partner institutions like the National Institute for Literacy. Its partnership with federal bureaus and international corporations suggests the 
wide-appeal of family literacy programming as a "commonsense" solution for perceived educational deficits, based on "beliefs about language, literacy and generational transmission of school-appropriate reading and writing skills" (Hendrix 339).

From its inception, NCFL has prioritized family education for racially and linguistically marginalized communities, through partnership with government bureaus and large national corporations; in 1996, the organization partnered with the Bureau of Indian Education (formerly the Bureau of Indian Affairs) to employ its Parent-and-Child education programs on reservations across the country. As stated elsewhere, however, NCFL's ideology concerning racially and linguistically diverse families has been widely critiqued in literacy and education scholarship for its focus on white, middle-class educational values across the communities it serves. Critiquing the family literacy model in NCFL's first decade, Hendrix points out its narrow, school and federal-guideline based definition of "literacy" and process of erasing cultural difference: "alternative practices of literacy, language, learning, and family, marked by complex differences of class, race, ethnic origin, gender, sexual orientation, and location are identified (though perhaps not overtly), silenced, and then erased under compensatory [or deficit] models of family literacy education" (340). NCFL's documents from its first decade support Hendrix's observation. A widely circulated NCFL publication from 1991 states "Family literacy means changing attitudes, values, and in some cases cultures" ("Spreading the Seed," 7, cited in Hendrix 341). The need to examine educational structures that privilege white, middle-class literacy practices is not mentioned.

NCFL's language surrounding cultural difference has shifted over the past 30 years to recognize "cultural strengths," but their program model has stayed largely the 
same, at least as its represented in program documents. By 1995, "strengths" language was being widely employed in family literacy programs, as an explicit opposition to "deficit" views. Then as now, strengths models purported "building on [participants'] wealth of resources," and "honor[ing] their capabilities," as whole learners (Potts 3, cited in Auerbach 645). Despite this more positive framing, however, deficit language persisted, even within the same organization. Teenage mothers, for instance, were said to be "trapped in the same environment which limited their childhood achievements," creating "a family heritage of undereducation" and poverty (Darling 3, quoted in Auerbach 646). Poverty was often described using disease language, which both blamed populations seeming educational apathy, and forwarded a helplessness narrative surrounding intergenerational poverty. It seems then, that despite positive public-facing language, the rationale behind family literacy programs - to end a cycle of poverty through interventions in mothering practices - continued to inform methods and structures. Family literacy, then, was not a partnership that built on existing values, but an antidote for a community disease (Auerbach).

How could strengths and deficit language, so clearly in opposition to one another, issue from the same organization? The first reason operates at the ideological level. Deficit language stems from a stock story about the immorality of poverty at an individual and community level, and the need to re-shape minority communities in the image of white communities to eradicate it. In this way, it's closely related to "global mothering" discourse, which posits that wealthy white women can and should act to lift poor brown children out of poverty, because their own mothers are ill-equipped. The second reason is methodological, stemming from the difficulty of joining theories of 
cultural strength to practice. A methodology exists for intervening in home lives and working to "lift families out of poverty." NCFL's public-facing "strengths-based" documents, on the other hand, fail to articulate a set of practices for "honor[ing] capabilities" or "build[ing] on a wealth of resources." This suggests that resources are assumed but not explored or used in planning. Despite cultural shifts that have influenced program attitudes and understandings of minority families' literacy practices, I see the under-exploration of a methodology for recognizing and building on community wealth as a persistent problem in NCFL as an organization. As a result, their deficit-model thinking persists in program planning, and partners like Americana must wrestle with those values as they establish programmatic structures.

The following sub-section works through NCFL's 2019 version of “Defining Our Work," to point out places where NCFL uses strengths language to describe its goals, despite still employing a methodology that assumes individual and cultural deficit within participating families. Acknowledging the gap between the language and methodology, I argue, reveals spaces for partners to shift narratives about the communities they serve, through articulating practices and re-framing outcomes that draw on cultural community wealth rather than assuming community lack.

\section{Key Trends in "Defining Our Work"}

Published and circulated in January 2019, NCFL's “Defining Our Work: Families

Learning Together," is consistent with its historical approach to family literacy but contains several references to "cultural responsivity" and "building social capital" (Jacobs, et. al). It thus not only provides places for grassroots organizations to create more participant-centered programming within the NCFL heading, but also opportunities 
for gentle pushback from grassroots partners. The document describes the organization's three-tiered approach to family intervention and the central programs within each tier, with data on institutional accomplishments over the past thirty years. It also defines core terms, including "family literacy," "family engagement," and "social capital" as NCFL uses them. The document offers a cohesive outline for programmatic goals at each tier, and the structures that each should include and is thus an important document for understanding NCFL's family literacy model.

Three key trends in the "Defining Our Work" document help clarify the way it sees its work as a literacy education provider and school/family partner. ${ }^{13}$ Understanding NCFL's view of its goals and practices is key to effective institutional critiques because, while Bousquet warns against "using the language of the prince," visibility and understanding remain essential for making changes for organizations that rely on continued support and partnership. The first two trends demonstrate NCFL's grounding in deficit-model thinking and uptake of mothering discourse. I demonstrate these trends clearly but quickly because they uphold existing literature. The third trend, which has been explored much less, looks at slippery moments in the document—particularly places that it references social capital and the need for cultural responsivity—which provide a point of intervention. This is where I end the section, arguing that while NCFL provides no indication of either current work with community wealth or a desire to employ a strengths-based perspective, the language it uses still leaves space for institutional change. Given that NCFL is one of the largest and most influential providers of family

\footnotetext{
${ }^{13}$ I use this phrase, even though its commitment to families' goals (over, say, school-based norms) has been questioned, because NCFL's description of its role indicates that it very much sees itself as a mediator between schools and families, and a partner to both.
} 
literacy programming, and that its model has been taken up nationally and internationally, this is an argument worth exploring.

"Defining Our Work" opens, "Since 1989, the National Center for Families Learning (NCFL) has worked to eradicate poverty through education solutions for families" (Jacobs, et. al. 1). This introduction, tying NCFL to its origins, clearly identifies NCFL's work as starting from a point of deficit and upholds the "poverty and undereducation as disease" metaphor that Auerbach pointed out in 1995. NCFL is explicit about assuming community deficit and its own role as helper across programs. The document reiterates its goal to "break the cycle" and "lift a family out of poverty" seven times across thirteen pages, and references "building" or "improving skills" twenty-three times. NCFL defines its terms and goals using federal standards; the phrases "federal definition" and "federally recognized" occurs eleven times in the document, demonstrating NCFL's clear choice to tie into national educational and employability standards, which assume white, middle-class positionality, as indicators of success. The word "strength" never occurs, nor do references to building on cultural or community knowledge within programs. Despite early references to NCFL's historical relationship to the Bureau of Indian Education and its dedication to the "growing educational needs of immigrant families," cultural and linguistic responsivity is only referenced twice: once as a section heading, and once instructing Parent Time teachers that facilitation should occur "in parents' native language" $(4 ; 8)$. I attend to these specific word choices because they highlight NCFL's understanding of its role as a giver of linguistic, educational, and workplace skills, federally defined, rather than a partner with marginalized and minority communities. 
A central way that "Defining Our Work" connects "building literacy" with "breaking poverty cycles" is through the image of mother as "first and best teacher." The document stresses "multi-generational" family engagement as a "fundamental and distinguishing aspect of [NCFL's] work" (Jacobs, et. al. 1). Fathers are never explicitly named, however and extended family members and caretakers are referred to as generally benefitting from dual-generational (mother and child) involvement. Even when "parents" are mentioned, mothering discourse is central to understanding NCFL's rationale. For example, the document refers to parents as a child's primary or most influential teachers five times, but only references mothers' educational levels as impactful for children's educational outcomes, citing a 2014 report that mothers' education and literacy levels are the greatest indicator of a child's success in school. In their exploration of mothering discourse, Smythe and Isserlis label this discourse "maternal responsibility," linking children's educational struggles to mothers' educational "failures." As noted in the first chapter, referring to a parent as the child's "first and best teacher" is not necessarily a vote of confidence. In this document, it becomes a warning, and a central reason for intervention. Rather than elaborating on the ways that mothers' influence or knowledge might become a starting point for programs, NCFL elaborates on its own role as teacher - using phrases like "support," "help," and "provide opportunities for."

When applying this document to work with populations like Americana's, which is nearly $100 \%$ immigrant and refugee, global mothering discourse is also at play. The document assumes teachers and program administrators who are not members of the parenting community they serve, as indicated by their use of federal definitions and lack of reference to existing community skills or knowledge within the context of cultural 
responsivity. ${ }^{14}$ Following global mothering discourse, white female instructors compensate for the educational and linguistic shortcomings of brown mothers, not only through linguistic instruction but by teaching them how to parent for educational success. The goals of Parent and Child Together sessions, including to "assist parents in their role as first teacher of their children [and] provide parents with an opportunity to practice interacting with their children in a supportive environment," indicate an underlying belief that parents don't know how to interact with children in ways that facilitate growth. The kinds of literate capital that participants demonstrated in the previous chapter, for instance, are ignored, leading readers to assume that they either do not exist or that they are irrelevant for American educational settings.

Thus far, this section has shown that despite describing their work as a "culturally responsive," "holistic approach" to family literacy, NCFL's "Defining our Work" focuses on what the organization gives and teaches families. It does not outline a plan for discovering or incorporating existing cultural capital within a community as "cultural responsivity" suggests. Even so, I see the "Defining Our Work" document as a key place for beginning the process of institutional critique, not in spite of but in light of NCFL's articulation of goals and values. Within this document, NCFL is clear about its values, definitions, and desired outcomes across programs, but it's fairly vague about how those goals should be accomplished. The document outlines very few practices, in fact, especially concerning cultural and linguistic responsivity. Thus, despite a clear deficitmodel ideology, NCFL inadvertently leaves space for partners to shift master narratives about immigrant families as they describe effective community-wealth based practices.

\footnotetext{
${ }^{14}$ It is critical to note that not all of Americana's Family Education instructors are white and that the organization frequently looks for community members to move into leadership roles.
} 
A clear example of re-interpreting NCFL's goal language occurs in the first page of "Defining Our Work":

NCFL believes that shifting families from participation in school activities to an engaged approach of working with families to help them meet their own specific goals is the secret sauce of family engagement. This approach moves the needle from families being involved at school to families being engaged with their children, each other, their schools and their communities. (1, emphasis added)

Here, NCFL describes their interest in programming for family-defined goals, rather than school-defined outcomes. The language is similar to Americana staff's description of "holistic development," a core value that, in Americana's practices, seeks out complex, multi-faceted solutions, rather than quick fixes, and responds to community-defined goals, rather than institutional aims. I emphasize the language NCFL uses because they leave out a discussion of practices in their description of "an engaged approach." The quote lacks a description of searching out and utilizing community knowledge-making practices, highlighting NCFL's belief in its own role as community teacher and problemsolver. However, it also does not specify practices that specifically assume a need for compensatory teaching, even if the examples and research used throughout the rest of the document imply this. Thus, an organizational partner could easily demonstrate their ability to "work with families to $[\ldots]$ meet their own specific goals" in ways that demonstrate cultural wealth. By employing similar goal-language, but showing the efficacy of participant-focused programs, an organization like Americana can begin redefining what "an engaged approach" looks like in practice.

Institutional critique does not happen through merely making different choices within a single program or organization, however. Rather, it occurs as organizations speak up to funders and partners. Program documents provide a clear opportunity for 
critique because they are a central source of communication and relationship-building. They provide evidence that an organization achieves its goals and can be trusted in the future. Program documents also help to create programmatic habits - models that can be followed and goals that can be taken up by future programs. Thus, they have potential to make long-term shifts in institutional narratives, by demonstrating alternative ways of meeting outcomes. I mean to be realistic here: while I do not think that Americana has the potential to shift NCFL's national rhetoric from deficit-model structures to a truly strengths-based view of minority communities, I do think that, within Louisville, the organization has the potential to redefine service models in ways that make immigrant and minority communities visible on their own terms. By re-defining NCFL's terms in ways that shift narratives away from traditional deficit models, Americana can open space for programs that make participants fuller partners. The following section looks closely at Mamas Together's End-of-Program Document, informed by participants' literate history interviews, and establishes three ways that it could help NCFL re-interpret its relationship to immigrant communities and role as partner.

\section{Mamas Together's End-of-Program Document as Institutional Critique}

In discussing funder and partner relationships, Julie, the programs director at Americana, emphasizes the importance of steady relationship building with like-minded sponsors: "We've been fortunate enough to build over time relationships and show that 'yes, Americana does what we say we're gonna do; we have the data to $[\ldots]$ show that [our programming] does make improvements [...] in people's lives.” As an organization builds credibility, she says, "it gets to a point where you can say like "Look, here are some ideas we have. What would it take for this to be a thing that we get funded?" A lot 
of the data that demonstrates Americana's impact comes from post-program reports, in which participant and organizer perspectives demonstrate a programs' success and project future outcomes. The Mamas Together pilot was created, in part, to collect data that demonstrated young mothers' desire for programming while their children were under two, so that Julie and the director of development could ask funders (NCFL included) "what would it take to for this to get funded"? And yet, because Mamas Together was not an NCFL program it was in a prime position to try out other facilitation methods for family literacy programs, separate from the NCFL model.

This section examines Mamas Together's End-of-Program document, a 2.5 page write-up that makes a case for funding and expanding a mother-centric program like Mamas Together, using focus group findings, end-of-program surveys, weekly staff reflections, and the literate history interviews (LHIs) that I conducted with core participants. The document was co-written by the three facilitators--Leah (Americana staff facilitator), Danielle (AmeriCorps Vista) and me (university partner) — following a program recap meeting. During the meeting, we drew on trends in participant surveys, feedback I had gathered in personal interviews, and our own assessments of strengths and challenges, often collected in our weekly reflection documents. We focused on all three of these sources, rather than just a reflection of our notes, to keep our participants' views at the center of the document. Further, as explored in the first chapter, all three of us had like-minded but distinct visions for the program, and our experiences reflected both those visions and our individual roles. Leah compiled the final document, but it's multi-vocal in that it includes notes from our recap meeting as well as Danielle's and my observations, taken verbatim from our "write-up" emails after the meeting. I relate its 
origins and creation process to show the ways we intentionally worked to check our own observations against participants' and fellow facilitators' views.

The document is made up of five sections: Purpose of Pilot Creation, Program Goals, Program Objectives, Participant Feedback and Facilitator Feedback. The first three sections explain the gaps that Mamas Together was created to fill, as expressed through focus groups and staff observations; the goals we outlined, tied directly to focus group findings; and the objectives or practices that we implemented to meet each goal. "Participant Feedback" includes data from participant interviews and post-program surveys, as well as brief interpretations of the data. "Facilitator Feedback" draws from staff observations made during and after the program that expand on themes found in other parts of the document, but that participants may not have talked about directly. Taken together, the sections explain the set-up and successes of Mamas Together, and amass data joined to brief, clear conclusions to argue for expansion and funding. They also treat participant perspectives as centrally important to the creation and future of the program, which is key throughout the trends I discuss.

I analyze this document to point out three ways of interrupting the deficit-frame represented in NCFL's “Defining Our Work": 1) an emphasis on specific, structural gaps as women expressed them 2) a focus on women's ability to build "social capital" and 3) an explanation of spatial choices and their impact on relationships. Within the discussion of each trend, I acknowledge the material and genre constraints that grass-roots organizations face when asking for funding and analyze the current End-of-Program document's potential as a piece of institutional critique. While I would like for Mamas Together to have a future run, to fill a gap for participants and to further flesh out a 
strengths-based program model, I echo Isaacs and Kolba in arguing that the program need not exist in its original form if its model of participant interaction can be taken up in other Americana programs.

\section{Interruption 1: Structural Gaps, Not Cultural Deficits}

Written as the start of a grant narrative or needs assessment, the End-of-Program document begins with an emphasis on organizational deficits and the resulting community needs, as participants expressed them in focus groups and Mamas Together sessions. As such, it acknowledges both the real, material and social needs of this population and community organizations' role in helping to meet them. Leaving out a discussion of needs and the potential impact of the program would both make the program illegible to funders and partners, by ignoring genre constraints, and would disregard the structural barriers that inhibit immigrant mothers' ability to draw on their strengths as parents and literate subjects. As with analyses of cultural community wealth in the previous chapter, pretending that women's literate repertoire only allows them fluid social movement is not only inaccurate, but actually reinforces a deficit-model narrative: if a document points out women's rich literate repertoires but ignores the structural barriers or gaps that make drawing on literate wealth difficult, then the struggle to meet goals can continue to be read as a reflection on individual intelligence and work ethic.

The difference between a needs assessment that assumes deficit and one that interrupts deficit-model structures, then, exists in the way gaps are described, and in who has the power to identify and outline solutions to that issue (Grabill). Acknowledging this, the End-of-Program report talks about gap identification as a collaborative process, focusing on participant perspectives and staff observation: 
After noticing a need in the Family Education Program for families who have children aged 0-2 years, Americana asked for participant feedback [...] through 3 focus groups [on] what was lacking in the community [e.g., institutional supports] and programming at Americana. The women noted several factors that impeded them during this time: lack of community resources, lack of a bond with other women, feelings of loneliness and mental exhaustion, lack of education on the U.S. system in regards to parenting, and lapse of English language education for 2 years.

There are a few things to note here. First, by describing known gaps in Americana's programs, including NCFL-sponsored Family Education, the document still fits the constraints of the grant and needs assessment genres, but disrupts the expectation of empathy rhetoric so often present in these kinds of texts. A focus on clear participant involvement shifts the document's narrative away from a focus on poverty storieswhich use empathy rhetoric to construct a hero/victim binary—and toward a depiction of facilitators and community members as partners. It also ties the program's design to participants' understanding of programming gaps in Americana and the larger Louisville area, further solidifying a vision of participants as collaborators, not helpless receivers. Needs are thus depicted as the result of stressful life circumstances and gaps in organizational structures rather than cultural or community deficit. Beginning with participant feedback makes it easier to demonstrate both the program's responsiveness to "needs voiced by families," which NCFL prioritizes, and participants' centrality to the process of program design, which Americana advocates ("Defining Our Work" 6).

The document also draws a clear distinction between two types of needs: family and community well-being, like mental health care, and skills-based structural deficits, like English and computer skills. Referencing my research interviews, the document explains that while $100 \%$ of participants "noted a personal desire for $[\ldots]$ English- 
language learning, [they] wanted it tacked onto a program like Mamas Together, not as a replacement." This is a key moment of critique, because "Defining Our Work" often collapses these needs, positing that family literacy creates a healthier, more meaningful life for immigrant families through teaching educational and parenting skills. ${ }^{15}$ When a lack of parenting knowledge and literate education is seen as a personal or cultural deficit, this conflation makes more sense: to fix family and community relationships, one must fix a mother's role as "first and best teacher" and teach her community engagement strategies (Smith, Auerbach, Smythe and Isserlis). By separating these two types of needs, the End-of-Program document interrupts the assumption that family literacy builds relationships or supports mental health through teaching educational skills. Instead, it advocates for a deeper definition of holistic care—one that adjusts program practices based on the expressed needs of participants.

The commitment to design based on participants' stated needs can also be seen by attending to the goals we list and those we leave out. The report never lists early childhood education or helping families out of poverty as a goal for Mamas Together because women did not express a desire around that kind of programming. Rather the statement of purpose focuses on the specific skills—namely English language learning and computer skills - that focus group and program participants saw as important to their goals. Women do want formal English classes, because as Win notes, "it is really hard to live [in the US] without the language skills." This is a specific barrier, not a cultural

\footnotetext{
${ }^{15}$ Brian Street describes this as the "autonomous" model of literacy. It works from the assumption that "literacy in itself - autonomously - will have effects on other social and cognitive practices." It also disguises the "cultural and ideological assumptions that underpin it," so that literacy practices seem neutral and universally applicable, rather than laden with Western values (7-8).
} 
deficit tied to undereducation. The document does not completely discount teachercentered classes, but it does give them a specific role in helping families thrive.

Thus, the End-of-Program document counters deficit assumptions, while also acknowledging structural needs. It also demonstrates, however, that a shifted focus, in which women define their own goals and form relationships without structured top-down teaching, can still meet NCFL's goals and have a positive impact on the families they serve, which is central to the organization approving short-term funding and, long-term, adjusting Family Education's practices. The following interruption digs more deeply into the End-of Program documents' discussion on building relationships, specifically as a separation from NCFL's discussion on "building social capital."

Interruption 2: Peer-to-Peer Relationships Provide Holistic Support

In "Defining Our Work," NCFL emphasizes the need for participants to build "social capital" during Parent Time, supporting a focus on using family literacy programs to create community networks. Specifically, it says:

In addition to connecting parents to their children's learning, Parent Time also connects parents to each other. These new and deliberate connections will result in the formation of new social capital. This social capital includes the relationships and aspects of relationships that allow for the transmission of resources and institutional support. (9)

It further charges the teacher with "teaching parents how to maximize these relationships for their own family's gain." It does not, however, expand on the ways that a teacher might make room in the lesson plan for relationship-building, stating elsewhere that proximity "naturally" leads to meaningful connections. It also does not address the benefits of parent-to-parent relationships beyond sharing institutional knowledge and resources. This provides a second way to take up NCFL's outcome language, while 
shifting the narrative toward holistic care practices that prioritize women's mental health and relationships to one another.

As previously noted, creating avenues whereby women could build social and navigational capital was a major goal of Mamas Together because 1) women in focus groups expressed a need for community resources and 2) women reported lacking deep connections to other mothers with young children (“End-of-Program Report” par. 1). Thus, the majority of our practices were, as the End-of-Program report states, "designed to create a safe space where moms could share knowledge and feel supported during a loosely structured instructional time" (par. 4) As in the previous interruption, the report uses language in line with NCFL's description of its goals for building "social capital," but reframes an assumption of deficit and adds an explicit description of our choices. In detailing our choice to have women "share knowledge" and support one another, for instance, we clarify women's ability to act as one another's support networks and to share resources, strengths, and challenges among themselves as they felt comfortable. We stress these times of sharing as equally important to the use of invited speakers in connecting women to community supports and each other, which is a clear divergence from NCFL.

The End-of-Program report also clarifies our view of "holistic" development. NCFL uses this term to talk about the need for intervention in home and community life, as well as educational spaces. We specify our definition as "caring for the whole person" rather than intervening in multiple spaces. This can be specifically seen in participants' calls for emotional and mental health support, and the practices we created in response: 
The women noted several factors that impeded them during this time [including] lack of a bond with other women [and] feelings of loneliness and mental exhaustion. (par. 1)

By creating a holistic environment focusing on mental health, moms were able to create a strong bond and utilize [community] resources. (par. 2)

Using practices from trauma-informed care and holistic wellness trainings, practices were designed with the mental and emotional health of participants in mind. (par. 4)

Particularly in the first two instances, the document reiterates NCFL's focus on "deliberate action" in the process of "building social capital," but re-frames staff practices and program hierarchies. To allow social and navigational capital to develop, the document asserts, a facilitator must intentionally make space for it, which is different than teaching students how to build or utilize it. Our role shifts, then, from teaching women how to parent or build relationships - thus positioning ourselves as "global mothers"- to facilitating discussions in which women feel safe, comfortable, and supported as they share parenting experiences with peers.

The End-of-Program reports' primary purpose is to demonstrate the program's ability to fulfill its goals, which, as Julie says, builds trust between Americana and its partners and grants future asking power. Thus, it points out the efficacy of asset-based practices in meeting family literacy goals, using language potential funders will recognize. Rather than explicit critique, the challenges to deficit-model narrative comes through articulating practices that assume participants' intelligence and parenting expertise. One of the strengths of using an End-of-Program report for institutional critique is its focus on a single program's success: it builds rapport with large funders, by showing that an organization "does what it says," and it demonstrates the efficacy of a different approach without explicitly criticizing either the funder or other deficit-based 
programs. ${ }^{16}$ It demonstrates the success of the program's approach in the specific community it serves. In this instance, the End-of-Program report indicates that when we considered women's socio-emotional wellbeing, they felt more comfortable developing relationships and seeking out community resources- "building social capital" in NCFL's terms. In making this claim, the End-of-Program report implies women's abilities to draw on their own cultural capital and wealth of experiences and clarifies organizers' role as facilitating partners.

The next interruption further considers the End-of-Program document's discussion of space during the program as a rhetorical move that encouraged relationshipbuilding through creating a safe, comfortable environment. It thus continues to show Mamas Together as a local, situated program, and suggests the potential for like-minded programs to take a similar approach.

Interruption 3: Using Space to Invite Relationships

Rather than noting a material constraint, the third example of interrupting deficitmodel discourse invites a material focus. As explored in the previous section, creating a sense of safety was an important aspect of Mamas Together, and the End-of-Program document emphasizes the ways that space and environment create comfort, allowing women to share their lives, while "building social capital" and "accessing resources." Considering space is an important piece of institutional critique. Porter, et al. describe attention to spatial rhetoric as "offering considerable potential for the interrogation of

\footnotetext{
${ }^{16}$ Again, this is not to discount the place of outright criticism and a clear break with deficit models. Rather, Porter et. al. stress that for institutional critique to be effective at the local and material level, it needs to demonstrate an understanding of local realities. Global critique is too easily dismissed by "local realities," but a critique that demonstrates knowledge of the community, and is supported by effective practices, can develop leverage over time (616).
} 
resistance and agency in institutions" (620). In other words, the way one sets up and uses a space makes arguments about what's important within a program.

Physical space was important to the success of the program and it comes up several times in Mamas Together's End-of-Program document. In particular, we discuss the atmosphere we created through spatial choices, referencing them as intentional ways of meeting our goals. Below, I emphasize the atmospheric details:

Sessions were created to be informal, with chairs in a circle all facing inwards so that facilitators and speakers sat with participants instead of in an authoritative position. [...] The purpose of these spatial and rhetorical choices was to create a sense of warmth and familiarity, so that everyone would feel comfortable sharing and listening. (emphasis added)

Here, we set up Mamas Together as a subtle contrast to a top-down program like NCFL's Family Education, which has clear delineations between teacher and students. We do not critique Family Education specifically; that isn't the purpose of the document, and we recognize that our "sister program" has different goals and structures. However, we do point out the ways that our "spatial and rhetorical choices" impacted women's sense of comfort and helped the program fill the gaps that participants outlined. One such stated need is a "lack of bond with other women." Again, NCFL says bonding should happen naturally within the Parent Time portions of programs like Family Education. By focusing on spatial choices, the End-of-Program document suggests this is not the casethat women's proximity to one another does not necessarily approximate the kinds of relationship building that NCFL describes as useable "social capital."

Bolstering this point, the report also examines the discomfort created by a shift in our spatial choices, making a more direct argument for re-thinking how room layouts constrain or allow peer-to-peer relationships. Specifically, we note the changes we made 
during our post-program discussion and survey completion, which we conducted at tables instead of in our usual circle:

Staff noted that participants responded well to the set-up of Mamas Together. During the final class, however, participants struggled with giving feedback. This is concluded to be [because] the setup was different, with participants sitting at a table, instead of in a circle with chairs facing inwards, thus creating a less comfortable atmosphere.

It is important to note the role that this observation plays in contrast to the one before. By pointing out the difference in room configuration, we make a statement about the relationships that different spaces allow for. Sitting at tables with a head teacher leading the discussion creates distance between facilitator and participants, the document implies. Thus, if the goal is a comfortable, "student-centered" atmosphere, as NCFL says it wants to create, then a typical classroom setting might not achieve that goal. Where the first mention of space shows other options for setting up a family literacy classroom, this quote demonstrates potential problems with not examining room set-ups.

At no point in the document do we explicitly mention the deficit and mothering discourses that our choices work against, such as NCFL's stated belief that family literacy programs exist to enlighten otherwise deficient participants, or their implied belief that white American women, as "global mothers," and representatives of Western parenting norms are ideal teachers for immigrant and refugee women. We also do not to criticize other programs, keeping our focus on the effects of our choices. Still, moments like those above make subtle critiques, as we observe the differences between creating a comfortable, peer-to-peer space, and utilizing a more traditional classroom setting that suggests teacher control. The discussion on space, in particular, implies that if a program 
wants to create a space where women feel comfortable and supported to share their resources, you must make physical and pedagogical choices to support such a goal.

These three ways of interrupting NCFL's beliefs about immigrant and refugee families, expressed in "Defining Our Work," offer rich examples of using an outwardfacing program document to critique institutional narratives. Each interruption demonstrates consistency with NCFL's goal language but specifies practices that provide richer ways of listening to participants at every stage of the program. In doing so, the End-of-Program not only demonstrates that there are multiple ways to achieve family literacy goals, but also subtly indicates that some are better than others at building on [participants'] wealth of resources," and "honor[ing] their capabilities," as whole learners (Potts 3, cited in Auerbach 645).

\section{Conclusion}

Rather than dwelling on the heartbreak of watching a thoughtfully crafted, wellliked program end, this chapter takes a critical look at the tensions between small organizations and institutions to ask "how can the work we did continue making a difference? Once we have done the work of studying our listening practices, and asking for new stories of community wealth, what can we do with them?” Despite Mamas Together's short run, I argue, we still have a responsibility to our participants and to future programs to use the stories women shared and data we collected to push back against dominant, marginalizing discourses.

I am not the first person to say this. Trends in "unsustainability" scholarship point out the sticking points between creating small, short-lived, tactical programs that adhere to a program's values, and tying into large institutional narratives that force negotiation. 
Program growth requires funding, for instance, but that those doing on-the-ground work are rarely the same as those funding the work. Sometimes value misalignment or misunderstanding leads to a loss of funding. Other times, as in the case of Mamas Together, even when partners appreciate a program's work, funding structures are still unpredictable. When they shift, they do so to reflect the funder's priorities much more often than the organization's goals.

Attending to these issues, I note the temptation to employ deficit discourses in the documents we create to gain support for our communities. Drawing on transnational feminist scholarship, in particular, I point to the re-marginalizing effects of global motherhood discourse and empathy rhetoric - two commonly employed tropes in documents that seek support and compassion for women like Mamas Together's participants. To avoid this temptation, I argue for re-defining sustainability to include a program's ability to influence organizational culture even after its run (Sheridan, Mathieu "After Tactics, Isaacs and Kolba). This definition of "sustainability" provides options outside of reliance on deficit-model narratives even while working within a large institution's funding structure. Mamas Together would have ended whatever language we used in documents, but the longevity of a short-lived program can exist in in the documents it creates that tell complicating stories about the participants that continue to rely on large institutions and other organizational programs for support.

Institutional critique methodology, I argue, creates a path between completely independent operation and changing thoughtful work to reflect deficit institutional values. I demonstrated this through analyzing Mamas Together's End-of-Program document, written for use in grants and program proposals, as an interruption to NCFL's 'Defining 
Our Work" document. Using outcome language, but keeping the focus on participant knowledge, literate repertoires, and desires for holistic care demonstrates the benefits of beginning with an asset-based frame. To be clear, I do not see these kinds of small-scale critiques as having the power to change an institution at its core or affect NCFL programs nationwide. I do, however, think that it could make programming at Americana more responsive to participants, since Julie and other staff have developed strong relationships with NCFL and the public school system, and programs already exist rely on cultural community wealth. If Mamas Together's End-of-Program report could be used even to create structures within Family Education that "build social capital" through creating space for women to share their lives and expertise, I would call it a success, because what organizations program for becomes an expectation and creates avenues for more programs that listen for cultural community wealth and prioritize holistic care principles. 


\section{CHAPTER FIVE}

\section{CONCLUSION: USES AND NEXT STEPS}

\section{Introduction}

Near the end of his 2019 CCCC address, Asao B. Inoue addresses the difference between cultivating a listening attitude and building listening structures:

I'm not saying we have to change our perspectives, soften our hearts. [...] In fact, I'm actually saying the opposite, that we cannot change our biases in judging so easily, and that [the] perspectives that you've cultivated over your lifetime [are] not the key to making a more just society [...]. The key is in changing the structures, cutting the steel bars, altering the ecology, in which your biases function in your classrooms and communities. ("How Do We Language So People Stop Killing Each Other?’)

As I interrogated the gaps between intentions and consequences, especially in community literacy programs, the need to attend to structures and the process by which they were created and evaluated came up again and again. Within the pilot program this dissertation examines, it was not enough to simply insist on enacting better listening practices; listening, as both an act and an attitude, was already at the heart of Mamas Together, infused throughout its processes. My listening began with immigrant and refugee mothers' responses to open-ended focus group questions. The listening process started much earlier for Americana staff, as they spent time with families in coaching sessions and "kept an ear to the ground" in the community (Julie, personal interview). During 
Mamas Together's six sessions, listening continued as facilitators made women's stories - their fears and joys, experiences and expertise — an integral part of our conversations. Every week, facilitators reflected on what we heard and made adjustments for the next week. In these ways, listening attitudes shaped our practices, and by the end of the program, participants had begun developing a support system and organizers had a richer understanding of what young mothers in the Americana community wanted from literacy programs during this life stage.

Even so, as chapter two notes, organizers always felt tension between our desire for participant-centered programming and the push to "teach" women parenting skills as we provided resources. Acting on what we heard from participants was not as simple as putting our ethical commitments into practice within Mamas Together's context. We also felt the tug of other programs' goals and objectives imported into our planning and practice space. While it is well-established that previous experiences and beliefs shape action, what's less explored is the impact of these experiences on our active listening processes and the resulting practices. I wanted a way to study the consequences of listening through unacknowledged discourses. The genesis of this project came from wondering, as Inoue does, "How are [we] attending, exactly? What are the markers of [our] compassionate attending?" To this, I add, "What else are we attending to, without realizing the soundtrack of other voices that impacts our 'compassionate attending?"”

Beginning with these questions, I articulated a listening methodology that begins with critical self-reflection and results in using participants' counter-narratives to help reframe deficit discourses at multiple levels within community literacy organizations. In chapter two, I outlined a methodology for studying our current listening processes, which 
I termed "listening back." Through this process, I argued, we could attend to the unintended, unrecognized discourses about our participants that mixed with Americana's carefully designed core values. We could study, for instance, where previous programs had created antecedent genres of practice that spoke into our planning sessions. We could also attend to the presence of deficit discourses, so often at work in family literacy and immigrant education programs, and test the assumptions we made about participants as we planned. By listening critically to the voices of deficit discourses and previous practices, we could trace their impact on the structures we built and animated during Mamas Together. Chapter three searches out new narratives about immigrant women's and families' literacy practices to counter the deficit-model discourses. The chapter uses a methodology from Critical Race Theory, analyzing women's literate history interviews (LHIs) through a community cultural wealth lens. Analyzing women's experiences in this way, I counter specific myths within dominant stock stories about linguistically marginalized families. I also show points of friction and loss, where women may possess deep literate reservoirs, but have difficulty drawing from them due to structural marginalization. These two data chapters are inwardly-focused, attending to the relationships between listening and creating program structures. Specifically, I ask how structures shape our ability to hear people, and what shifting our listening stance might do to alter program structures and relationships. Chapter four moves beyond Mamas Together, arguing that once we have attended to different stories, organizers have a responsibility to speak up to funders and partners outside of their individual programs. Despite the power differentials between large funding institutions and grassroots organizations, I argue that organizers still have outlets through which to advocate for 
more representative narratives about participants. I analyzed Mamas Together's End-ofProgram report, which will be used in grant narratives and future program proposals, as a counter to NCFL's “Defining Our Work” document. By using similar goal language, but describing strengths-based practices, the End of Program report shows that Mamas Together can meet NCFL outcomes while amplifying community wealth discourses.

This concluding chapter traces the through lines in previous chapters' conversations and looks forward toward future work. I discuss future possibilities for this work in two distinct ways. First, I outline ways that my dissertation could be expanded to contribute to the scholarship in draws on: community literacy scholarship, listening studies, and transnational feminist applications in literacy conversations. Second, I imagine how a project like this dissertation might become useful and useable to community organizations like Americana, for whom it was originally theorized and written, and in rhetoric and composition departments, like the one that helped shape this project. This second aim is particularly important for me, since a major goal of this dissertation has been to help thoughtful organizations better attend to the families they serve. In its current form, however, Americana staff would be hard-pressed to use my findings in program design or staff trainings. The dissertation genre simply does not lend itself to these kinds of concrete uses. Thus, before turning to limitations and future work for this dissertation, I discuss three tangible ways that my research could be used to develop tools for community literacy organizations like Americana.

\section{Through Lines and Uniting Choices}

Chapters two to four are meant to build on one another, each getting its impetus and direction from the preceding chapter. Once organizers have critically studied current 
listening practices, we are better prepared to search out other discourses that inform the programmatic culture we want to create. Likewise, once we know that literate wealth narratives can re-shape an individual program's work, program facilitators have a responsibility to make room for counterstories in the larger work of the organization. The structural logic of these chapters means that they grow from one another and contain several consistent themes, or through lines, that need to be teased out as I consider the scholastic and organizational interventions that this dissertation currently makes as well as possibilities for future development. In this section, I focus on three through lines that I see as contributing to scholarly interventions and practical uses for this study, setting up for a discussion of the dissertations' contributions in the section that follows.

\section{Through Line 1: Traditional Frames and Interventions from Scholars of Color}

As a white feminist scholar researching and creating programming for brown transnational women, I have remained particularly aware of the need to choose my theoretical and methodological frames carefully. In each chapter, I paired traditional composition and literacy methodologies with frames that focus explicitly on intersectional marginalization. In chapter two, community listening and transnational feminist interventions critiqued rhetorical listening, a more traditional listening frame that draws on classical rhetorical practices. In chapter three, I conducted literate history interviews (LHIs), a data collection method that has been used since the early 1990s to learn about literacy's work in communities. I drew on Critical Race Theory to analyze interviews through a community cultural wealth frame, listening to the ways LHIs

counter deficit stock narratives. In chapter four, I forwarded institutional critique—often 
used in composition departments and community literacy programs - and coupled it with transnational feminist critiques of institutional discourses.

My goal was to bring established methodologies in the Composition, Literacy, and Rhetoric (CLR) into productive conversation with frames forwarded by scholars of color, especially as they worked with communities of color. In doing so, I hoped to make some of the implicit concerns within those traditional methodologies more explicit. While scholars of color have productively used rhetorical listening (Inoue), literacy history interviews (Vieira), and institutional critique (Underhill), other scholars have argued that CLR needs to re-consider the impact of majoritarian logics within the methodological frames we use (García, Jackson and DeLuane). Further, as Romeo García points out, scholars from racially and linguistically marginalized communities do not need traditional frames to do powerful work in the field. Rather, he says, scholarship should pay more careful attention to the cultural logics of the people we research. By coupling commonly used frames in the field with work motivated by anti-racist and/or antinationalist concerns, then, I hope to make those themes more explicit within CLR. In other words, each of three field-specific methodologies named above has been used to study racially and linguistically marginalized communities, but not always in explicitly anti-racist ways. When coupled with interventions from Critical Race Theory and Transnational Feminism, those themes take a more central place, and require intersectional marginalization to be marked rather than remaining assumed but unnamed. Thus, I forefront explicitly race- and gender-based frames to demonstrate one way (among many) of drawing on the kinds of community logics that García advocates. 
Throughout the dissertation, I pay particular attention to transnational feminist scholarship for two reasons: first, my study participants are transnational women and the white women creating programming for them. Transnational feminist scholarship is consistently interested in the relationships between white feminists and the brown, twothirds world women they want to help—-both specific interactions and the circulating discourses and negotiated logics that direct interactions. While rhetoric and composition has borrowed from several cultural philosophies that study the abstract forces informing relationships and textual creation, transnational feminism largely has not been used. There are exceptions: Wendy Hesford studies how visual texts depict transnational women for a white audience. Katrina Powell examines refugees' rhetorical agency as they craft migration narratives to meet their needs. Rebecca Dingo traces the circulation of global policy to its local effects. Each of these scholars is firmly rooted in rhetoric and uses an explicitly transnational feminist frame to examine textual power. There is a disconnect, however, between the frames rhetoricians use, and those used by literacy scholars, even when studying the same communities. This suggests a gap between theory and practice in our field, or perhaps between critique and implementation. While community literacy scholars are not currently using transnational feminist frames to study their program structures or their relationship to participants, the same concerns taken up by rhetoricians apply at the grassroots level. By attending closely to transnational feminist concerns and examples as I set up the pieces of my own study, I begin bridging that gap.

I see this first through line as a potential contribution to the ways we study intersectionally marginalized populations. Fishman and Rosenberg remind us that we 
cannot truly displace our communities' knowledge — which may include disciplinary frames - as we listen or act, but that we are still responsible to "find new levels of meaning," and "to challenge assumptions and biases as well as preconceptions" (3-4). Throughout the dissertation, I have worked to be aware of my position as a white feminist scholar working within methodological frames theorized by majority white academics.

As an early scholar, I will not pretend that my efforts to couple traditional methodologies with more explicitly anti-racist frames are perfect. I am aware of some places in which using frames to question and amplify one another remains clumsy. I know, from studying the pervasive nature of privileged whiteness, that there are other points where my inability to hear my own privilege conflicts with my goals. Even so, I am committed to hearing others on their own terms, from the theoretical to the practical level, and to letting what I hear critique my own ways of knowing. Thus, I am not delineating a hard and fast model by which CLR scholars should combine traditional methodologies with anti-racist frames like CRT or transnational feminism, but rather an attitude and a willingness to engage with that work at multiple levels.

\section{Through Line 2: Balancing Empathy and Critical Engagement}

A central goal throughout my dissertation is to call out and combat unexamined discourses about immigrant and refugee families, especially as they concern motherhood and education. Each of my chapters points to the presence and effects of specific deficit narratives that marginalize families like those in Mamas Together, the argues for the need to increase and awareness for community literacy facilitators and their partners at multiple levels of organization. Thus, assessing institutional culture is central to my dissertation's work. At the same time, relationships are equally central to each stage of 
the listening process I outline, from evaluating current listening practices to correcting institutional partners' narratives regarding immigrant mothers and families. I made a choice early on to work alongside a research partner in ways that balance empathy with critical engagement. Specifically, I explicitly recognize their expertise, deep care for participants, and relationships to other institutions. I join calls in community literacy for developing an attitude of grace that leads to thoughtful action, so that we can remain clear-eyed in the work. In outlining rhetorical listening, Krista Ratcliffe stresses the need "to proceed from within a responsibility logic, not from within a defensive guilt/blame one" (204, emphasis in original). Likewise, in their special issue theorizing community listening, Fishman and Rosenberg describe "listeners" as standing "in a position of generous openness," from which "it becomes possible to pay ongoing unflinching attention where it is needed most, heedful of dynamics of identity that $[\ldots]$ must always be part of our considerations" (3). An empathetic stance, as these explain, still requires critical engagement to discover where and why listening efforts fall short of creating equitable structures. Such an attitude does not mean giving undue grace to those in power while continuing to marginalize those without. I see two central purposes in this dissertation, and in community literacy work more broadly, for balancing empathy with critique. First, such a balance prioritizes a trust-based relationship with community partners. Second, it allows small organizations to speak up to large institutions while maintaining needed connections.

In my work with Americana and Mamas Together specifically, balancing empathy and critical engagement means starting from an assumption that the women I partnered with—both facilitators and participants—-have knowledge that I do not. This 
acknowledgment requires a shift in focus, away from a scholastic temptation to arrive at a firm stance and toward a commitment to hold space for difference. I see this stance at work in chapter two, as I explore how my position as a composition instructor and Leah's position as family coach informed our divergent understandings of program goals. Extending empathy toward both of our stances helped us negotiate our goals during the program's run. While writing, empathy allowed me to use her stance and expertise to question my conclusions, and vice versa. In this way, I did not need to settle on who was right and could instead look at the consequences of both of sets of enacted intentions. I also worked to practice an empathetic stance as I listened to and analyzed participants' literate histories in chapter three-committing to representing women's literate histories in the ways women expressed them, rather than imposing my own frames, as a white feminist scholar. I want to clarify that when I talk about extending “empathy" to Mamas Together participants, I distinguish it from the kind of victimizing "empathy rhetoric" that Theresa Kulbaga warns against, which pictures transnational women as always, only victims of oppression, defined through white pop-feminist frames. In contrast, the kind of empathy that works to be "heedful of dynamics of identity" (Fishman and Rosenberg 3) pays attention to the complex ways in which women discussed experiences in home countries, refugee camps, and post-immigration communities. Critical engagement with these stories, likewise, seeks to demonstrate their complexity rather than flattening them for the sake of finding themes. Throughout the process of interviewing, analyzing, and drafting, I remained aware of the moments in which I was not able to hear women as they meant to be understood, and thus should tread lightly, and note the possibility for misunderstanding. Even now, I know that there 
remain stories I did not hear as they were intended, and important but unasked questions that might have provided different kinds of insight. Balancing empathy and critique, especially when attending to transnational women's stories, means holding space for being wrong in my scholarship and taking responsibility where I can.

A third version of the relationship between empathy and critique, explored in chapter five, involves grassroots organizations' relationship to large institutional funders. In the previous paragraphs, an attitude that prioritized understanding provided a different stance from which to examine motivations, choices, and identities. Here, since the grassroots organization is less powerful than the funding partner institution, an "empathetic" stance provides the rhetorical frame for expressing critique. While chapter four demonstrates NCFL's institutional logic as largely deficit-based, Americana depends on it as a funder and program partner. Thus, their relationship with NCFL as funder and program partner means that they do not necessarily have the means or power to reject their vision of immigrant's literacy practices outright. Further, my partners have not expressed any desire to do so. NCFL is an established provider of family literacy programming and offers services that immigrant and refugee families depend on as part of a network of resources. And yet, as a scholar committed to calling out marginalizing discourses, and as a university partner committed to Americana, I have a responsibility to help distinguish and fill gaps between intentions and consequences. Thus, chapter four explores a generous approach to critique — one that uses the language of an institution, plus equitable, strengths-based practices to shift NCFL's values and vision of transnational families. Empathy, here, is a tactic as much as a stance. It's an expression of understanding, though not solidarity, toward a more powerful entity. While head-on 
critique would be unproductive, a critique that establishes common ground first, by using goal language, might make more headway.

My dissertation study starts from a place of trust: believing that my community partners know what they are doing and care deeply about their participants, just as I believe that the women attending programs have knowledge and resources that can transform community literacy spaces. Thus, many moments of pointing out tensionsbetween intentions and consequences, for instance, or organizational and partner values - began in conversations with fellow facilitators and were spurred on by their desire to create programs that cared for the whole person and invited participants in as partners in knowledge-making. My commitment to honor my partners' expertise, as well as participants' voices, is a key feature of this project, because it exemplifies a partnership between university and community partners that is built on trust and mutual benefit. While critique is part of my role as researcher, the goal does not have to be shutting down or calling out. I see this work as building on, and sometimes refining, the excellent work and ongoing conversations that preceded my time at Americana and will continue after I leave Louisville.

\section{Through Line 3: Considering Material Realities}

Beyond demonstrating that critical work can be born out of mutual respect in partnership, grounding my work in partners' concerns meant attending to the messy material realities of community literacy organizations. Any theorizing or imagining was thus situated in what Americana and organizations like it could reasonably accomplish given their assets and limitations. That kind of grounding is key for a dissertation that aims to be useful beyond contributions to theoretical scholarship and to enable better 
listening and more equitable practices for real partners. As Porter, et. al argue "institutions can far too easily ignore global arguments for local reasons" (616). Thus, each chapter's conversation considers the situated, local realities of the program and participants I am studying. Specifically, I consider the constraints on people, programs, and grassroots organizations to make arguments for listening practices that might be practically achieved.

When considering the elements that constrained people in Mamas Together, I focus on time, experience, and busy individual lives. In the first chapter, for instance, I note the realities of organizers' time and knowledge, and the ways that our previous experiences (or sometimes lack of experiences) and present time commitments (including prospectus writing and maternity leave) contributed to the early shape of our program. These were unchangeable realities and acknowledging them serves as a reminder that 1) community literacy programs never exist in the abstract and; 2) program facilitators' identities, like those of participants, are complex both in and outside of the programs they help run. I also find that recognizing constraints on individual lives helped me voice findings and suggestions realistically. For instance, knowing that Leah was out for maternity leave during planning, I was writing my prospectus, and Danielle was writing early lesson plans on her own helps me see some of the differences in our imagined pilot program with more grace and realism. We did not have the time or opportunity to always "be on the same page," or figure out how to enact goals perfectly pre-program. That does not mean that we aren't accountable to reflect on listening practices or have critical conversations as we go. In fact, having a way to study listening already in place might have helped us articulate our visions. But it does provide needed perspective. 
Attending to the relationship between grassroots community programs and their larger partners and funders provides a second clear way of acknowledging material realities. In pointing out the deficit discourses at work in existing programs, for instance, I clarify the need to negotiate values in work with outside partners, arguing that organizations like Americana can't always control how their values are taken up by outside speakers or staff members from partner organizations. Recognizing this, I argue for teasing out the ways previous programs" practices have "spoken into" new planning processes. In the final chapter, I return to the relationship between tactical programs ${ }^{17}$ and large, "sustainable" institutions. Here, I make a clear case for why small programs might align themselves with large funders who can provide long-term resources for their community. While taking seriously the reality of power differentials between organizations and funders, I also advocate for finding ways to share what we know about people's literate and familial lives. I make suggestions for how program documents can be used within a long-term relationship to change institutional culture-making many small, deliberate changes over time.

Acknowledging material realities is part of balancing empathy with critique, because it understands that lives and organizations are messy, and are limited to the times, spaces, and resources at their disposal. The dissertation thus celebrates what programs and people can accomplish with what they have, while making contributions that account for limitations. Attending carefully to material constraints is important to any scholarship focused on practical implications, since it bridges a gap between grand ideals and feelings of helplessness — both hindrances to sustainable change.

\footnotetext{
${ }^{17}$ As a reminder, Mathieu defines "tactical" programs as small, nimble, and driven by community desires, while "strategic" programs start with institutions - government or non-profit agencies for instance - and tend to be large and financially sustainable.
} 
Each of the above through lines requires balancing between compassion for the present moment and a need to move forward and reimagine possibilities. I see the practice of negotiating between what is and what can be, and holding space for both, as key to enacting a thoughtful listening methodology that results in change. In this way, the dissertation works to cultivate what a "collaborative imagination," which Feigenbaum describes as the "capacities to imagine $[\ldots]$ more just, more tolerant, more compassionate, more sustainable [worlds]" and then to "employ mutually derived, rigorous methods for realizing these worlds" (5-6). Attending to empathetically to material realities grounds the process of "imagin[ing] new worlds," while negotiating between perspectives ensures that they remain "mutually derived." Thus "realizing these worlds" is a process grounded in deep understanding for the present and clear plans for the future. The following section continues thinking through the trends in this dissertation, paying particular attention to the contributions it makes for both scholarship and grassroots community literacy work.

\section{Scholastic and Practical Contributions: How This Work Helps Us Hear the Gap and Imagine New Possibilities}

Concurrent with the Mamas Together timeline, scholars in community literacy and CLR were calling for greater attention to listening processes on a national scale. Fishman and Rosenberg's guest issue of Community Literacy Journal, forwarding “community listening," as a term, came out in fall 2018, as Leah, Danielle and I prepared for Mamas Together's initial run. The following spring, during Mamas Together's last week as a program, Asao B. Inoue's CCCC keynote invoked Royster and Ratcliffe as he asked white composition teachers to attend to the consequences of their current listening processes in the classroom. In each instance, scholars asked for greater attention to the 
gap between intent and reality. They also stressed the importance of listening theories and practices that paid attention to marginalized groups' knowledge-making practices and cultural logics. The call for listening, 25 years after Jackie Jones Royster's keynote stressing the same themes, indicates that despite CLR's theoretical commitment to include diverse voices in community programs and classrooms, a disconnect remains between our scholarly calls and our organizational structures. Part of the issue, as Rowan and Cavallaro note, is that more scholarship calls for listening than demonstrates how critical, empathetic listening happens. We need both urgent pleas and clear, complex methodologies to guide and critique our listening, especially across power differentials.

This dissertation starts in the gap between intentions and consequences - between what we say we want and what our structures enable. In moving past a study of current listening practices, it also offers alternate discourses to "stand under," and possibilities for transformation. Given current calls for listening, this section offers potential contributions in three areas. First, I discuss interventions in community literacy scholarship, where my work is most firmly grounded. Second, while this is centrally a community literacy project, rhetoric and composition departments are asking similar questions about critical listening practices. Thus, I think through how listening practices might be beneficial in composition contexts. Finally, because my dissertation began and ended as a means of bridging gaps in a community organization, I conclude this section by sketching three ways that parts of the study could be adapted for community organizations like Americana. 


\section{Interventions in Community Literacy Scholarship and Composition Departments}

Community literacy scholarship has done rich work creating programs that include participant voices at every stage. Further, scholars' and community partners' attention to relationships, power dynamics, and reciprocity has informed the work of this dissertation from program planning to final revisions. As noted above, however, community literacy work currently lacks clear, complex methodologies for studying and enacting literacy practices. In the spirit of reciprocity, I see two ways that my scholarship helps answer this lack.

First, "listening back" offers a wider scope than previous listening methodologies. In studying current listening practices, it attends to the voices of past programs and traces their potential effects. As such, it offers those working in and researching community literacy programs a way to listen beyond a present moment of tension to untangle some of the causes of misunderstanding, such as misalignment between current goals and past patterns of practice. I find this contribution to community literacy studies especially useful for scholars struggling to negotiate goals or practices with partner organizations, because it allows both parties to take a broad view of their current practices and to attend to the gap between intentions and consequences by hearing a fuller range of the "voices" speaking into a program.

Second, community literacy studies can benefit from the ways I attend to the results of listening practices, demonstrating the potential for new relationships between community organizers and both participants and funders. I chose to create three interrelated studies with distinct methodological frames to demonstrate the consequences of critiquing current listening practices in the case of Mamas Together. Thus, readers 
have a model for "what happens next" at each point in the process-uncovering tensions in goals, understanding competing discourses, hearing new stories as cultural wealth, and finally using those stories to make change at the institutional level to reduce future tension in goals. While the details of my study are unique to this situation, the process of listening, planning, implementing, analyzing and talking about a program with overseeing institutions is common in community literacy organizations. Thus, a significant contribution of this dissertation is its ability to make interventions at every point in the process, while leaving the flexibility for application to a variety of programmatic situations.

While my work is grounded in community literacy studies, it has wider application in composition departments as well. As my study demonstrates, a soundtrack of other voices determines creative and interpretive choices, even as we argue for amplifying marginalized perspectives. That soundtrack may determine, for instance, who we ask for input on anti-racist task forces and program initiatives. It may keep research frames grounded in our disciplines, many of which use white, majoritarian logics that obscure issues of race and language as "one concern among many" rather than marking them explicitly. In cases where non-white, non-English speaking perspectives are asked for, unattended soundtracks may interpret asked-for perspectives through previous programmatic or departmental practices, so that the values a program or department has fought hard to outline are undermined by "the way things have been" or what I've called antecedent genres of practice.

I suspect that, despite the attention listening has garnered in the past few years, unawareness of our current listening practices is a more common problem than we 
realize, either in community literacy or rhetoric and composition. Again, until we understand how we listen—what I've called the "soundtracks" of other discourses or value sets - we cannot productively outline and implement better listening practices. I see "listening back" as a productive methodology for examining current listening practices for several reasons. First, it examines both the ways values are defined and the ways they're enacted, paying attention to the process of negotiating values as they inform practices. Using rhetorical listening's attention to "standing under" circulating discourses, the methodology I outline assumes that discourses have power to shape our imaginations and understandings of marginalized communities and, further, that the ways we imagine a group determines the structures we build for their needs. Relatedly, listening back attends to the processes of negotiating values in partnerships with other organizations, and potentially other departments. It demonstrates how resulting entanglements can continue to shape an organizations' or departments' listening practices in unintended ways. These two contributions to rhetoric and composition broadly, and community literacy specifically, have potential to reshape both the ways we study listening practices in research and the ways we enact listening practices in our planning and implementation processes.

\section{Contribution to Community Organizations}

The dissertation originated as a means to help Americana, as community partner, better understand gaps in their service to immigrant and refugee women. Thus, any conversation about contributions must include a discussion on how community partners might benefit from the work of this project. Below, I've outlined three ways that this dissertation might be developed further for use within an organization like Americana. 
Each use corresponds to one of my body chapters and considers who might use a piece of the project, how, and at what point in a program's life.

Application 1: "Listening Back” As a Tool for Self-Reflective Critique in Planning

"Listening back" helps organizations study ongoing listening practices to increase awareness of biases and circulating discourses. In the context of the dissertation, listening back provides a deep dive into the origins and choices of a specific program. The process could be developed into a more structured tool to help program organizers work through different understandings of spoken goals, or between intentions and consequences within a program.

The purpose of a "listening back" tool would be to help program organizers attend to the way past experiences, relationships with partners, and the presence of deficit-model discourse shaped the structures of current programs. To be able to bring all of those things together, a tool would need to help organizers: 1) define values and then reflect on their application in past programs; 2) name the differences between current and past program goals; 3) locate differences between their goals and those of partner organizations; 4) attend to the presence of deficit-model thinking at each of these stages. In interviews, I asked explicitly about items 1-3, and then, through observation and analysis, located the presence of deficit discourse. I imagine that a short-answer questionnaire would be a good starting place for eliciting conversation during planning or reflection meetings.

Listening back could also work well with other reflective tools meant to increase organizers' understanding of their own practices and intentions. For instance, it could be coupled with a tool like Stevens, Brydon-Miller, and Raider-Roth's structured ethical 
reflection (SER), in which project partners name and define their core values in conversation with one another. SER creates space for future conversation about values when decisions need to be made. It assumes that even when partners voice similar values, they define their terms slightly differently. Thus, SER seeks to head off confusion between partners, stemming from differently-defined values, and provides a way to talk through misunderstandings when they do arise. Listening back, likewise, asks program organizers to name and define values, and then to locate them within current positions and past program experiences. It could be used to extend SER, however, because while it helps tease out hidden assumptions, it does so to uncover deficit discourses and dissimilar goals leftover from previous programs.

On its own or joined with another tool like SER, a tool for listening back could be useful in organizational trainings, like Americana's staff facilitator trainings, or partner meetings. such as those between Americana and JCPS teachers, or staff facilitator trainings. A next step for this project, then, is to develop such a tool for use in community literacy organizations. Rather than developing a tool for community organizations, however, I would like to develop and pilot it alongside partners, who would have a better sense of their need and the usefulness of such a tool.

At this point, I am unsure of how to ask questions that help program organizers attend to deficit discourses, without also providing explicit training or reading in that area. While grassroots organizations like Americana certainly work to combat the structural racism and institutional marginalization their participants face, it can be difficult to hear and analyze deficit-model thinking, especially given how often it can look like strength-based language instead. At the same time, understanding the power of 
deficit-model thinking is critical to understanding the gap between intentions and consequences. Thus, in addition to developing a tool with community partners, I would also like to have pointed conversations about how to make some of the more theoretical language used in the "listening back" model accessible for staff.

Application 2: Cultural Community Wealth's Application to Literate Repertoires Can Reframe "Strengths" Language

While cultural community wealth has been used some in education, and especially in education scholarship, it has not been widely employed in community and family literacy programs. This may be unsurprising, given the frequent gap between educational research and practice, both in K-12 and para-educational programs, but it's nonetheless unfortunate. In an organization like Americana, community cultural wealth would give language and a frame to ideas that organizers already voice. The idea that women have rich literate repertoires and difficulty drawing on them would not be surprising to staff, but a focus on the language of community cultural wealth would make it easier to talk about how women's literate strengths can be included and accounted for at every level of programming - from vision-casting to program structures to daily practices. It might also make it easier to locate deficit-model discourse, mentioned in the previous application, through differentiating majoritarian stock stories from stories of cultural community wealth.

A staff training on developing practices that anticipate counterstories and on listening for cultural community wealth could help facilitators name unvoiced assumptions of deficit and shift toward an understanding of how women can and cannot draw on their literate capital in the community and even within family literacy programs. At Americana, I can see such a training being included in the annual "Welcome 
Navigator" training Julie leads, which teaches staff "how to work with people from across spectrums of culture and across the matrices of inequality" (Julie, personal interview). Again, such a training would be developed with the help of a community partner who knows their staff's needs and organizational culture far better than an outside researcher.

Application 3: Creating Program Documents with Institutional Critique in Mind

Given institutional critique's focus on tangibility and local action, the easiest use to imagine for this dissertation may be advocating for program documents that are written to make institutional change. I outline this last, both in my dissertation and in this section, because I see it as contingent on an understanding of current listening practices and a commitment to letting women's literate counternarratives re-shape program practices. After engaging with that kind of internal and relational work, an organization is better situated to help outside partners re-frame their narratives about marginalized populations. That's not to say that listening work should, or can, be completed before speaking up to institutional partners. As the preceding sections explain, the tools I'm outlining can be used internally—with one or two staff in conversation —or externally, as part of large trainings that include outside partners. Instead, I mean that the more work facilitators have done to uncover deficit discourses in their own programs and thinking, and the more robust their practices of listening to counterstories, the better equipped they are to understand the gap between a strengths and needs-focused model of family programming.

In advocating for using program texts to shift partners' and funding institutions' narratives about the communities being served, I imagine grant narratives, program proposals, and End of Program reports as the central tools for change. I also imagine 
them surrounded by the other communicative touchpoints that build relationships. Emails, planning meetings, and casual conversations all contribute to institutional relationships, and as an organization's culture shifts to include new stories and understandings of wealth, so do those touchpoints. Texts are a more formal indication of an organization's vision and priorities.

\section{Limitations, Next Steps and Conclusions}

Although this dissertation adds to listening scholarship discussions and makes room for new processes in community organizations, it is still limited by time, scope, and my position as an early scholar. It is neither the beginning nor the end of the conversation about critical listening practices, literate counternarratives, or critiques of family literacy institutions. This section acknowledges the limitations and lingering questions of this project and outlines next steps for scholarship and community programs taking up the project I have outlined in the last two hundred pages. While there are certainly limitations within each chapter, I focus on three ways that the study, taken as a whole, might be expanded or revised in future work. The first two limitations - time and sample sizefocus on how I could expand the study that this dissertation begins to refine assumptions and make findings more robust. The third area for future development concerns my choice to combine traditional CLR methodologies with literature from explicitly antiracist, anti-nationalist areas of scholarship.

As with so many studies on a clearly delineated timetable, time was a central limiting factor. The program sessions and participant interviews used in this study all took place in a three-month span. Mamas Together ran for seven weeks, with a one week break in the middle, and interviews were completed within two weeks of the program's 
close. While I had hoped for follow-up interviews with women, a combination of intense medical treatments in Fall 2019 and the COVID-19 pandemic in 2020 made that difficult. Further, because Mamas Together closed before another run, the early findings from interviews could not be utilized or studied during follow-up programs. Thus, one hopedfor future project would be to apply some of the suggestions my dissertation makes in a similar program, perhaps even at Americana. This proposed future study would further refine assumptions about the link between listening and acting and potentially demonstrate where findings can be adapted for other community literacy organizations. Another limiting factor was my small interview sample. Because I used Mamas Together as a central site for studying listening in action, I chose to interview only those women involved in its creation and implementation: four staff members and three core participants. I combined interviews with session observations and texts that traced listening processes as they informed practices (namely, focus group notes, staff reflections, and the End-of-Program report). On one hand, the data I chose enabled me to study the relationship between listening and structure creation from before the program began to just after its run. As I stated above, this kind of long view is an uncommon process in listening studies, which usually include moments of listening. Having a larger scope so that we can trace present moments of goal/practice misalignment back to earlier practices, value negotiations, etc. Gathering a lot of data on a single program also allowed me to single out the "voices" that spoke into Mamas Together from other programs. A smaller interview sample from women I had spent seven weeks with (or more, in the case of Leah and Danielle) also allowed for a great deal of depth. Despite only having one interview each, I knew my interview subjects fairly well by the time of 
our formal interviews. I had spent time getting to know them in weekly sessions, reflection and planning meetings, and casual conversations as we made crafts with our children.

On the other hand, deep data on a single program does not allow for crossprogram comparisons. While generalizable data is not the goal of this kind of study, being able to study trends in programs would make it easier to study enacted listening practices and detail a more robust listening methodology for both community literacy scholarship and grassroots organizations to employ. Future work, however, could look at family literacy programs more broadly, using concepts like "listening back" and literate capital to examine the structures of multiple programs in an organization. Thus, future work with this project would not only conduct follow-up interviews with original participants but would also expand interview invitations to women in Family Education as well. Using a larger group of participants and including a program with top-down teacher/student relationships (but similarly stated goals to Mamas Together) would allow for a comparison of listening processes and would test some of my assertions about programs being better able to build holistic community when women's cultural wealth is considered in program structures.

While the previous two limitations focus on the study and its findings, I think that the work of this dissertation could also be strengthened in a key theoretical way. A central through line, as I explore early in this chapter, is the choice to combine accepted methodologies from CLR with frames that prioritize scholars and communities of colortransnational feminism, community listening, and critical race theory. In this iteration of analysis, I prioritized the disciplinary methodologies I had chosen to show how coupling 
them with explicitly anti-racist, anti-nationalist scholarship could strengthen their application in scholarship focused on transnational women. I think the secondary frames I used could be better amplified. While I talked about "intersectional marginalization" and the impacts of deficit discourse at length, I do not overtly suggest anti-racist practices that program organizers could deploy. Since each chapter uses explicitly anti-racist frames, the project could easily make those themes much more overt.

While there is always room for refining and expanding, a central strength of this dissertation is the careful, gracious attention it pays to the people who make up a program: the facilitators who create texts and reflect on their practices, the speakers who share expertise, the women who bring experiences and knowledge with them to class. Its primary goal has been to "demonstrate [...] honor and respect [for] the person talking and what that person is saying," with the intention of "translat[ing] language and action, into the creation of an appropriate response" (Royster 38). In doing so, it has outlined a methodology for self-critique and careful listening practices. My hope is that in studying our listening practices, we can become more attentive to "the person talking" out of her history, experiences, and desires, separating as much as possible, the woman in front of us from the cultural imaginations that seep into cross-cultural exchanges. In doing so, my goal is to transform not just individual relationships, or brief pilot programs, but also the larger landscape of literacy institutions that immigrant and refugee families rely on for everyday life. 


\section{REFERENCES}

Alvarez, Steven. Brokering Tareas: Mexican Immigrant Families Translanguaging

Homework Literacies. SUNY Press, 2017.

Auerbach, Elsa. "Considering the Multiliteracies Pedagogy: Looking through the Lens of Family Literacy." Transformations in Language and Learning: Perspectives on Multiliteracies, edited by Mary Kalantzis and Bill Cope, Common Ground, pp. 99-112.

---. "Deconstructing the Discourse of Strengths in Family Literacy." Journal of Reading Behavior vol. 27, no. 4, 1995, pp. 643-661.

Barton, David, and Mary Hamilton. Local Literacies: Reading and Writing in One Community. Routledge, 1998.

Brandt, Deborah. Literacy in American Lives. Cambridge University Press, 2001.

---. "Sponsors of Literacy." College Composition and Communication, vol. 49, no. 2, 1998, pp. 165-185.

Bousquet, Marc. "Composition as Management Science: Toward a University Without a WPA.” JAC, vol. 22, no. 3, 2002, pp. 493-526.

Brandt, Deborah and Katie Clinton. "Limits of the Local: Expanding Perspectives on Literacy as a Social Practice.” Journal of Literacy Research, vol. 34, no. 3, 2002, pp. 337-356. 
Certeau, Michel de. "Walking in the City." The Practice of Everyday Life. Translated by Steven Rendall, University of California Press, 1984.

Christoph, Julie Nelson. "Sponsoring Education for All: Revisiting the Sacred/Secular Divide in Twenty-First Century Zanzibar." In Literacy, Economy, and Power: Writing and Research after Literacy in American Lives, edited by John Duffy, et al., Southern Illinois University Press, 2013, 79-96.

Collins, Alice. "Mothers as Teachers-Teachers as Mothers." Redefining Motherhood: Changing Identities and Patterns, edited by Sharon Abbey and Andrea O'Reilly, Second Story Press, 1998, pp. 92-102.

Compton-Lilly, Catherine, Rebecca Rogers, and Tisha Y. Lewis. "Analyzing Epistemological Considerations Related to Diversity: An Integrative Critical Literature Review of Family Literacy Scholarship." Reading Research Quarterly, vol. 47, no. 1, 2012, pp. 33-60.

Crooks, Stacey. Family Literacy and Colonial Logics. 2017. University of Toronto, PhD dissertation. TSpace, http://hdl.handle.net/1807/79686.

Crenshaw, Kimberlé W. On Intersectionality: Essential Writings. The New Press, 2017. Cushman, Ellen, et al. "Family and Community Literacies." Research on Composition: Multiple Perspectives on Two Decades of Change, edited by Peter Smagorinsky, Teachers College Press, 2006, pp. 187-216. 
---. "The Rhetorician as an Agent of Social Change." College Composition and Communication, vol. 47, no. 1, 1996, pp. 7-28.

Deans, Thomas. Writing Partnerships: Service-Learning in Composition. National Council of Teachers of English, 2000.

De Certeau, Michel. "Walking in the City." The Practice of Everyday Life. Translated by Steven Rendall, University of California Press, 1984.

Delgado, Richard. "Storytelling for Oppositionists and Others: A Plea for Narrative." Michigan Law Review, vol. 87, no. 8, 1989, pp. 2411-2441.

---, and Jean Stefancic. "Norms and Narratives: Can Judges Avoid Serious Moral Error." Tex. L. Rev., vol. 69, 1990, 1929-84.

Delgado Bernal, Delores. "Critical Race Theory, LatCrit Theory and Critical RacedGendered Epistemologies: Recognizing Students of Color as Holders and Creators of Knowledge," Qualitative Inquiry, vol. 8, no. 1, 2002, pp. 105-126. DeNicolo, Christina Passos, et al. "Teaching through Testimonio: Accessing Community Cultural Wealth in School." Journal of Latinos and Education, vol. 14, no. 4, 2015, pp. 228-243.

DePouw, Christin. "When Culture Implies Deficit: Placing Race at the Center of Hmong American Education." Race Ethnicity and Education, vol. 15, no. 2, 2012, pp. 223-239. 
Dingo, Rebecca. Networking Arguments: Rhetoric, Transnational Feminism, and Public Policy Writing. University of Pittsburgh Press, 2012.

Dreher, Tanja. "Eavesdropping with Permission: The Politics of Listening for Safer Speaking Spaces.” Borderlands, vol. 8, no. 1, 2009, pp. 1-21.

Duffy, John. Writing from These Roots: Literacy in a Hmong-American Community. University of Hawaii Press, 2007.

Feigenbaum, Paul. Collaborative Imagination: Earning Activism through Literacy Education. Southern Illinois University Press, 2015.

---. "Tactics and Strategies of Relationship-Based Practice: Reassessing the Institutionalization of Community Literacy." Community Literacy Journal, vol. 5, no. 2, 2011, pp. 47-66.

Fernandes, Leela. Transnational Feminism in the United States: Knowledge, Ethics, and Power. NYU Press, 2013.

Fishman, Jenn and Lauren Rosenberg. “Guest Editors' Introduction: Community Writing, Community Listening." Community Literacy Journal, vol. 13, no.1, 2018, pp. 1-6.

Flower, Linda. Community Literacy and the Rhetoric of Public Engagement. SIU Press, 2008.

Foley, Douglas E. "Deficit Thinking Models Based on Culture: The Anthropological 
Protest," The Evolution of Deficit Thinking: Educational Thought and Practice, edited by Richard Valencia, The Falmer Press, 1997, 113-131.

Foucault, Michel. Discipline and Punish. Translated by Alan Sheridan, Gallimard, 1975.

Fraser, Nancy. "From Discipline to Flexibilization? Rereading Foucault in the Shadow of Globalization." Constellations, vol. 10, no. 2, 2003, pp. 160-171.

García, Romeo. "Creating Presence from Absence and Sound from Silence," Community Literacy Journal, vol. 13, no. 1, 2018, pp. 7-15.

---. "Haunt (ed/ing) Genealogies and Literacies." Reflections, vol.19, no. 1, 2019, pp. $230-248$.

Gedalof, Irene. "Birth, Belonging and Migrant Mothers: Narratives of Reproduction in Feminist Migration Studies.” Feminist Review, vol. 93, no.1, 2009: pp. 81-100.

Gee, James P. "New Literacy Studies.” The Routledge Handbook of Literacy Studies, edited by Jennifer Rowsell and Kate Pahl, Routledge, 2015, pp. 35-48.

Gibson-Davis, Christina M. and Jeanne Brooks-Gunn. “Couples' Immigration Status and Ethnicity as Determinants of Breastfeeding." American Journal of Public Health, vol. 96 , no. 4 , 2006, pp. 641-646.

Gindlesparger, Kathryn J. "The Sadder the Story, the Bigger the Check: Reciprocity as an Answer to Organizational Deficit Models." Community Literacy Journal, vol. 5, no. 1, 2010, pp. 91-106. 
Goldblatt, Eli. Because We Live Here. Hampton Press, 2007.

Grabill, Jeff. Community Literacy Programs and the Politics of Change. SUNY Press, 2001.

---. "Community-Based Research and the Importance of a Research Stance." Writing Studies Research in Practice: Methods and Methodologies, edited by Lee Nickoson and Mary P. Sheridan, Southern Illinois University Press, 2012, 210219.

Gregory, Eve and Ann Williams. City Literacies: Learning to Read Across Generations and Cultures, Psychology Press, 2000.

Grewal, Inderpal. Transnational America: Feminisms, Diasporas, Neoliberalisms. Duke University Press, 2005.

---, and Caren Kaplan, eds. Scattered Hegemonies: Postmodernity and Transnational Feminist Practices. U of Minnesota Press, 1994.

Griffith, Alison I. and Dorothy E. Smith, "Constructing Cultural Knowledge: Mothering as Discourse." Women and Education: A Canadian Perspective, edited by Jane Gaskell and Arlene McLaren, Detselig Enterprises Limited, 1986, pp. 87-103. Grumet, Madeleine R. Bitter Milk: Women and Teaching. University of Massachusetts Press, 1988.

Hall, Stuart. "Foucault: Power, Knowledge and Discourse." Discourse Theory and 
Practice: A Reader, 2001, pp. 72-81.

Hartsock, Nancy. "The Feminist Standpoint: Developing the Ground for a Specifically Feminist Historical Materialism.” Discovering Reality, edited by Sandra Harding and Merill B. Hintikka, D. Reidel Publishers, 1983, pp. 283-310.

---. "Foucault on Power: A Theory for Women?" Feminism/Postmodernism, edited by Linda Nicholson, Routledge, 1990: 157-175.

Hawkins, Roberta. “'One Pack= One Vaccine'= One Global Motherhood? A Feminist Analysis of Ethical Consumption." Gender, Place and Culture, vol. 18, no. 2, 2011, pp. 235-253.

Hendrix, Scott. "Family Literacy Education: Panacea or False Promise?" Journal of Adolescent \& Adult Literacy, vol. 43, no. 4, 1999, pp. 338-346.

Hesford, Wendy. "The Malala Effect." Watson Conference Responsivity: Defining, Cultivating, Enacting, special issue of $J A C$, vol. 34, no. 1/2, 2014, pp. 139-164.

---. Spectacular Rhetorics: Human Rights Visions, Recognitions, Feminisms. Duke University Press, 2011.

Hoffman, Diane M. "How (Not) to Feel: Culture and the Politics of Emotion in the American Parenting Advice Literature.” Discourse: Studies in the Cultural Politics of Education, vol. 30, no. 1, 2009, pp 15-31.

Hostettler, Karin. "Under (Post) Colonial Eyes: Kant, Foucault, and Critique." 
Decolonizing Enlightenment: Transnational Justice, Human Rights and

Democracy in a Postcolonial World, edited by Nikita Dhawan, Barbara Budrich

Publishers, 2014, pp. 79-93.

House, Veronica, Seth Myers, and Shannon Carter. "Introduction: Envisioning Engaged Infrastructures for Community Writing.” Community Literacy Journal, vol.11, no. 1, 2016, pp. 1-9.

Huber, Lindsay Pérez. "Challenging Racist Nativist Framing: Acknowledging the Community Cultural Wealth of Undocumented Chicana College Students to Reframe the Immigration Debate." Harvard Educational Review, vol. 79, no. 4, 2009, pp. 704-730.

Inoue, Asao B. "How Do We Language So People Stop Killing Each Other, Or What Do We Do About White Language Supremacy?" Conference on College Composition and Communication, Annual Convention, 14 March 2019, Pittsburgh, Pennsylvania. Keynote Address.

International Human Rights and Conflict Resolution Clinic (Stanford Law School) and Global Justice Clinic (NYU School of Law). Living Under Drones: Death, Injury, and Trauma to Civilians from US Drone Practices in Pakistan, 2012.

Isaacs, Emily, and Ellen Kolba. "Everyone Loved It and Still It Closed: When a Writing 
Program Isn't a Core Mandate." Unsustainable: Re-imagining Community

Literacy, Public Writing, Service-learning, and the University, edited by Jessica

Restaino and Laurie Cella, Lexington Books, 2013: 79-98.

Jackson, Rachel C. and Dorothy Whitehorse DeLaune. "Decolonizing Community

Writing with Community Listening: Story, Transrhetorical Resistance, and Indigenous Cultural Literacy Activism.” Community Literacy Journal, vol. 13, no.1, 2018, pp. 37-54.

Jacobs, Kim, Josh Cramer, Tracy Noles, and Patricia Lovett. "Defining Our Work: Families Learning Together.” National Center for Families Learning. January 2019. Accessed 15 February 2021.

James, Jennifer Hauver. "Caring for 'Others': Examining the Interplay of Mothering and Deficit Discourses in Teaching." Teaching and Teacher Education, vol. 28, no. 2, 2012, pp. 165-173.

Janes, Helena, and Hengameh Kermani. "Caregivers' Story Reading to Young Children in Family Literacy Programs: Pleasure or Punishment?” Journal of Adolescent \& Adult Literacy, vol. 44, no. 5, 2001, pp. 458-466.

Jayakumar, Uma, Rican Vue, and Walter Allen. "Pathways to College for Young Black Scholars: A Community Cultural Wealth Perspective." Harvard Educational Review, vol. 83, no. 4, 2013, pp. 551-579. 
Jones, Alison. "The Limits of Cross-Cultural Dialogue: Pedagogy, Desire, and Absolution in the Classroom," Educational Theory, vol. 49, no. 3, 1999, pp. 299316.

--- and Kuni //Jenkins. "Rethinking Collaboration: Working the Indigene-Colonizer Hyphen/m/m k om." Handbook of Critical and Indigenous Methodologies, edited by Norman mKImoons, 2008, pp. 471-486.

Kanazawa, Satoshi. "Breastfeeding is Positively Associated with Child Intelligence Even Net of Parental IQ." Developmental Psychology, vol. 51, 12, 2015, pp. $1683-$ 1689.

Karsli-Calamak, Elif. "Syrian Mothers Producing Counterstories in Co-Constructed School Spaces: Rethinking the Role of Schools in Engaging Refugee Families." European Education, vol. 50, no. 1, 2018, pp. $42-57$.

Kelly, Laura. "Welcoming Counterstory in the Primary Literacy Classroom." Journal of Critical Thought and Praxis, vol. 6, no. 1, 2017, pp. 38-52.

Kinloch, Valerie, Carlotta Penn, and Tanja Burkhard. "Black Lives Matter: Storying, Identities, and Counternarratives." Journal of Literacy Research, vol. 52, no. 4, 2020, pp. 382-405.

Kulbaga, Theresa. "Pleasurable Pedagogies: Reading Lolita in Tehran and the Rhetoric of Empathy." College English, vol. 70, no. 5, 2008, pp. 506-521. 
Lagman, Eileen. "Literacy Remains: Loss and Affects in Transnational Literacies." College English, vol. 81, no. 1, 2018, pp. 27-49.

Lam, Wan Shun Eva, and Doris S. Warriner. "Transnationalism and Literacy: Investigating the Mobility of People, Languages, Texts, and Practices in Contexts of Migration." Reading Research Quarterly vol. 47, no. 2, 2012, 191-215.

Leonard, Rebecca Lorimer. Writing on the Move: Migrant Women and the Value of Literacy. University of Pittsburgh Press, 2018.

Lu, Min-Zhan, and Bruce Horner. "Translingual Literacy, Language difference, and Matters of Agency." College English, no. 75, vol. 6, 2013, pp. 582-607. MacDonald, Michael T. "Emissaries of Literacy: Representations of Sponsorship and Refugee Experience in the Stories of the Lost Boys of Sudan." College English, vol. 77 , no. 5 , 2015, pp. 408-28.

Martinez, Aja Y. “A Plea for Critical Race Theory Counterstory: Stock Story Versus Counterstory Dialogues Concerning Alejandra's 'Fit' in the Academy. Composition Studies, vol. 42, no. 2, 2014, pp. 33-55

Mathieu, Paula. Tactics of Hope: The Public Turn in English Composition. Boynton/Cook Publishers, 2005.

---. “After Tactics, What Comes Next?” Unsustainable: Re-imagining 
Community Literacy, Public Writing, Service-learning, and the University, edited by Jessica Restaino and Laurie Cella, Lexington Books, 2013: 17-32.

McDonald, Michael. "Keywords: Refugee Literacy.” Community Literacy Journal, vol. 7, no. 2, 2013, pp. 95-99.

Mindry, Deborah. 'Nongovernmental Organizations, 'Grassroots,' and the Politics of Virtue. Signs, vol. 26, no. 4, 2001, pp. 1187-1211.

Mohanty, Chandra Talpade. Feminism Without Borders: Decolonizing Theory, Practicing Solidarity. Zubaan, 2005.

Moll, Luis C., Cathy Amanti, Deborah Neff, and Norma Gonzalez. "Funds of Knowledge for Teaching: Using a Qualitative Approach to Connect Homes and Classrooms." Theory into Practice, vol. 31, no. 2, 1992, pp. 132-141.

Morris, Jerome E. "Can anything good come from Nazareth? Race, Class, and African American Schooling and Community in the Urban South and Midwest.” American Educational Research Journal, vol. 41, no. 1, 2004, pp. 69-112. Moss, Beverly J. “'Phenomenal Women,' Collaborative Literacies, and Community Texts in Alternative 'Sista' Spaces."” Community Literacy Journal vol. 5, no. 1, 2010, pp. 1-24.

National Center for Families Learning. "Mission Statement." National Center for Families Learning, NCFL, last modified 2021, www.familieslearning.org/mission 
---. "Family Literacy Program Quality Self-Study.” NCFL, 1994.

Nichols, Amy McCleese, and Bronwyn T. Williams. "Centering Partnerships: A Case for Writing Centers as Sites of Community Engagement." Community Literacy Journal, vol.13, no. 2, 2019, pp. 88-106.

Pahl, Kate. Materializing Literacies in Communities: The Uses of Literacy Revisited. Bloomsbury Publishing, 2014.

Parks, Stephen J. Gravyland: Writing Beyond the Curriculum in the City of Brotherly Love. Syracuse UP, 2010.

---. "Strategic Speculations on the Question of Value: The Role of Community Publishing in English Studies." Unsustainable: Re-imagining Community Literacy, Public Writing, Service-learning, and the University, edited by Jessica Restaino and Laurie Cella, Lexington Books, 2013: 55-78.

Perry, Kristen. "From Storytelling to Writing: Transforming Literacy Practices among Sudanese Refugees." Journal of Literacy Research, vol. 40, no. 3, 2008, pp. 317 358.

Phelps, Louise Wetherbee. “Institutional Invention: (How) Is It Possible?” Perspectives on Rhetorical Invention, edited by Janet M. Atwill and Janice M. Lauer, The University of Tennessee Press, 2002, pp. 64-95.

Porter, James E, et al. "Institutional Critique: A Rhetorical Methodology for Change." 
College Composition and Communication, vol. 51, no. 4, 2000, pp. 610-642.

Powell, Katrina M. Identity and Power in Narratives of Displacement. Vol. 22.

Routledge, 2015.

---. "Rhetorics of Displacement: Constructing Identities in Forced Relocations." College

English, vol. 74, no. 4, 2012, pp. 299-324.

Queen, Mary. "Transnational Feminist Rhetorics in a Digital World." College English, vol. 70, no. 5, 2008, pp. 471-489.

Ratcliffe, Krista. Rhetorical Listening: Identification, Gender, Whiteness. SIU Press, 2005.

---. "Rhetorical Listening: A Trope for Interpretive Invention and a "Code of CrossCultural Conduct." College Composition and Communication, vol. 51, no. 2, 1999, pp. 195-224.

Restaino, Jessica. "Motherhoods: Feminist Solidarity and Fear Rhetoric." thirdspace: a journal of feminist theory \& culture, vol. 8, no. 1, 2008. https://journals.sfu.ca/thirdspace/index.php/journal/article/view/restaino/225

Restaino, Jessica, and Laurie Cella, editors. Unsustainable: Re-Imagining Community Literacy, Public Writing, Service-Learning and the University. Lexington Books, 2013.

Rito, Ana Isabel, et al. "Association Between Characteristics at Birth, Breastfeeding and 
Obesity in 22 Countries: The WHO European Childhood Obesity Surveillance Initiative-COSI 2015/2017." Obesity Facts, vol. 12, no. 2, 2019, pp. 226-243.

Rousculp, Tiffany. Rhetoric of Respect: Recognizing Change at a Community Writing Center. National Council of Teachers of English, 2014.

Rowan, Karen and Alexandra J. Cavallaro. "Toward a Model for Preparatory Community Listening." Community Literacy Journal, vol. 13, no. 1, 2018, pp. 23-36.

Roy, Laura A. and Kevin C. Roxas. "Whose Deficit Is This Anyhow? Exploring CounterStories of Somali Bantu Refugees' Experiences in 'Doing School.'” Harvard Educational Review, vol. 81, no. 3, 2011, 521-541.

Royster, Jacqueline Jones. "When the First Voice You Hear Is Not Your Own." College Composition and Communication, vol. 47, no. 1, 1996, pp. 29-40.

Saldaña, Johnny. The Coding Manual for Qualitative Researchers, SAGE Publications, 2013.

Shah, Rachael Wendler. "The Courage of Community Members: Community Perspectives of Engaged Pedagogies." College Composition and Communication, vol. 70, no. 1, 2018, pp. 82-110.

---. Review of Collaborative Imagination: Earning Activism through Literacy Education, by Paul Feigenbaum. Community Literacy Journal, vol. 12, no. 1, 2017, pp. 104109. 
Sharp-Hoskins, Kellie. "Imagining Pedagogical Engagement." Writing for Engagement:

Responsive Practice for Social Action, edited by Mary P. Sheridan, Megan J.

Bardolph, Megan Faver Hartline, and Drew Holladay, Lexington Books, 2018, pp. 61-74.

Sheridan, Mary P. Girls, Feminism, and Grassroots Literacies: Activism in the GirlZone. SUNY Press, 2008.

Shome, Raka. “'Global Motherhood': The Transnational Intimacies of White Femininity." Critical Studies in Media Communication, vol. 28, no. 5, 2011, pp. 388-406.

Smith, Dorothy E. "The Standard North American Family: SNAF as an Ideological Code," Journal of Family Issues vol. 14, no. 1, 1993, pp. 50-65.

Smythe, Suzanne and Janet Isserlis. "The Good Mother: Exploring Mothering Discourses in Family Literacy Texts." Literacy and Numeracy Studies, vol. 13, no. 2, 2004, pp. 23-39.

Stacy, Jen. "Shared Literacy Sponsors: Moments that Sustained Learning and Challenged Neo-Deficit Ideologies in Programmatic Family Literacy.” Ethnography and Education, vol. 15, no. 4, 2020, pp. 395-411.

Stevens, Douglas M., Mary Brydon-Miller, and Miriam Raider-Roth. "Structured Ethical 
Reflection in Practitioner Inquiry: Theory, Pedagogy, and Practice." The

Educational Forum, vol. 80, no. 4, 2016, pp. 430-443.

Street, Brian V. Literacy in Theory and Practice. Cambridge University Press, 1984.

Stoler, Ann Laura. Race and the Education of Desire: Foucault's History of Sexuality and the Colonial Order of Things. Duke University Press, 1995.

Solórzano, Daniel G. and Tara J. Yosso. "Critical Race Methodology: CounterStorytelling as an Analytical Framework for Education Research." Qualitative Inquiry, vol. 8, no. 1, 2002, pp. 23-44.

Taylor, Denny. Family Literacy: Young Children Learning to Read and Write. Exeter, 1983.

Valencia, Richard R. The Evolution of Deficit Thinking: Educational Thought and Practice. Taylor \& Francis, 1997.

Vieira, Kate. American by Paper: How Documents Matter in Immigrant Literacy. Minnesota University Press, 2016.

---. "Doing Transnational Writing Studies: A Case for the Literacy History Interview." Composition Studies, vol. 44, no. 1, 2016, pp. 138-140.

Weinstein, Stephanie, and Arthur Wolfson. "Toward a Due Process of Narrative: Before You Lock My Love Away, Please Let Me Testify.” Roger Williams UL Rev. vol. 11, no. 1, 2005, pp. 511-520. 
Williams, Bronwyn T. Literacy Practices and Perceptions of Agency: Composing Identities. Taylor \& Francis, 2017.

Yosso, Tara J. (2005) "Whose Culture Has Capital? A Critical Race Theory Discussion of Community Cultural Wealth." Race, Ethnicity and Education, vol. 8, no. 1, pp. 69-91.

Young, Vershawn Ashanti. “"Nah, We Straight': An Argument Against Code Switching.” $J A C, 2009$, pp. 49-76 


\section{APPENDIX}

\section{INTERVIEW QUESTIONS ${ }^{18}$ FOR MAMAS TOGETHER ORGANIZERS AND}

\section{PARTICIPANTS}

\section{Questions for Organizers:}

1. How would you describe Americana's goals? How do you see those playing out:
a. At a programmatic level?
b. In individual interactions?
c. Describe how those goals play out in a typical day.

2. What are some of the ways that those goals are assessed? By whom?

3. How do you see those goals at work in Mamas Together?

4. When imagining a program like Mamas Together who do you imagine participating? How does that/did that shape the program in your head?

5. In planning and implementing Mamas Together, what other experiences, programs, knowledge did you draw from?

6. What do you think people assume about immigrant mothers? Where does that info come from, do you think?

7. How do you think this program (or Americana as a whole) works against those assumptions? Any ways that we reflect those assumptions?

8. How would you describe your role as program organizer? Can you tell me a story that you think exemplifies $x$ role?

9. Can you tell a story about negotiating $x$ and $y$ roles?

10. Can you describe a time where goals had to shift or imagined perceptions had to shift to accommodate the reality of the program? How did that play out?

\footnotetext{
${ }^{18}$ Interviews were conducted as semi-structured conversations. These questions represent a topical plan and were approved by UofL's Institutional Review Board in February 2019.
} 
11. When you look at (text) where do you see what was important to us? Can you talk about some of your choices in creating this text? Why did you do what you did?

\section{Questions for Participants:}

1. How would you describe yourself as a mother? Can you tell me a story about being a mom that you think shows you in $x$ and $y$ way?

2. How is being a mom in the US different from being a mom in (home country)? Can you tell me a story about those differences?

3. What does a typical day look like for you?

4. What do you want people to know about immigrant mothers? (Or how did you figure out how to be a mom here)

5. When you need advice about being a mom, who do you go to? What about when you need advice about getting resources or parenting in the US?

6. What are your goals for yourself? How do you meet them?

7. Has having children made those goals more difficult or changed them? How?

8. Do you participate in many programs? What has that experience been like?

9. Why did you decide to participate in this program? How did you find out about it?

10. What did you expect from it? What was it like in comparison to your expectations?

11. What do you think the goals of the program were?

12. What was the experience like? What did you take away from it?

13. Something about the teaching style if that doesn't come up. 


\title{
CURRICULUM VITAE
}

\author{
Megen Farrow Boyett \\ 710 Gwendolyn St. \\ Louisville, Ky 40203 \\ megen.boyett@louisville.edu \\ 540.455 .1615
}

\section{EDUCATION}

Ph.D. Rhetoric and Composition | University of Louisville, expected May 2021

Dissertation: "Acting on What We Hear: The Impact of a Listening Methodology in a Community Literacy Program"

Committee: Mary P. Sheridan (Chair), Bronwyn T. Williams, Ann Elizabeth Willey, and Katrina M. Powell

M.A. English | University of Louisville, May 2014

Culminating Project: "Benefits and Challenges of Working with Multilingual Students in the Virtual Writing Center"

\section{B.A. English: Writing Concentration | Christopher Newport University, May 2009}

\section{PROFESSIONAL APPOINTMENTS}

Graduate Assistant, Anne Braden Institute for Social Justice, 2020-2021

Assistant Writing Center Director, University Writing Center, 2019-2020

Assistant Director of Composition, English Department, 2017-2019

\section{PUBLICATIONS}

\section{Refereed Publications}

Boyett, Megen F. “(Re)Uniting 'Christ-haunted' and 'the South': Bringing Allegory and Culture Together in Flannery O'Connor's Criticism." Caesura: Journal of Philological and Humanistic Studies, vol. 2, no. 2, 2015, pp. 57-71. 


\section{Under Review}

Day, Michelle L., Megen Farrow Boyett, and Megan Faver Hartline. "Service-Learning Off the Tenure-Track: Identifying Pedagogical Resources and Support for Non-Tenure Track Instructors." Journal of Service-Learning in Higher Education

Abstract: Reflects on authors' early community-engaged teaching efforts to argue for increased departmental support for contingent faculty developing community projects. Offers suggestions to departments for creating stronger professional development structures to support pedagogical training in this area.

\section{Manuscripts in Progress}

Boyett, Megen F. "End-of-Program Reports as Institutional Critique." (10,000 words) Abstract: Tactical, community-based programs are nimble and community designed, but often short-lived. Thus, they struggle to change the narratives about the communities they serve, perpetuated by larger institutional forces. Documents like end-of-program reports and grant narratives can extend the reach of small tactical programs and adjust funders' and institutional partners' view of historically marginalized communities.

\section{Digital Textbooks}

Boyett, Megen F., Michael Baumann, Michelle Day and Beth Willey. Introduction to Key Concepts in Composition, Softchalk, 2018.

https://www.softchalkcloud.com/lesson/serve/C7pDAldvEQyNt1/html

\section{Shorter Digital Pieces}

Megen Farrow Boyett, ed. The Subversive, vol. 14, UofL Anne Braden Institute for Social Justice Research, 2020. https://louisville.edu/braden

Boyett, Megen F. "Adjusting to Life as a Graduate Student." University Writing Center. University of Louisville. 2020. https://youtu.be/ufAwNxhGIAY

\section{PRESENTATIONS}

\section{Selected Conference Presentations}

"Instructor Labor in Community Writing Projects," Conference on College Composition and Communication, Spokane, WA, April 2020 (Upcoming).

"Making Participant Voices Visible in Assessment," Conference on College Composition and Communication, Milwaukee, WI, March 2019 (Conference cancelled due to Covid19).

"Doing the Work but Leaving Space," Conference on Community Writing. Philadelphia, Pa. October 2019 (Unable to attend due to medical treatment).

"Writing Identities in Displaced Motherhood." Graduate Student Regional Research Conference (GSRRC). Louisville, Ky. February 2019. 
"Speaking Back to Spectacles of Suffering" Thomas R. Watson Bi-annual Conference. Louisville, Ky. October 2018.

"Public Rhetorics and Literacy Practices of Refugee Mothers." Conference on Community Writing. Boulder, Colorado. October 2017.

"Academic Mothering and Mobility." (Panel) Feminisms and Rhetorics Conference. Dayton, Oh. October 2017

"Oral and Electronic Traditions in the Writing Classroom: A Useful Relationship." Presenter. Rhetoric Society of America Conference. San Antonio, Tx. May 2014.

"The Renaissance Schoolboy: Navigating Gender Constructions in the Literacy Classroom." Panel Chair and Presenter. Louisville Conference on Literature and Culture. Louisville, Ky. February 2014.

\section{Invited Lectures and Workshops}

"Writing Literature Reviews," The Graduate School, PLAN Workshop, UofL 2020

"Writing for Different Audiences," Grad Seminar: Health Promotion \& Behavioral Sciences, UofL Health Sciences Campus, 2019

"Adapting Strategies for Writing in Graduate School," Lunch and Learn, UofL Health Sciences Campus, 2019

"Teaching Community-Engaged Classes," UofL Dept of Composition, Belknap Campus, 2017

“PTL Life" Networking Workshop for Adjunct Faculty, UofL Dept of Composition, 2015

\section{TEACHING EXPERIENCE}

Graduate Teaching Assistant, University of Louisville

Scientific and Technical Writing (ENGL 303), Fall 2018 (1 section)

Business Writing (ENGL 306), Spring 2017 (1 section)

First Year Composition Sequence (English 101 and 102), 2016-2021 (6 sections)

\section{Part-Time Instructor, University of Louisville}

First Year Composition Sequence (English 101 and 102), 2014-2016 (9 sections)

\section{ADMINISTRATIVE EXPERIENCE}

Graduate Assistant, Anne Braden Institute for Social Justice Research, University of Louisville 2020-2021 (Ongoing Appointment)

Organizing and publicizing African-American rare books collection. Co-organized first virtual Braden Memorial Lecture. Assisted with cross-listed engaged course (WGST and History), 
partnering with Muhammad Ali Center. Drafted and edited annual newsletter. Helped reshape structures and day-to-day practices to carry out the institute's mission during Covid, including increasing social media presence.

Assistant Writing Center Director for Graduate Students and Faculty, University of Louisville 2019-2020

Facilitated weekly graduate and faculty writing group (face-to-face and virtual). Designed and led lunch-and-learn and invited classroom lectures on graduate student writing. Helped organize SWCA Director's Day Out. Staffed face to face and virtual Dissertation Writing Retreats

Assistant Director of Composition, University of Louisville. 2017-2019 Co-wrote and edited a SoftChalk textbook for departmental use. Helped plan and facilitate four-day composition orientations that provided training to graduate teaching assistants, and conducted semester-long mentor groups. Directed the Celebration of Student Writing. Designed and led pedagogy workshops, including community-engaged pedagogy.

University Consultant, Mamas Together Pilot Program, Americana Community Center. 2018-2019

Designed and ran a seven-week pilot program with Americana staff members. Led three focus groups with immigrant and refugee mothers. Wrote and revised curriculum and program surveys. Conducted follow-up interviews with core participants.

Graduate Teaching Assistant, University of Louisville Writing Center. 2013-2014 Contributed to the writing center's campus and community presence through video creation, blogposts, and co-hosting Writing Center events, in addition to daily consultations.

\section{GRANTS, AWARDS, AND HONORS}

Barbara M. Plattus Award for Excellence in Graduate Teaching, University of Louisville, $2019, \$ 300$

Graduate Network of Arts and Sciences, University of Louisville, \$250 for interview translation, 2018-2019

Graduate Student Council, University of Louisville $\$ 500$ for interview translation, 20182019

\section{UNIVERSITY SERVICE \& PROFESSIONAL DEVELOPMENT}

\section{Departmental and University Service}

Council on the Status of Women Graduate Representative, University of Louisville, 2020-2021

Anti-Racist Task Force, University of Louisville Composition Department, 2020-2021

Community Engagement Academy, 2016-2017 
Outcome: Created K-12 curriculum with partner organization

Louisville Digital Composition Colloquium, University of Louisville, Summers 2015 and 2016

Outcome: "Concept in 60 Seconds" FYC Digital Media Unit and Visual Rhetoric Analysis Unit

English Graduate Organization Executive Board MA Student Liaison, University of Louisville 2013-2014

\section{Mentoring}

Mentor Group Leader for MA Consultants, Writing Center, Spring 2020

Mentor Group Leader for First Semester Teachers, Composition Dept, 2017-2019

PhD Peer Mentor, University of Louisville, 2017-2019 Academic Year

MA Peer Mentor, UofL, 2013-2014

\section{AFFILIATIONS}

Coalition for Community Writing

National Council of Teachers of English

Rhetoric Society of America

\section{REFFERENCES}

Mary P. Sheridan

Professor of English

Bingham Humanities 315

2216 S. $1^{\text {st }}$ Street

University of Louisville

Louisville, Kentucky 40292

maryp.sheridan@louisville.edu

502-333-8795

\section{Ann Elizabeth Willey}

Associate Provost of

Undergraduate Education

Professor of English

Bingham Humanities 315

2216 S. $1^{\text {st }}$ Street

University of Louisville

ann.willey@louisville.edu

502-852-0510

\section{Bronwyn Williams}

Director, University Writing Center

Professor of English

Bingham Humanities 315

2216 S. $1^{\text {st }}$ Street

University of Louisville

Louisville, Kentucky 40292

bronwyn.williams@louisville.edu

502-852-2173 